\title{
NBSIR 87-3643
}

\section{Research for Electric Energy Systems -- An Annual Report}

R. E. Hebner, Editor

\author{
U.S. DEPARTMENT OF COMMERCE \\ National Bureau of Standards \\ Center for Electronics and Electrical Engineering \\ Electrosystems Division \\ Gaithersburg, MD 20899
}

\author{
December 1986 \\ Issued September 1987
}

\section{Prepared for}

Department of Energy

Division of Electric Energy Systems

1000 Independence Avenue, SW

$-Q C$

in, DC 20585

100

.456

\#87-3643

1987

C.2 

U.S. DEPARTMENT OF COMMERCE

National Bureau of Standards

Center for Electronics and Electrical Engineering

Electrosystems Division

Gaithersburg, MD 20899

December 1986

Issued September 1987

Prepared for

Department of Energy

Division of Electric Energy Systems

1000 Independence Avenue, SW

Washington, DC 20585

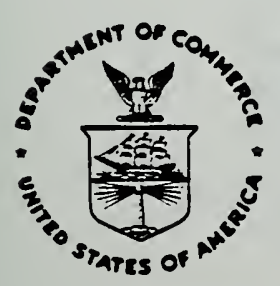

U.S. DEPARTMENT OF COMMERCE, Clarence J. Brown, Acting Secretary NATIONAL BUREAU OF STANDARDS, Ernest Ambler, Director 

TABLE OF CONTENTS

Foreword............................. iv

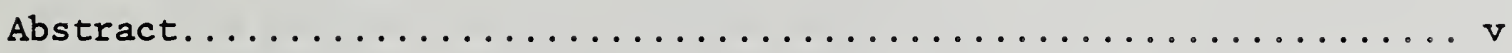

1. Introduction. . . . . . . . . . . . . . . . . . . . 1

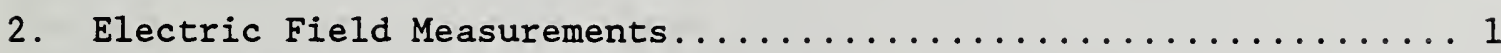

2.1 Introduction. . . . . . . . . . . . . . . . . . .

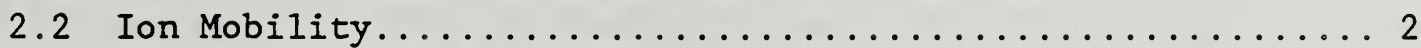

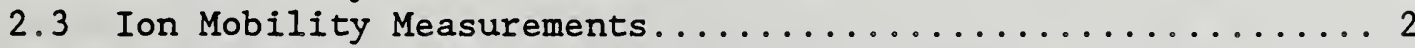

2.4 Corona Detection by AM Radio................... 8

3. Gaseous Dielectrics Research...................... 10

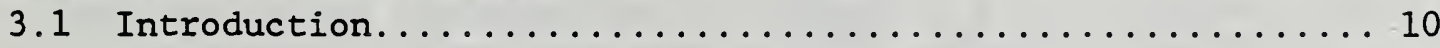

3.2 Evaluation of the Consistency among Electron........... 11 Collision, Transport, and Dielectric Strength

Data for Binary Gas Mixtures

3.3 Gas-Phase Hydrolysis Rates for $\mathrm{SOF}_{2}$ and $\mathrm{SOF}_{4} \ldots \ldots \ldots \ldots 27$

3.4 Identification of Corona Discharge ffduced $_{16} \ldots \ldots \ldots \ldots \ldots 31$ $\mathrm{SF}_{6}$ Oxidation Meçhanisms Using $\mathrm{SF}_{6} / \mathrm{IO}_{2} / \mathrm{H}_{2}{ }^{16} \mathrm{O}$ and $\mathrm{SF}_{6} / \mathrm{IO}_{2} / \mathrm{H}_{2} \mathrm{I}_{\mathrm{O}}$ Gas Mixtures

3.5 Transfer of $\mathrm{F}^{-2}$ in $\mathrm{SF}_{6}^{-}+\mathrm{SOF}_{4}$ Collisions............... 37 and Its Influence on SOF $_{4}$ Yleld from Corona Discharges in $\mathrm{SF}_{6}$ - Containing Gases

4. Interfacial Phenomena in Liquids.................. 42

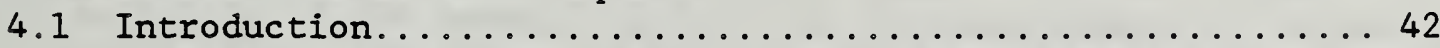

4.2 Streamer Initiation: Electro-optic Field Measurements.... 43

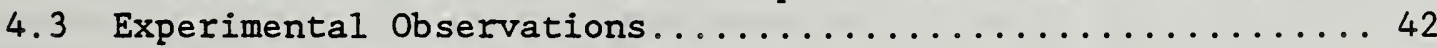

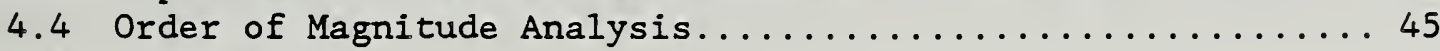

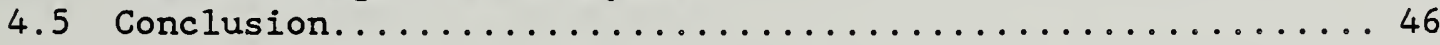

5. Nanosecond Breakdown in Power System Dielectrics..........47

5.1 The Use of E-Dot Sensors in Measuring Fast Rise Pulses.... 47

5.1 .1 Introduction....................... 47

5.1 .2 Sensor Characterization.................... 47

5.1 .3 Discussion......................... 51

5.2 Streamer Propagation in Transformer $0 i l$ under the ....... 51

Influence of Submicrosecond Rise-Time Pulses

5.2 .1 Introduction........................ 54

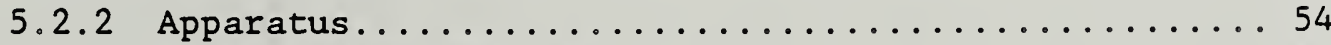

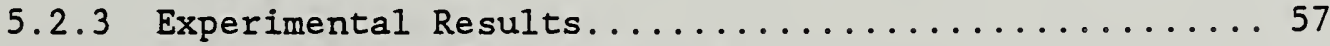

5.2 .3 .1 Slow Pulse Results................ 57

5.2 .3 .2 Fast Pulse Results............... 57

5.2 .4 Discussion........................ 60

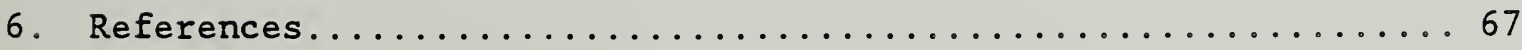




\section{Foreword}

This report summarizes the progress of five technical investigations during FY 86. Although reasonable efforts have been made to ensure the reliability of the data presented, it must be emphasized that this is an interim progress report so that further experimentation and analysis may be performed before the conclusions from any of these investigations are formally published. It is therefore possible that some of the observations presented in this report will be modified, expanded, or clarified by our subsequent research. 


\section{Abstract}

This report documents the technical progress in the five investigations which make up the project "Support of Research Projects for Electrical Energy Systems", Department of Energy Task Order Number 137, funded by the U.S. Department of Energy and performed by the Electrosystems Division of the U.S. National Bureau of Standards. To support the measurement of ions in the vicinity of dc transmission lines and in biological exposure facilities designed to simulate the line environment, techniques to measure ion mobility were evaluated. In addition, techniques were developed which biological researchers could use to determine the sensitivity of an AM radio to detect partial discharges in a biological exposure facility. Within the project to develop measurement techniques and obtain basic data for gaseous dielectrics, a theoretical method was developed to evaluate the consistency among electron collision, transport, and dielectric strength data for binary gas mixtures. In addition, the gas phase hydrolysis rates for $\mathrm{SOF}_{2}$ and $\mathrm{SOF}_{4}$ at room temperature were measured to be $(1.2 \pm 0.3) \times 10^{-23} \mathrm{~cm}^{3} / \mathrm{s}$ and $(1.0 \pm 0.3) \times$ $10^{-21} \mathrm{~cm}^{3} / \mathrm{s}$ respectively; the corona discharge oxidation mechanisms were identified using prepared samples containing ${ }^{16} \mathrm{O}_{2}$ and $\mathrm{H}_{2}{ }^{16} \mathrm{O}$ or ${ }^{18} \mathrm{O}_{2}$ and $\mathrm{H}_{2}{ }^{18} \mathrm{O}$; and the role of $\mathrm{SF}_{6}$ negative ions on the $\mathrm{SOF}_{4}$ yield was also determined.

Progress in the measurement of the electrical behavior at a liquid-solid interface included the optical measurement of the dynamic electric field distribution as a streamer initiates. Progress in developing measurements for nanosecond dielectrics was primarily in two areas. One is in the characterization of the sources of error in the measurement of voltage pulses using E-dot probes. The other is the identification of the reduction of breakdown voltage in oil as the characteristic time of the voltage pulse is reduced. 



\title{
1. INTRODUCTION
}

Under an Interagency Agreement between the U.S. Department of Energy and the National Bureau of Standards, the Electrosystems Division, NBS, has been providing technical support for DOE's research on electrical energy systems. This document summarizes the technical accomplishments of this program during fiscal year 1986. Section 2 of this report describes the work in ac electric and magnetic fields and dc field and ion measurements. Section 3 summarizes the development of the measurement techniques and the accumulation of fundamental data needed for gaseous dielectrics research. Section 4 describes the development of techniques to measure interfacial phenomena in liquids. The final technical project, which deals with the measurement of nanosecond breakdown in power system dielectrics, is summarized in section 5 .

\section{ELECTRIC FIELD MEASUREMENTS Tasks 01 and 02}

\author{
Martin Misakian and P. Michael Fulcomer \\ Electrosystems Division \\ National Bureau of Standards
}

\subsection{Introduction}

The objectives of this project are to develop methods to evaluate and calibrate instruments which are used, or are being developed, to characterize the electrical parameters in the vicinity of high voltage transmission lines and in laboratory apparatus designed to simulate the transmission line environment; to provide electrical measurement support for DOE-funded efforts to determine the effects of ac fields on biological systems; and to provide similar support for biological studies which are funded by the State of New York.

The electrical parameters of interest include the electric field strength, magnetic flux density, ion current and charge densities, ion mobility, and ion species. Earlier NBS studies have examined measurement techniques and sources of error associated with the determination of the electric field strength [1-14], magnetic flux density $[1,3,6,10,15]$, ion current density $[5,8,12,16]$, and ion charge density [17-20]. During 1986, an examination of techniques for measuring ion mobility spectra was begun with the view of identifying methods that could be readily adapted for use in bioeffects exposure systems. A brief investigation was also conducted of the practice of using portable am radios as a means for detecting corona in ac electric field exposure systems. NBS has also been active in the development of standards which provide guidance for the measurement of power frequency electric and magnetic fields. In June 1986, the IEEE Standards Committee approved the final draft of a standard for measurement of ac power line fields [21] and following a 6 -month balloting period, the members of International Electrotechnical Commission Technical Committee 42 approved in July 1986 a standard for measuring power frequency electric fields. The final drafts of both documents were prepared at NBS and include the results of NBS studies. 


\subsection{Ion Mobility}

The mobility of an ion, $\mathrm{K}$, as it moves through a gas under the influence of a weak electric field is defined as the ratio of ion drift velocity to electric field strength. Corrections for pressure and temperature are normally made to obtain a "reduced mobility." The measurement of average ion mobility, $K$, is useful for determining charge density, $\rho$, from the relationship $\vec{J}=\rho \mathrm{KE}$ where $\vec{J}$ is the ion current density and $\vec{E}$ is the electric field strength. Measurements of $\vec{J}$ and $\vec{E}$ have been routinely performed under dc transmission lines and in bioeffects exposure systems. Thus, the additional measurement of mobility permits for the determination of charge density. The charge density can be determined with an aspirator-type ion counter but the calibration of such devices is difficult [20] and the measurement of $\mathrm{J}, \mathrm{E}$, and $\mathrm{P}$ provides a means to calculate the accuracy of the ion counter.

Perhaps a more important reason for measuring ion mobilities is that the mobility provides a qualitative measure of ion size [22]. Ideally, the ion species are of interest when considering possible bioeffects due to exposure to ions, but sampling of ions at atmospheric pressure with a mass spectrometer is difficult and requires use of complex apparatus. Ion mobility spectra can be measured at atmospheric pressure with less complicated instrumentation and monitoring mobility spectra during a bioeffects study can serve as a form of "quality control" to insure that the types of ions that test animals are exposed to do not change dramatically. Such data also may be useful in establishing the equivalence of bioeffects investigations conducted in different laboratories.

\subsection{Ion Mobility Measurements}

Ion mobility can be determined directly by measuring the time required for an ion to travel a given distance in a known dc electric field. A device that has been used extensively for this measurement is the drift tube. Two prototype parallel plate drift tubes have been examined to determine their suitability for measuring ion mobilities at atmospheric pressure. Schematic views of the drift tubes are shown in figures 1 and 3 . Each device may be regarded as an ac time of flight drift tube because the electrical shutters which allow the passage of ions at certain times are controlled with ac voltages. Figure 1 shows a drift tube similar in principle to that employed by Bradbury and Nielsen to measure electron mobilities in gases [23]. The top shutter and bottom shutters consist of grid wires in parallel plates electrodes separated by a distance $D$ and having a dc potential difference $v$. The alternate wires in each shutter are connected electrically and sinusoidal voltages of opposite polarity are applied to adjacent wires to produce a localized electric field between the wires. The spacing between adjacent wires in the NBS drift tube was nominally about $0.5 \mathrm{~mm}$ and the wire diameter was $0.076 \mathrm{~mm}$. The voltages applied to each shutter are in phase. When the ac voltages are at near zero, the shutters allow the passage of ions. Ions which pass through the top shutter in figure 1 and travel to the bottom shutter in half a cycle of the ac voltage will pass through and be measured with an electrometer A. Measurement of ion current as a function of frequency results in a current maximum of a characteristic frequency, $F$, and at integral 


\section{BRADBURY-NIELSON TYPE ELECTRICAL SHUTTER FOR ION MOBILITY MEASUREMENTS}
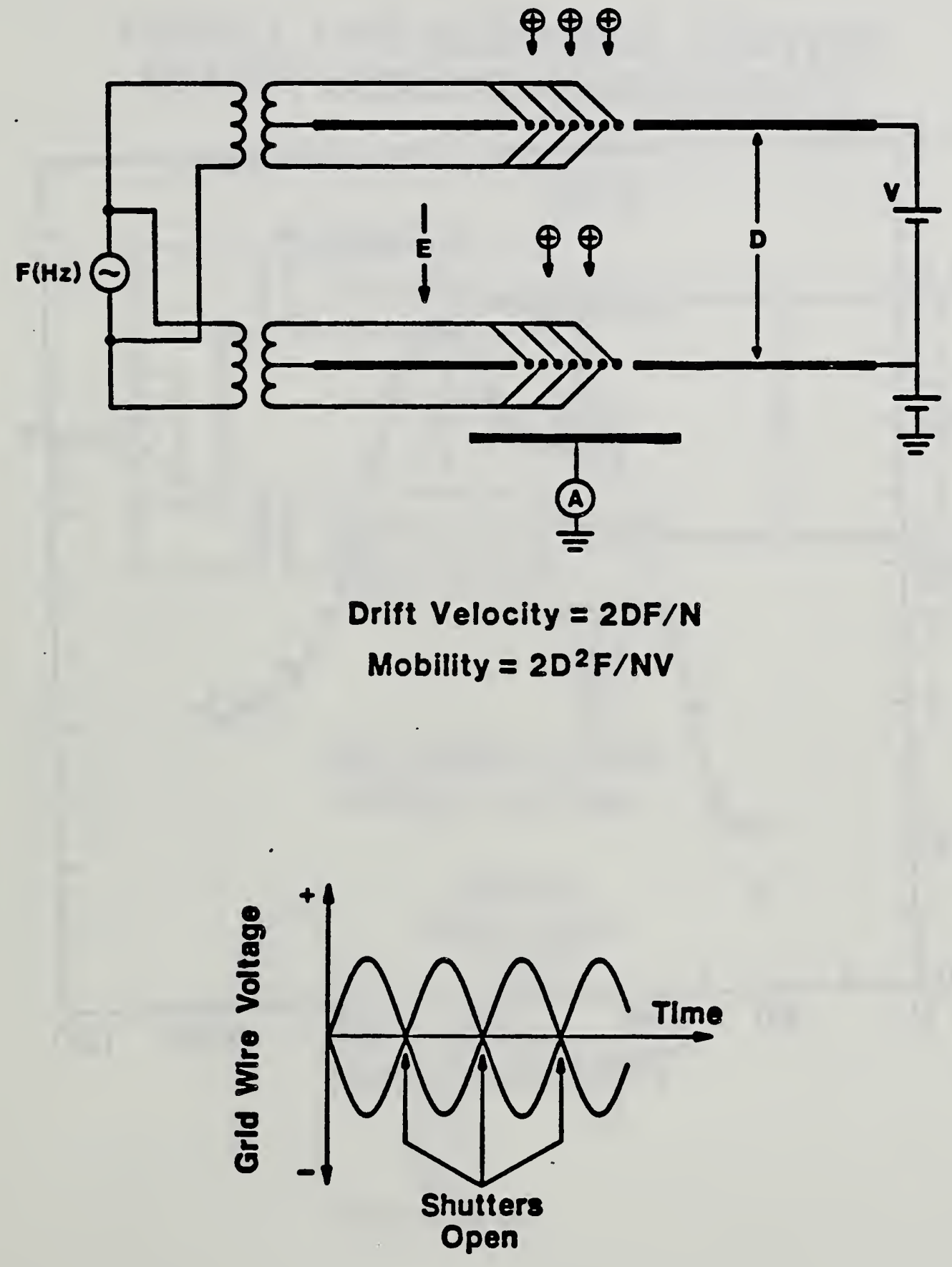

Figure 1. Schematic view of parallel plate drift tube similar in principle to that used by Bradbury and Nielsen to measure electron mobilities in gases. The shutters open when the ac voltages applied to the grid wires are at or near zero volts. 


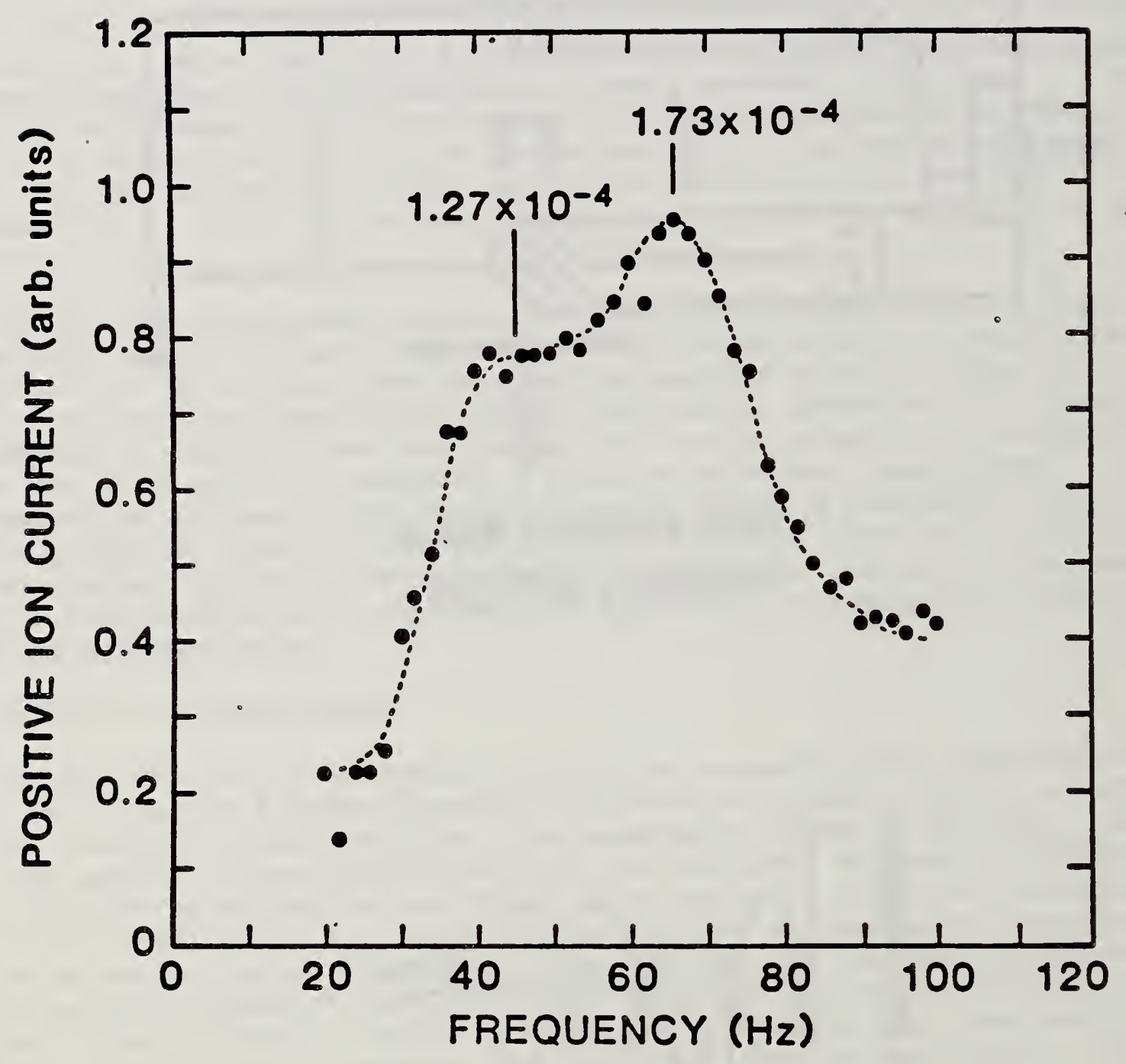

Figure 2. Sample data of positive Ion mobility as a function of frequency using the paraliel plate drift tube shown in figure 1. 


\section{TYNDALL TYPE ELECTRICAL SHUTTER FOR ION MOBILITY MEASUREMENTS}
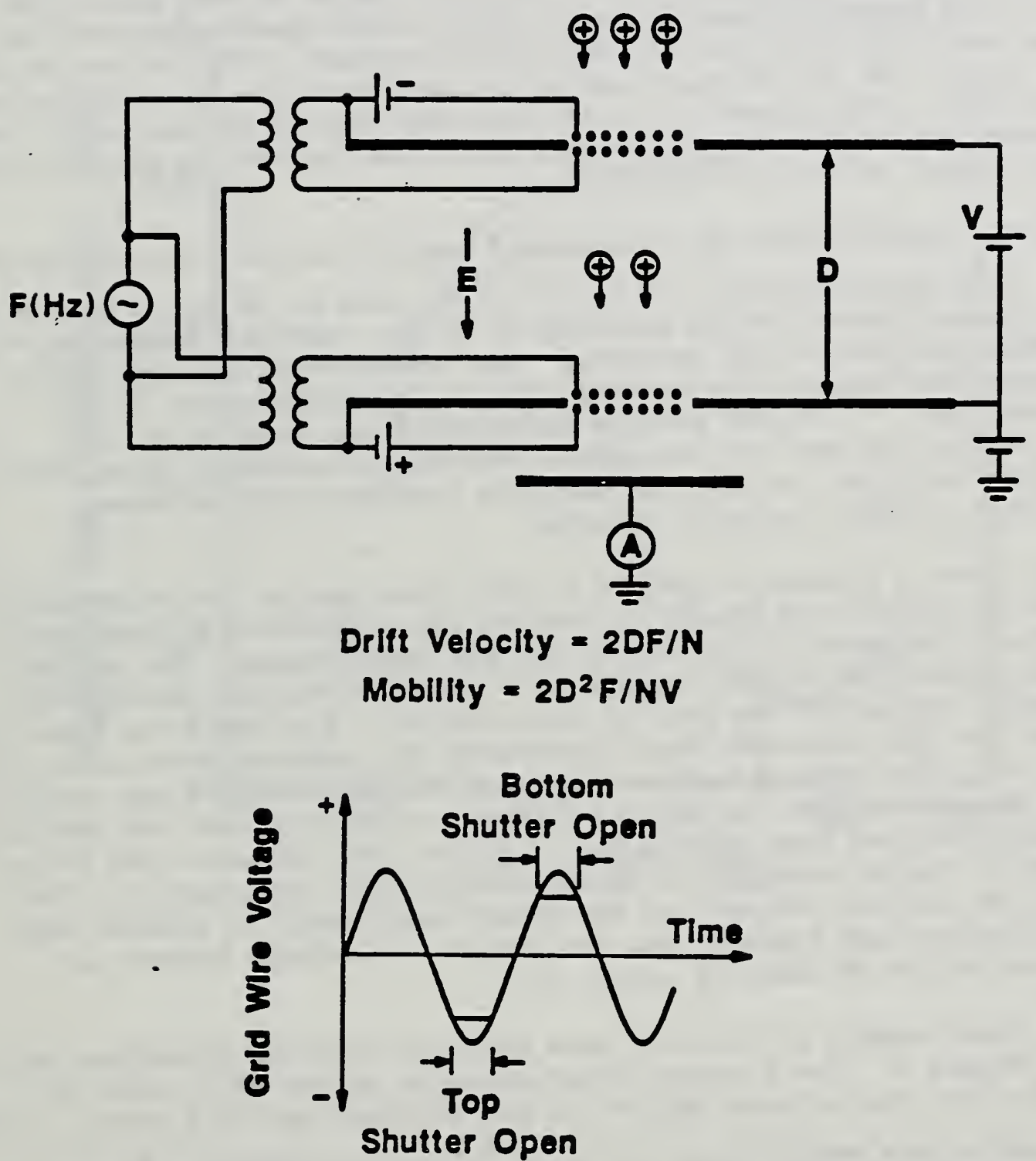

Figure 3. Schematic view of parallel plate drift tube similar in principle to that used by Tyndall and Powell to measure ion mobilities in gases. The top and bottom shutters open alternately near the peaks of the voltage. 
multiples of that frequency. The drift velocity, $v_{d}$, of the ion in the uniform field region is given by $v_{d}=2 D F / N$ where $D$ is the spacing of the parallel plates and $N$ is an integer. The mobility is given by $K=2 D^{2} F / N V$ where $V$ is the voltage applied to the parallel plates.

Figure 2 shows positive ion current measured as a function of frequency. The positive ions were produced by corona in air in a parallel plate apparatus that has been described previously [7]. The top shutter of the drift tube was positioned in the ground plane of this apparatus. The spacing between the shutters was near $0.05 \mathrm{~m}$ and the electric field strength (V/D) in the drift tube was $35 \mathrm{kV} / \mathrm{m}$. The rms voltage applied to the griú wires in each shutter was about 12 volts. The presence of more than one current maximum with its associated mobility is not unusual because more than one ion species typically results from corona activity in air [24].

A potential problem with the measurement results is the possible overlap of spectra. Ions with mobility $1.27 \times 10^{-4} \mathrm{~m}^{2} / \mathrm{Vs}$ near $45 \mathrm{~Hz}$ can also pass through the shutter system and be measured at $90 \mathrm{~Hz}$, possibly distorting the higher frequency portion of the spectrum. The Bradbury-Nielsen type drift tube may excessively broaden the spectra [25] so the seriousness of the overlap is not clear. A second problem encountered was difficulty in fabrication of the shutters and subsequent shorting of adjacent wires when the ac voltages were applied. After some use, the shorting problem became sufficiently bad to make the grids unusable.

Figure 3 shows a schematic view of a drift tube similar in principle to that employed by Tyndall and Powell to measure ion mobilities in pure gases at below atmospheric pressure [26]. During the NBS measurements, the shutters were normally closed with a bias voltage of 9 volts and opened periodically with ac voltages applied to one grid of each shutter. Each grid was made with no. 14 screen that had been made more transparent by removing every other wire in one direction. The spacing between the grids in each shutter was nominally $0.8 \mathrm{~mm}$. The expressions for ion drift velocity and mobility are the same as for the Bradbury-Nielsen type drift tube. However, the shutters open at and near the peaks of the ac voltages as shown schematically in figure 3 . The resolution of the shutter system used by Tyndall and Powell is greater than that used by Bradbury and Nielsen, but end effects reportedly prevent an absolute determination of mobility value [25].

Figure 4 shows sample preliminary data obtained with the prototype drift tube shown in figure 3. The electric field strength in the drift tube was near $31 \mathrm{kV} / \mathrm{m}$ and the rms voltage applied to the shutters was 12.5 volts. Only one current peak with a mobility of $1.11 \times 10^{-4} \mathrm{~m}^{2} / \mathrm{Ns}$ is evident in figure 4 and it may correlate with the lower mobility current maximum observed in figure 2 .

Future plans include a further evaluation of ac time of flight drift tubes, construction and evaluation of a pulsed-type time of flight drift tube, comparison of the ac and pulsed time of flight measurement techniques, and design of a high pressure ion source for the NBS mass spectrometer. 


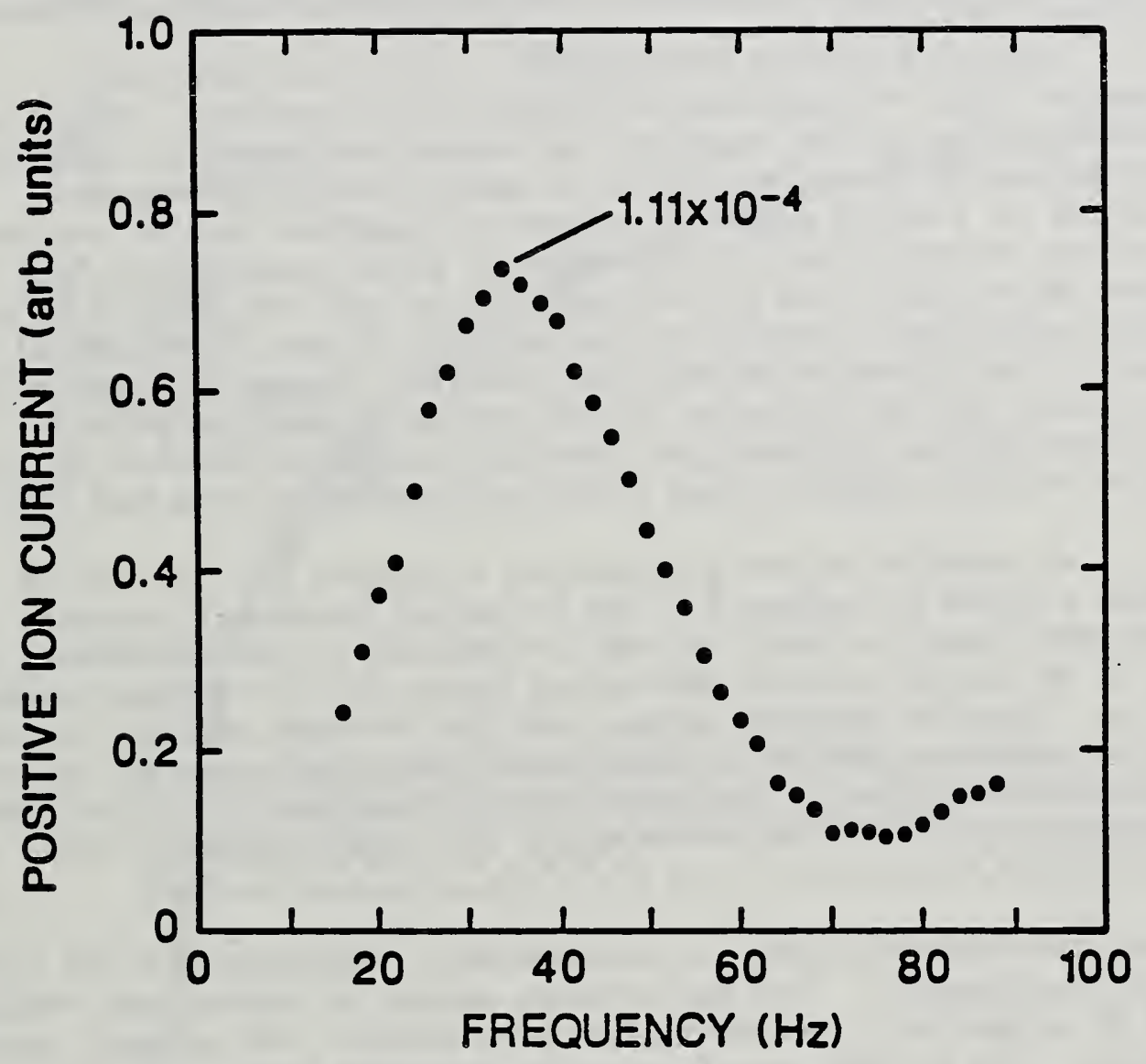

Figure 4. Sample data of positive ion mobility as a function of frequency using the parallel plate drift tube shown in figure 3. 


\subsection{Corona Detection by AM Radio}

A limited study on the use of portable AM radios as detectors of corona onset in ac electric field exposure chambers was completed during the past year. This study was prompted by the use of such devices to detect corona in biological exposure systems. Three radios were used in the study and were found to be highly sensitive for detecting either ac or dc corona in a parallel plate apparatus, provided the radio was placed in close proximity to either the high voltage supply wire or ground return wire of the apparatus. A radio simply placed in the same room with the apparatus did not give a reliable indication of corona.

Both ac and dc high voltage were utilized in the testing. The dc tests simplified determination of the magnitude of corona avalanche at inception and enabled investigation of polarity effects on sensitivity. Corona was generated by means of a sharp point or points of specified radius attached electrically to the bottom plate of the parallel plate apparatus. Two different points were used - one of radius $0.007 \mathrm{~mm}$ and the other $0.07 \mathrm{~mm}$. In some tests, both points were used at a spacing of $0.95 \mathrm{~mm}$. Other test variables were (1) the distance between the parallel plates, (2) the polarity of the dc corona and (3) the polarity of the corona generating point.

Variation in plate spacing produced gap spacings (distance between the corona generating point and the opposite flat plate) of between $2.5 \mathrm{~cm}$ and $10.5 \mathrm{~cm}$.

Figure 5 is an example of the information collected for one set of variables. Here a point of radius $0.07 \mathrm{~mm}$ at ground potential produces negative corona when positive high voltage is applied to the top plate. The plate spacing $15 \mathrm{~cm}$ and the corona generating point is $4.5 \mathrm{~cm}$ high, producing a gap of $10.5 \mathrm{~cm}$. Plotted against voltage are the average current due to corona and the approximate amount of charge per corona pulse. The inception of corona induced radio noise is indicated on the diagram [27]. The first measureable current (not shown on the diagram) was approximately $0.0005 \mu \mathrm{A}$ at $12.15 \mathrm{kV}$.

The voltage was measured with an electrostatic voltmeter and the average current with an electrometer. The approximate amount of charge per avalanche was determined by graphically measuring the area beneath the current waveforms of the avalanches. The current waveforms were observed with an oscilloscope that was connected across a $1000 \Omega$ resistor which was in series with the parallel plate ground lead.

Corona avalanches with 10 to 20 picocoulombs of charge were readily detected by means of the radio. The onset of corona as a function of voltage was also readily determined as shown in figure 5 . The radius of the initiating point, the presence of two points and the polarity of the points, had no significant effect on the results. Positive dc corona was easier to detect, than negative corona.

For the measurement conditions described above, the inception voltage for negative corona was less than that for positive corona. As a result, $60-\mathrm{Hz}$ corona could contain corona of both polarities or only negative corona. The difference in radio noise produced by different polarity corona is distinct because of the difference in magnitude of the positive and negative avalanches and because the frequency (number of pulses per unit time) of the positive 


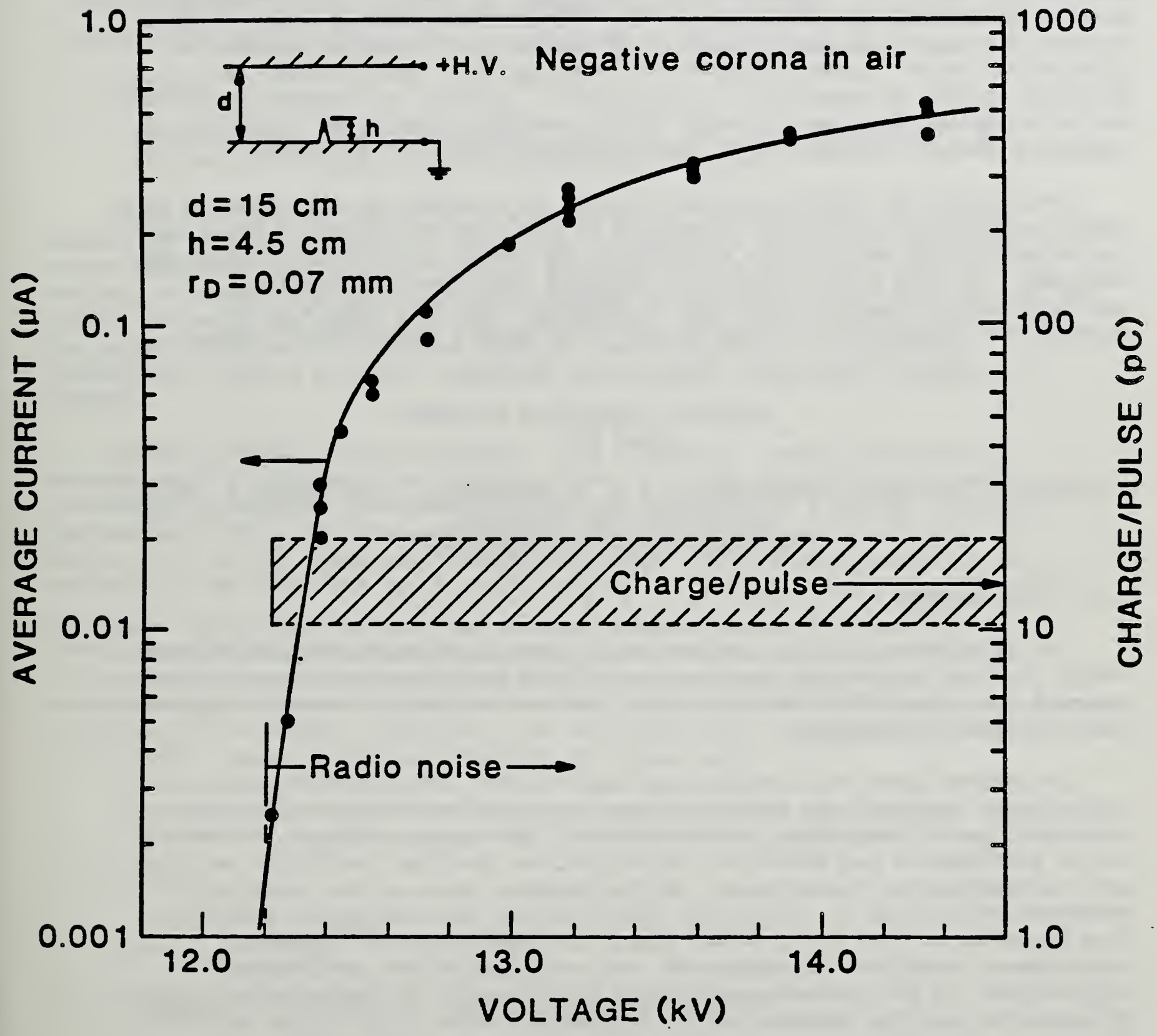

Figure 5. Typical data obtained during tests of AM radio noise as an indicator of corona onset in a parallel plate structure. Average corona current and approximate charge per corona avalanche pulse are plotted vs. voltage for negative corona. 
avalanches was normally less than for negative avalanches. The radio noise from positive corona pulses tends to overwhelm that from the negative corona if both are present.

Not mentioned above, but important from the stand point of the detection dc corona, is the observation that as the voltage continues to be increased beyond corona onset a region of glow discharge, free of pulses, will occur. Because of the absence of pulses, radio noise in the glow discharge region is not readily detected. Therefore, to determine if there is dc corona in a system, it is advisable to increase the voltage from zero in order to pass through the region of corona onset. AC corona can always be detected at elevated voltages, however, because the voltage will pass through the avalanche region at some point in the cycle. In fact, ac corona is somewhat easier to detect because the radio noise resulting from $60 \mathrm{~Hz}$ corona has a pulsating character compared to the more steady noise of dc corona.

The results of NBS measurements cannot be extended to all portable AM radios because there does not appear to be any industry standard which sets limits on minimum sensitivity of portable AM radios with ferrite-core loop antennas. However when "calibrated" against instruments providing quantitative information on corona discharges, and when placed in an appropriate location, AM radios appear to be useful detectors of corona.

\section{GASEOUS DIELECTRICS RESEARCH Task 03}

Richard J. Van Brunt, Motaganahalli C. Siddagangappa, and Arthur V. Phelps Electrosystems Division National Bureau of Standards

\subsection{Introduction}

The objectives of this project are to develop measurement capabilities and to provide fundamental data as part of the Department of Energy's basic research concerned with the development and evaluation of advanced compressedgas-insulation technology.

To reduce space requirements and improve the efficiency of high-voltage transmission systems, the electric power industry has turned toward more extensive use of compressed-gas insulation. To design meaningful tests of system performance and establish specifications for the quality of materials, more information is needed about the fundamental physical and chemical processes which lead to insulation deterioration and electrical breakdown. This research project is directed toward the evaluation of advanced measurement techniques as diagnostic tools of insulation performance; applications of gas chromatography-mass spectrometry to characterize corona by-products; and the acquisition of fundamental data, e.g. corona inception voltages, production rates of corona by-products, and the effects of contaminants on discharge initiation.

This report highlights four significant technical activities. The first is concerned with a theoretical method that has been developed to determine the consistency among electron transport, collision cross section, and 
dielectric strength data for binary gas mixtures. The second technical

activity concerns measurements of the hydrolysis rates for $\mathrm{SOF}_{2}$ and $\mathrm{SOF}_{4}$. The third concerns an investigation of $\mathrm{SF}_{6}$ oxidation mechanisms in corona

discharges using $\mathrm{SF}_{6} / \mathrm{O}_{2} / \mathrm{H}_{2} \mathrm{O}$ mixtures in which normally occurring ${ }^{16} \mathrm{O}_{2}$ or $\mathrm{H}_{2}{ }^{16} \mathrm{O}$ were replaced with ${ }^{18} \mathrm{O}_{2}$ and $\mathrm{H}_{2}{ }^{18} \mathrm{O}$ respectively. The fourth is concerned with a determination of the rate for $\mathrm{F}^{-}$transfer in $\mathrm{SF}_{6}{ }^{-}+\mathrm{SOF}_{4}$ collisions and the influence of this process on $\mathrm{SOF}_{4}$ production in negative, point-plane corona discharges.

3.2. Evaluation of Consistency among Electron Collision, Transport, and Dielectric Strength Data for Binary Gas Mixtures

This work was motivated by the need to find a convenient, objective method for evaluating data on dielectric strength or electrical breakdown in electronegative gas mixtures used as insulating or dielectric media in highvoltage systems. The method to be proposed here is relatively easy to use and offers not only the means for data evaluation, but also provides insight into the physical bases for observed behavior as a function of gas mixture composition such as pressure dependent or pressure independent synergistic effects.

Details of this method together with a critical review of previous methods used to parameterize breakdown data in terms of electron transport or fundamental collision cross section data are included in a recent archival publication [28]. The discussion given here is restricted to a brief description of the "pressure-independent" model and its application to the analysis of data for the gas mixtures $\mathrm{SF}_{6} / \mathrm{N}_{2}, \mathrm{SF}_{6} / \mathrm{CCl}_{2} \mathrm{~F}_{2}$, and $\mathrm{CCl} l_{2} \mathrm{~F}_{2} / \mathrm{N}_{2}$ which have been the subject of previous extensive experimental and theoretical investigations and for which there exist controversies in either reported values for dielectric strengths or in relevant cross section data. From analysis applied to these mixtures, it has been possible to determine the sets of dielectric strength, transport, and collision cross section data that exhibit the highest and lowest degrees of consistency.

The proposed method of analysis is based upon three assumptions. The first is that the kinetic energy distribution function, $f_{m}(\varepsilon)$, is maxwellian of the form

$$
f_{m}(\varepsilon)=2 \pi\left(\pi k T_{m}\right)^{-3 / 2} \exp \left(-\varepsilon / k T_{m}\right)
$$

which satisfies the normalization requirement

$$
\int_{0}^{\infty} f(\varepsilon) \varepsilon^{1 / 2} d \varepsilon=1
$$


and where $k$ is the Boltzman constant and $T_{m}$ is the electron temperature that depends on the electric field-to-gas density ratio $\mathrm{E} / \mathrm{N}$, and is related to the mean electron energy $\dot{\varepsilon}$ by

$$
T_{m}=2 \bar{\varepsilon} / 3 \mathrm{k}
$$

This assumption is reasonable provided the computation of the electron transport parameters needed to determine dielectric strength are insensitive to the detailed shape of $f_{m}(\varepsilon)$, since it is well known [28] that in general this function is not maxwellian. The relevant transport parameters are the ionization coefficient, $\alpha_{\mathrm{m}} / \mathrm{N}$, the electron attachment coefficient $\eta_{\mathrm{m}} / \mathrm{N}$, and the drift velocity $W_{m}$ that are given respectively by

$$
\begin{aligned}
& \frac{\alpha_{\mathrm{m}}}{\mathrm{N}}=(2 / \mathrm{m})^{1 / 2}\left[\mathrm{FI} \mathrm{m}_{1}+(1-F) I_{\mathrm{m} 2}\right] / \mathrm{W}_{\mathrm{m}}, \\
& \frac{\eta_{\mathrm{m}}}{\mathrm{N}}=(2 / \mathrm{m})^{1 / 2}\left[\mathrm{FH}_{\mathrm{m} 1}+(1-F) \mathrm{H}_{\mathrm{m} 2}\right] / \mathrm{W}_{\mathrm{m}}, \\
& W_{\mathrm{m}}=-\frac{\mathrm{e}}{3}(2 / \mathrm{m})^{1 / 2} \frac{\mathrm{E}}{\mathrm{N}} \mathrm{S}_{\mathrm{mm}},
\end{aligned}
$$

where $e$ and $m$ are the electronic charge and mass respectively, and

$$
\begin{aligned}
I_{m j} & =\int_{\varepsilon}^{\infty} \varepsilon f_{m}(\varepsilon) \sigma_{I j}(\varepsilon) d \varepsilon, \\
H_{m j} & =\int_{0}^{\infty} \varepsilon f_{m}(\varepsilon) \sigma_{A j}(\varepsilon) d \varepsilon, \\
S_{m m} & =\int_{0}^{\infty}\left(F \sigma_{M 1}(\varepsilon)+(1-F) \sigma_{M 2}(\varepsilon)\right]^{-1} \frac{d f_{m}(\varepsilon)}{d \varepsilon} \varepsilon d \varepsilon \\
j & =1,2 .
\end{aligned}
$$

In Eqs. (7)-(9), $\sigma_{I j}, \sigma_{A j}$, and $\sigma_{M j}$ are the ionization, attachment, and momentum transfer cross sections for the $j$ th gas constituent respectively, and $\varepsilon_{I j}$ is the corresponding ionization potential. For a binary mixture consisting of gas components $A$ and $B$ corresponding respectively to $j=1$ and $2, F$ is given by

$$
F=[A] /([A]+[B]) .
$$


In the case of electronegative gases considered here where $\eta_{\mathrm{m}} \neq 0$, it is convenient to define "dielectric strength" as the critical $E / N=(E / N)_{c}$ at which

$$
\alpha_{\mathrm{m}} / \mathrm{N}=\eta_{\mathrm{m}} / \mathrm{N}
$$

The second assumption is that the electron temperature for the gas mixture can be represented as a weighted linear combination of the electron temperatures for the individual gas components, i.e.

$$
\mathrm{T}_{\mathrm{m}}=\mathrm{g}(\mathrm{F}) \mathrm{T}_{1}(E / \mathrm{N})+(1-\mathrm{g}(\mathrm{F})) \mathrm{T}_{2}(E / \mathrm{N}) \text {, }
$$

where $g(F)$ satisfies the conditions

$$
\begin{aligned}
& g=1 \text { at } F=1, \\
& g=0 \text { at } F=0 . \\
& g>0 \text { for } 1>F>0 .
\end{aligned}
$$

The third and final assumption provides a prescription for finding the $E / N$ dependencies of $\mathrm{T}_{1}$ and $\mathrm{T}_{2}$ using known electron transport parameters for the individual gas components. The requirement from this assumption can be expressed mathematically as:

$$
x\left(\xi_{j}(x) / N\right)_{e x}=\beta_{j}\left(x \xi_{j}\left(T_{j}\right) / N\right)_{t h}
$$

where $x=E / N,\left(x \xi_{j}\left(T_{j}\right) / N\right)_{t h}$ is the product of $x$ and a transport parameter for the $j$ th gas component calculated using Eqs. (1) together with known cross sections, $\left(\xi_{j}(x) / N\right)_{e x}$ is the experimentally known transport parameter, and $\beta_{j}$ is a "correction factor" which can be used as an adjustable parameter to obtain the best fit to critical $E / N$ data, $(E / N)_{c}, m$, that have been determined experimentally. It is required that $\beta_{i}>0$, and it is evident that if the maxwellian distribution applies and the cross section and transport data are consistent, then $\beta_{j}=1$. Large deviations of $\beta_{j}$ from unity obtained in fitting $(E / N)_{C, m}$ data would indicate a failure of the maxwellian approximation, significant inconsistencies among the breakdown, transport, and cross section data, or a combination of both problems. In a sense, the $\beta_{j}$ can be viewed as consistency parameters.

The first step in making fits to dielectric strength, $(E / N)_{c}, m$, data is to determine the predicted $F$-dependence of $T_{m}$ using Eqs. (4) and (5) in Eq. (11), i.e. solving the equation

$$
0=\int_{0}^{\infty}\left\{F\left(\sigma_{I 1}(\varepsilon)-\sigma_{A 1}(\varepsilon)\right)+(1-F)\left(\sigma_{I 2}(\varepsilon)-\sigma_{A 2}(\varepsilon)\right)\right] \varepsilon f m\left(\varepsilon, T_{m}\right) d \varepsilon
$$


for $\mathrm{T}_{\mathrm{m}}$. The next step is to find the $\mathrm{E} / \mathrm{N}$ dependencies of $\mathrm{T}_{1}$ and $\mathrm{T}_{2}$ using Eq. (14). For the examples considered here, the ionization coefficient data were selected for use in Eq. (14), i.e. $\xi_{j}=\alpha_{j}$. Using linear representations of $\alpha_{j} / \mathrm{N}$ given by

$$
\alpha_{j} / N=A_{j 0}+A_{j 1}(E / N)
$$

Eq. (14) assumes a quadratic form

$$
\hat{A}_{j 1} \mathrm{X}^{2}+\hat{A}_{j 0} \mathrm{X}+3(2 / \mathrm{m})^{1 / 2} \hat{\beta}_{j}\left[I_{j j}\left(T_{j}\right) / S_{j j}\left(T_{j}\right) j=0\right.
$$

which can be readily solved numerically to find the $x$ and $\beta_{j}$ dependencies of $T_{j}$. In Eq. (17) $I_{j j}$ and $s_{j j}$ are respectively integrals like Eqs. (7) and (9) where $f_{m}(\varepsilon)$ for the mixture is replaced with $f_{j}(\varepsilon)$ for the $j$ th pure gas component.

Having found $T_{m}(F), T_{1}(E / N)$, and $T_{2}(E / N)$, Eq. (12) can be solved numerically to give the predicted $(E / N)_{c, m}$. In making the fits to experimental critical field data discussed below, it was initially assumed that $g(F)=F$, and the parameters $\beta_{1}$ and $\beta_{2}$ were adjusted within the restricted range $5.0>\beta_{j}>0.25$ to give the best least squares fit to $(E / N)_{c, m}$-versus-F data. Slight improvements to the fits could sometimes be found using one of the two parameterized forms for $g(F)$ given by

$$
g\left(F, \beta_{3}\right)=\beta_{3} F^{1 / 2}+\left(1-\beta_{3}\right) F \text {, }
$$

or

$$
g\left(F, \beta_{4}\right)=\beta_{4} F^{2}+\left(1-\beta_{4}\right) F \text {, }
$$

where $\beta_{3}$ and $\beta_{4}$ are adjustable constants that can assume any positive or negative value. It was found, however, that if $\beta_{1}$ and $\beta_{2}$ are close to unity when $g(F)=F$, then further improvements in the fits using Eqs. (18) or (19) are either not possible for $\beta_{3}, \beta_{4} \neq 0$, or are relatively minor and correspond to small parameter values, i.e. $\left|\beta_{3}\right|,\left|\beta_{4}\right|<0.2$. This suggests that Eq. (12), in which $g(F)=F$, generally gives a reasonable representation of $\mathrm{T}_{\mathrm{m}}(\mathrm{F})$ when consistent data sets are used.

A standard FORTRAN computer program was written to carry out the steps indicated above. If the parameters $\beta_{1}$ or $\beta_{2}$ were found to lie outside of the range indicated above, then the corrections to the calculated ionization coefficients were considered to be excessive and it was assumed that either 


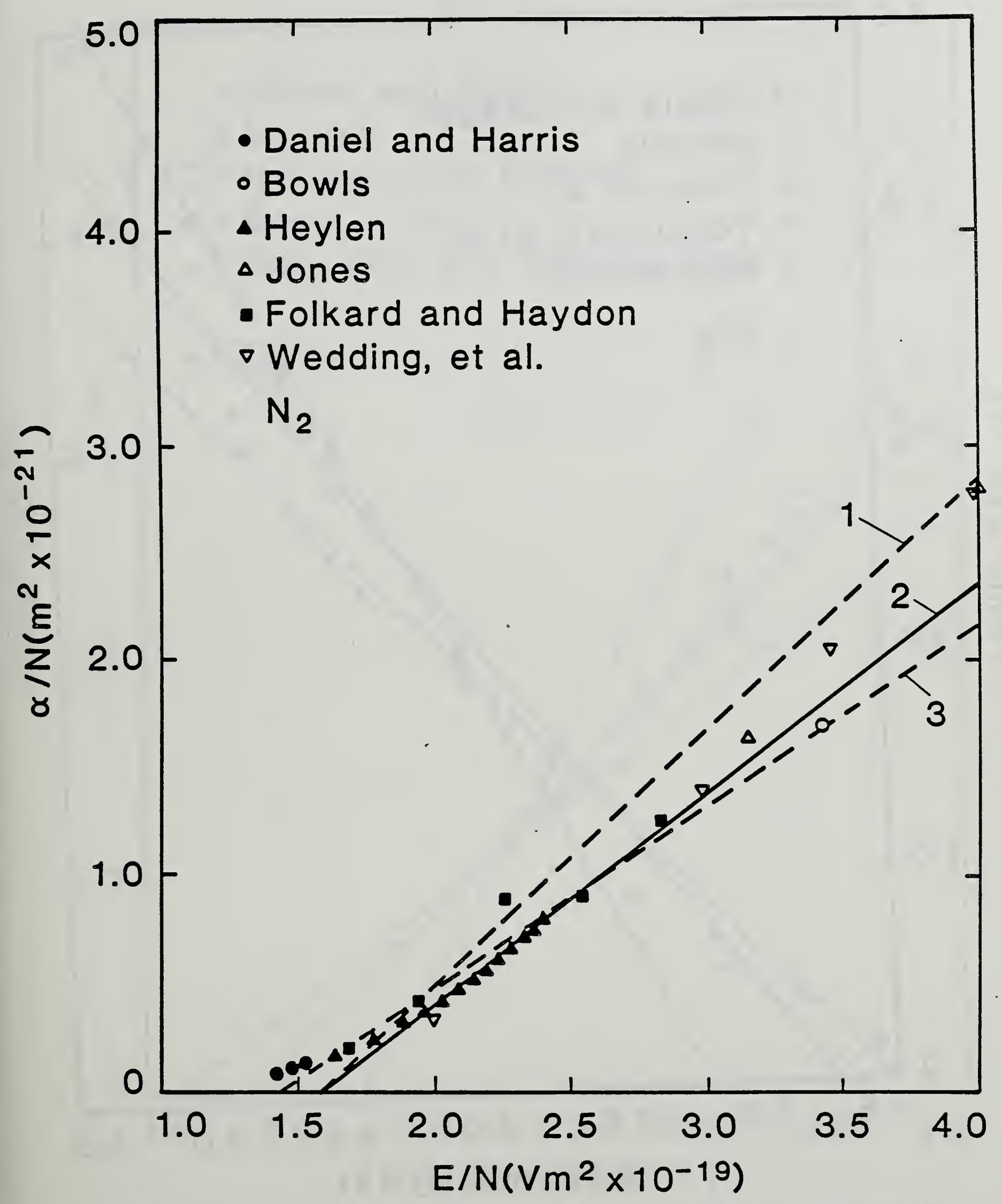

Figure 6. Ionization coefficient data for $\mathrm{N}_{2}$ from the various indicated sources, and linear representations of these data used in fitting dielectric strength data for $\mathrm{SF}_{6} / \mathrm{N}_{2}$ and $C C l_{2} \mathrm{~F}_{2} / \mathrm{N}_{2}$ gas mixtures. 


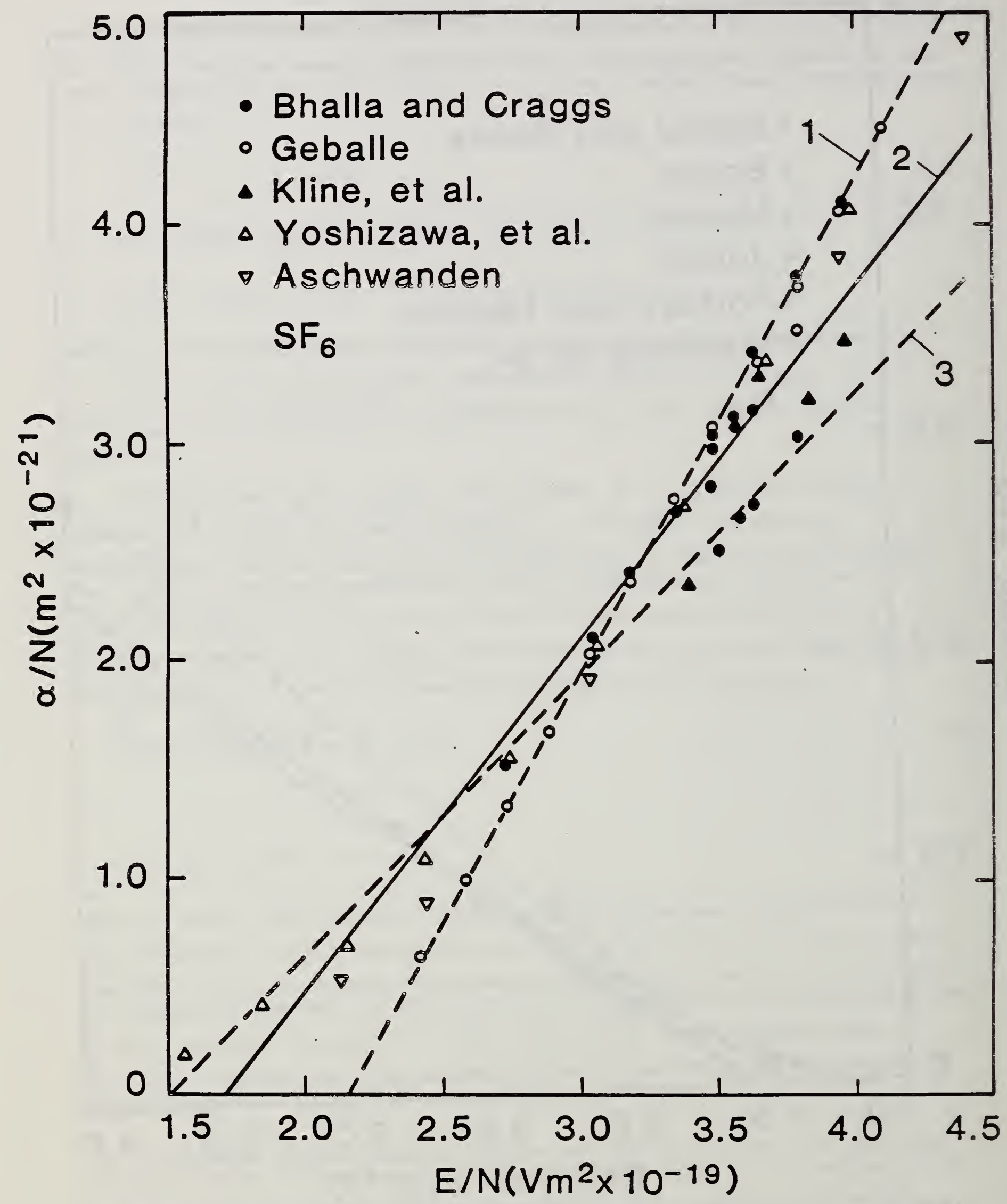

Figure 7. Ionization coefficient data for $\mathrm{SF}_{6}$ from the various indicated sources, and linear representations of these data used in fitting dielectric strength data for $\mathrm{SF}_{6} / \mathrm{N}_{2}$ and $\mathrm{SF}_{6} / \mathrm{CCl}_{2} \mathrm{~F}_{2}$ gas mixtures. 


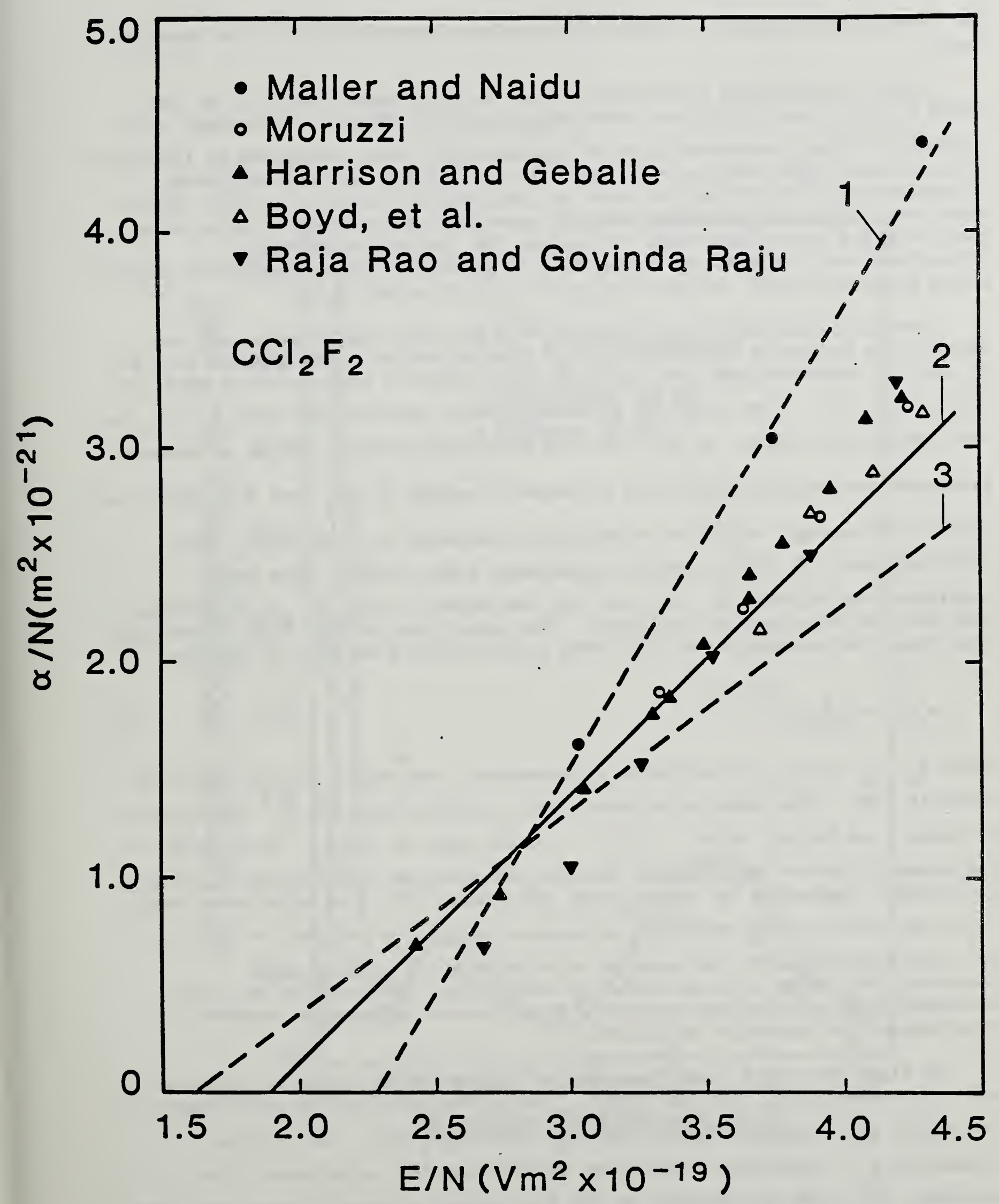

Figure 8. Ionization coefficient data for $\mathrm{CCl}_{2} \mathrm{~F}_{2}$ from various indicated sources, and linear representations of these data used in fitting dielectric strength data for $\mathrm{CCl}_{2} \mathrm{~F}_{2} / \mathrm{N}_{2}$ and $S F_{6} / \mathrm{CCl}_{2} \mathrm{~F}_{2}$ gas mixtures. 
the model did not apply or there was a serious inconsistency in the data set used.

Data on ionization coefficients used in the present analysis for the gases $\mathrm{N}_{2}, \mathrm{SF}_{6}$, and $\mathrm{CCl}_{2} \mathrm{~F}_{2}$ are shown respectively in Figs. 6-8 together with different linear representations of the data that were considered as indicated by the lines. The numbers 1,2 , and 3 in the figures indicate different parameters used in fitting the data as indicated in Tables I to III. These data were derived from various sources given in Refs. [28-32]. It is seen that over the narrow $\mathrm{E} / \mathrm{N}$ range of concern for dielectric strength determinations, the quality of the data is generally not sufficient to justify using representations that are higher than first order in $E / N$.

Available numerical cross section data for these gases were used to compute the integrals in Eqs. (7)-(9). The ionization cross section data for $\mathrm{N}_{2}$ and $\mathrm{SF}_{6}$ were obtained from [33] and the ionization cross section data for $\mathrm{CCl}_{2} \mathrm{~F}_{2}$ from [34]. The electron attachment cross section data used for $\mathrm{SF}_{6}$ was that reported by Kline, et al. [35] and represents the sum of all attachment processes including dissociative attachment leading to $\mathrm{SF}_{5}{ }^{-}$and $\mathrm{F}^{-}$formation as well as low-energy, collision stabilized attachment to form $\mathrm{SF}_{6}{ }^{-}$. Two different sets of $\mathrm{CCl}_{2} \mathrm{~F}_{2}$ electron attachment cross section data were considered as reported in [34] and [36] and shown in Fig. 9. It is obvious that the two data sets do not agree. The solid line in Fig. 9 is a convenient analytical representation of the cross section data from [32] of the form

$$
\sigma_{A}(\varepsilon)=\sum_{i=1}^{3} B_{i} \varepsilon^{b_{i}} e^{-a_{i} \varepsilon}
$$

where $B_{i}, b_{i}$, and $a_{i}$ are adjustable parameters, the values for which can be found in [28]. The momentum transfer cross section data for $\mathrm{SF}_{6}$ and $\mathrm{N}_{2}$ were obtained from Phelps, et al. [37-39]. In the case of $C C l_{2} F_{2}$, there exist at the present time no experimental data on the momentum transfer cross section. Following a suggestion by Govinda Raju and Hackam [40], the momentum transfer cross section for this molecule was assumed to equal a constant of $3.0 \times 10^{-15}$ $\mathrm{cm}^{2}$, which approximates the average value determined by Novak and Frechette [41] using fits to diffusion coefficient and mobility data from Boltzmann type calculations coupled with estimates of momentum transfer associated with inelastic collisions.

In Figs. 10-12 are shown examples of fits based on the model discussed above to experimental critical $(E / N)_{c, m}$ data obtained from the literature for the binary gas mixtures $\mathrm{SF}_{6} / \mathrm{N}_{2}, \mathrm{CCl} \ell_{2} / \mathrm{N}_{2}$, and $\mathrm{CCl} \ell_{2} \mathrm{~F}_{2} / \mathrm{SF}_{6}$. The fitting parameters $\beta_{j}$, ionization coefficient representations, attachment cross sections, etc. that corresponds to the fits shown in these figures are given in Tables I through III. The data selected for fitting were obtained from the 


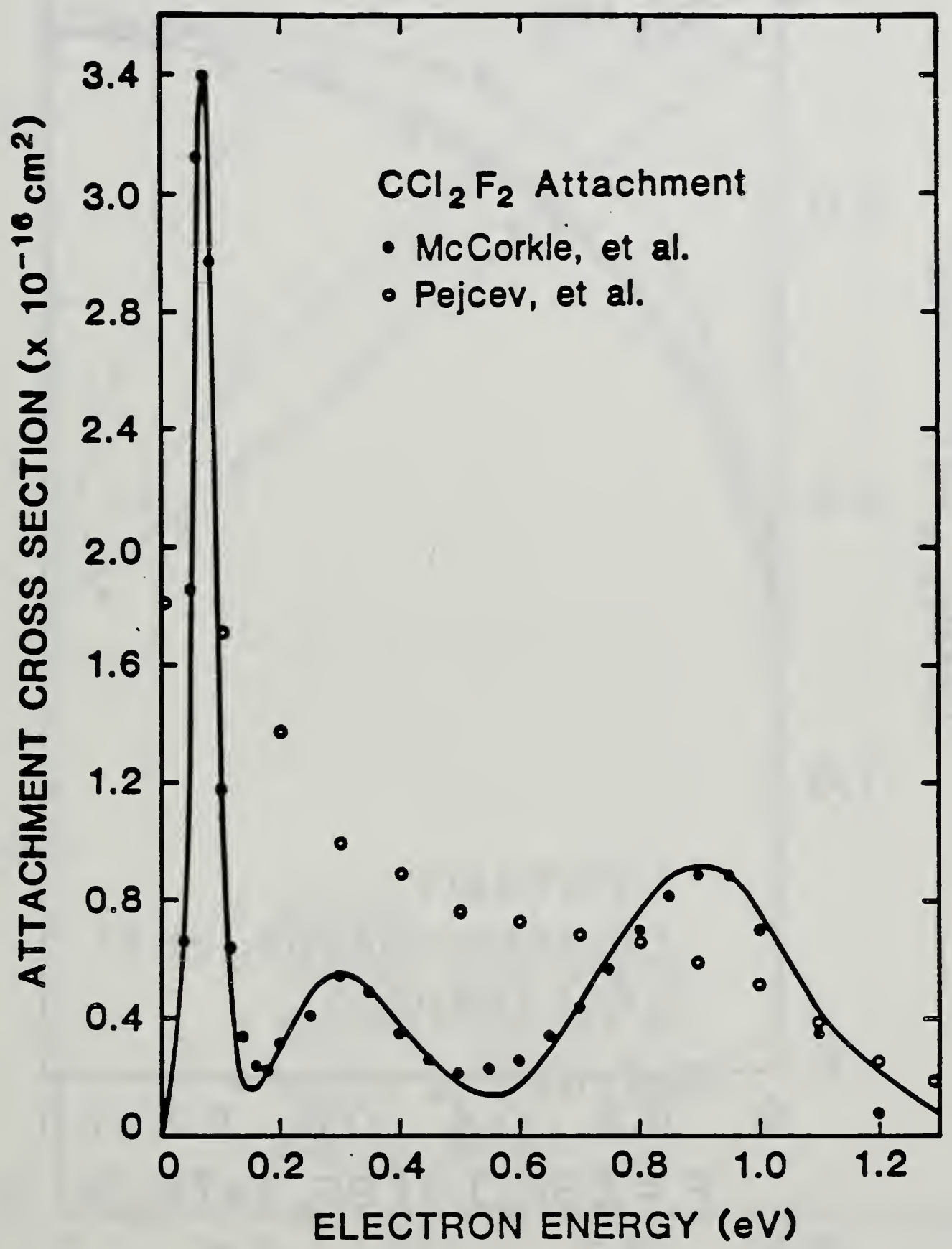

Figure 9. Energy dependencies of electron attachment cross section data for $C C{ }_{2} F_{2}$ from different indicated source. The solid line is a fit to the data of McCorkle. et al. using Eq. (20). 


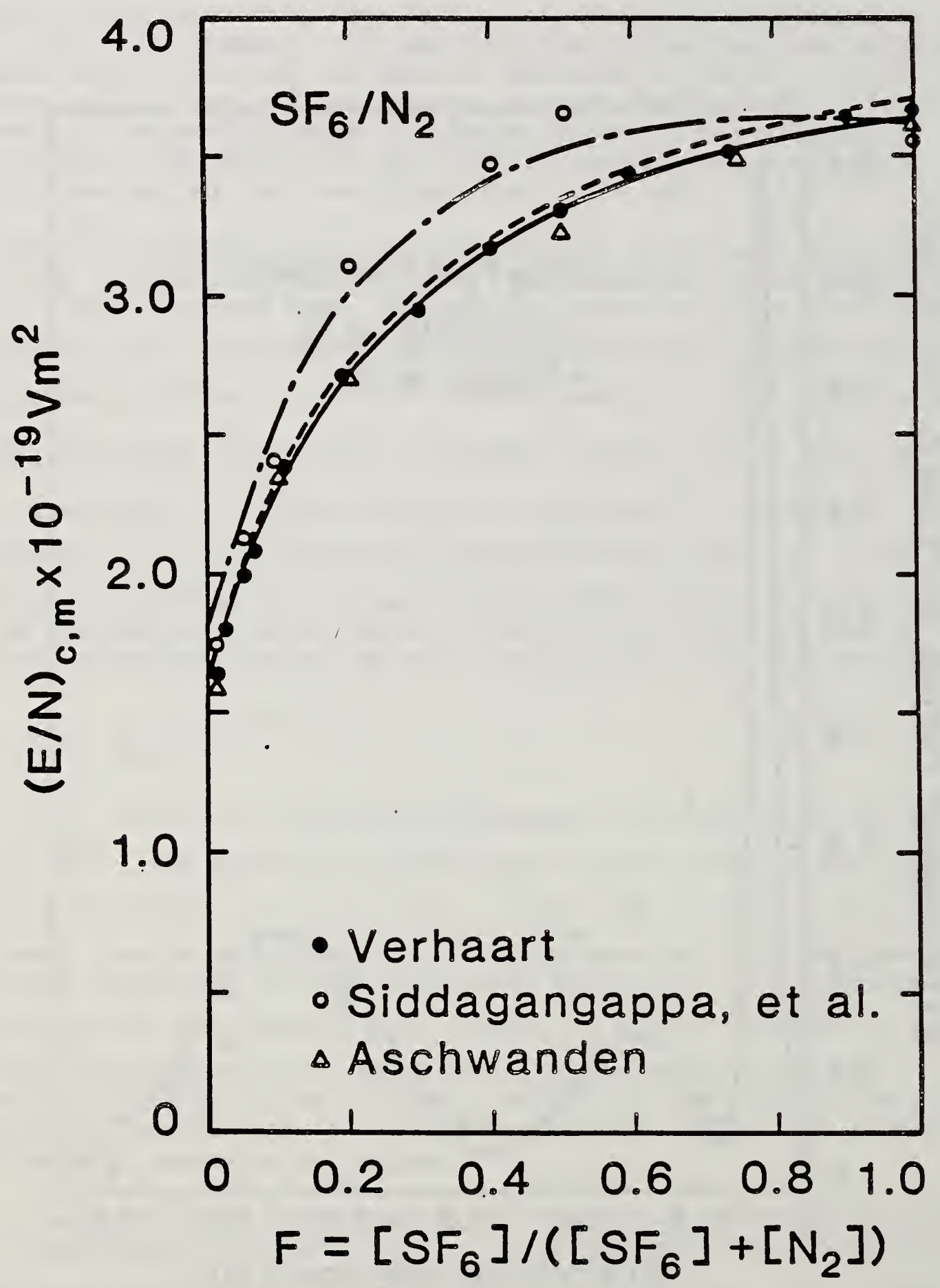

Figure 10. Best fits to the indicated dielectric strength data for $\mathrm{SF}_{6} / \mathrm{N}_{2}$, where the dash-dot curve is a fit to the data of Siddagangappa and co-workers [43] and the solid and dashed curves are fits to the data of Verhaart [42] using respectively numerical and analytical representations of the relevant cross sections (see Table I). 


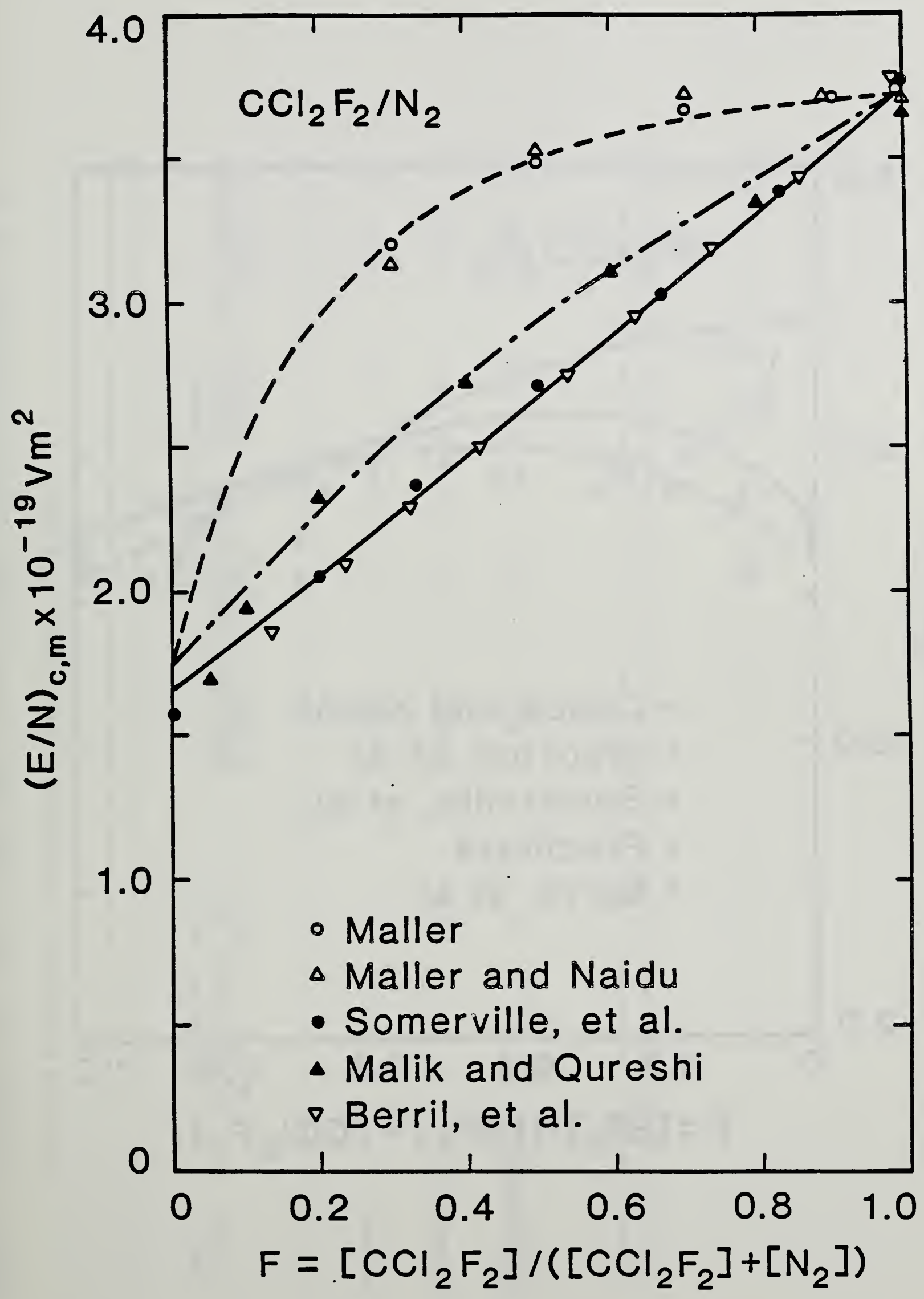

Figure 11. Best fits to the indicated $\mathrm{CCl}_{2} \mathrm{~F}_{2} / \mathrm{N}_{2}$ dielectric strength data for the highest degrees of consistency (see Table II). 


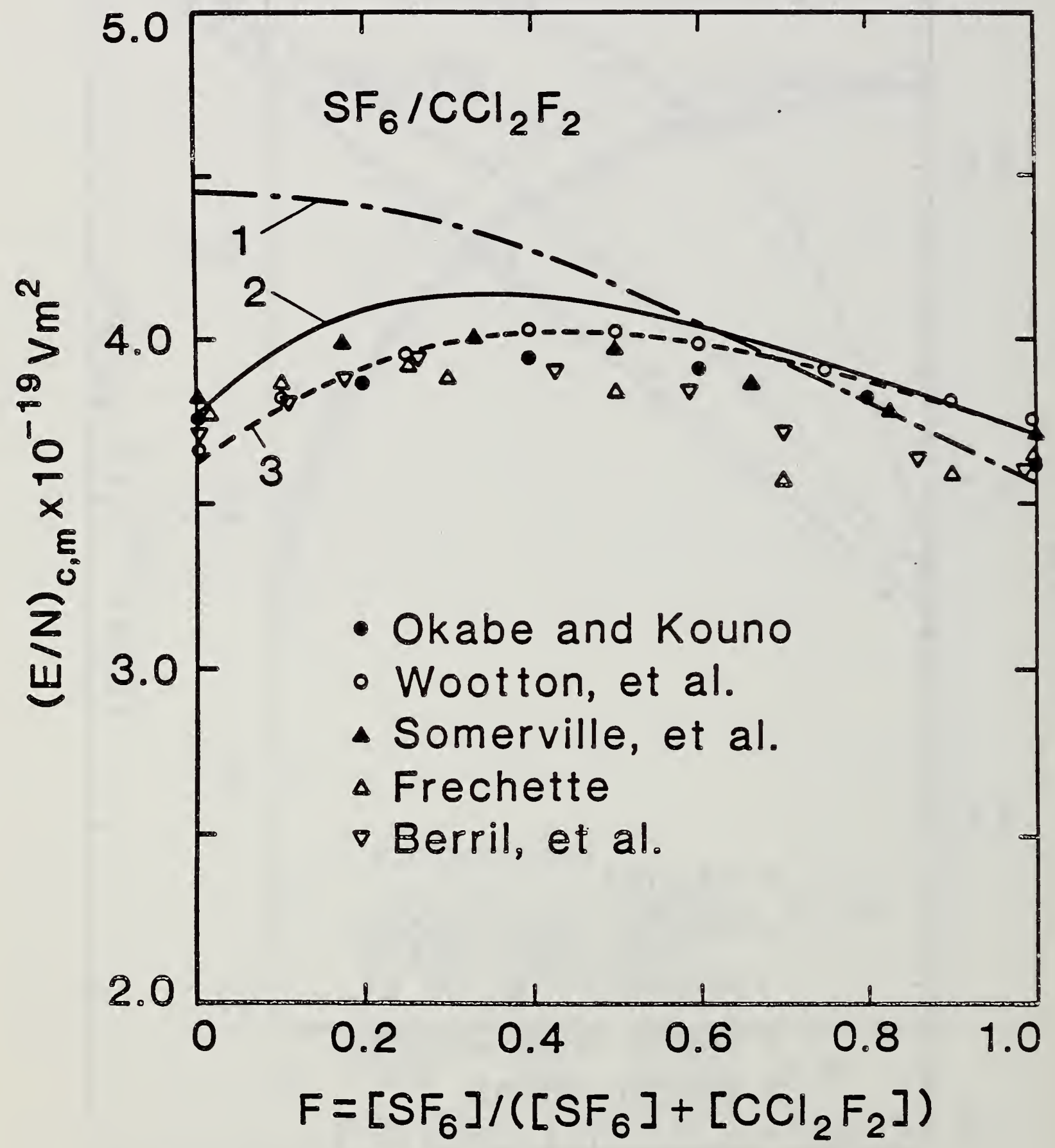

Figure 12. Dielectric strength data for $\mathrm{SF}_{6} / \mathrm{CCl}_{2} F_{2}$ mixture with best fits of highest consistency to the data of Wootton, et al. [48] (see Table III). 


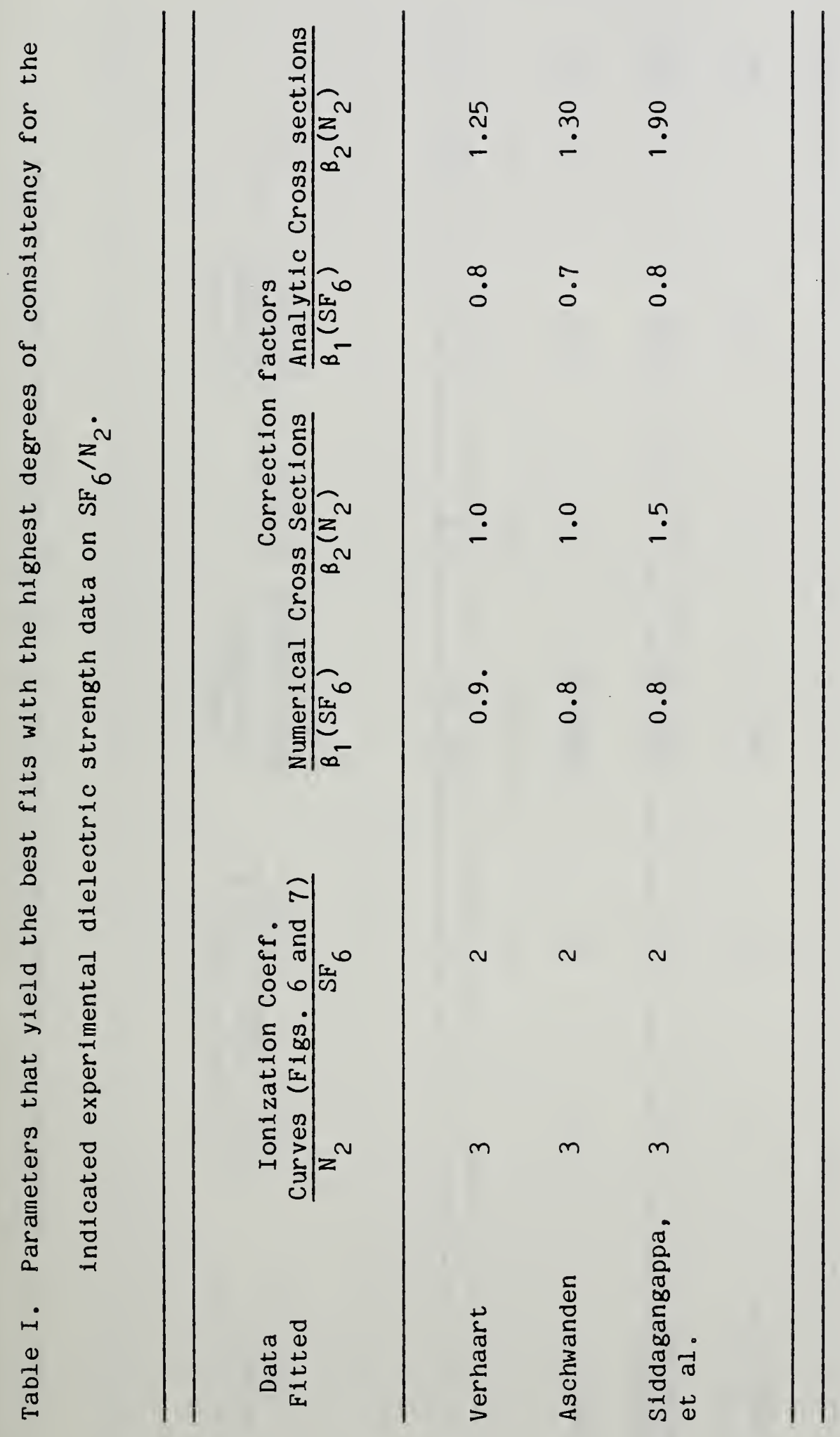




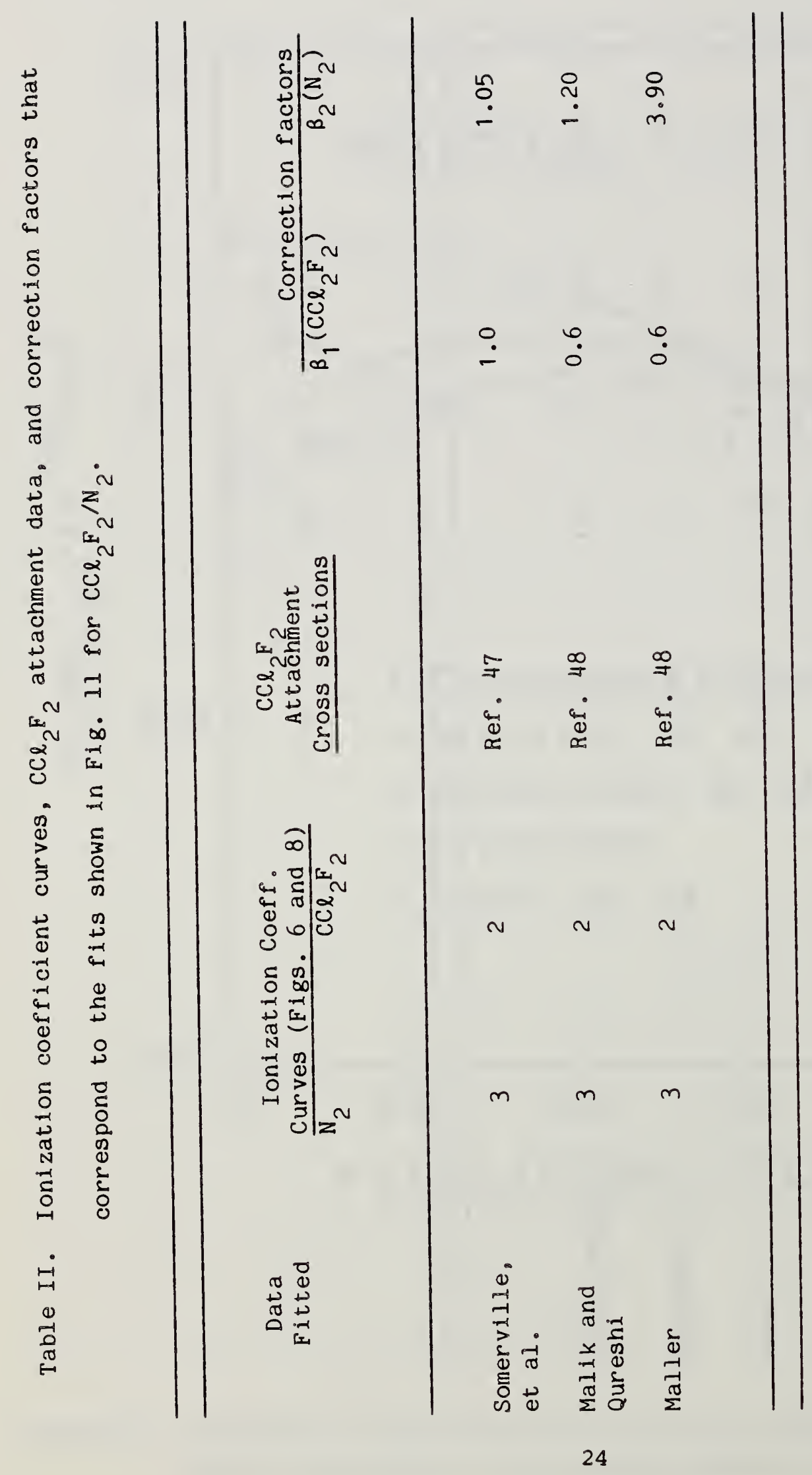




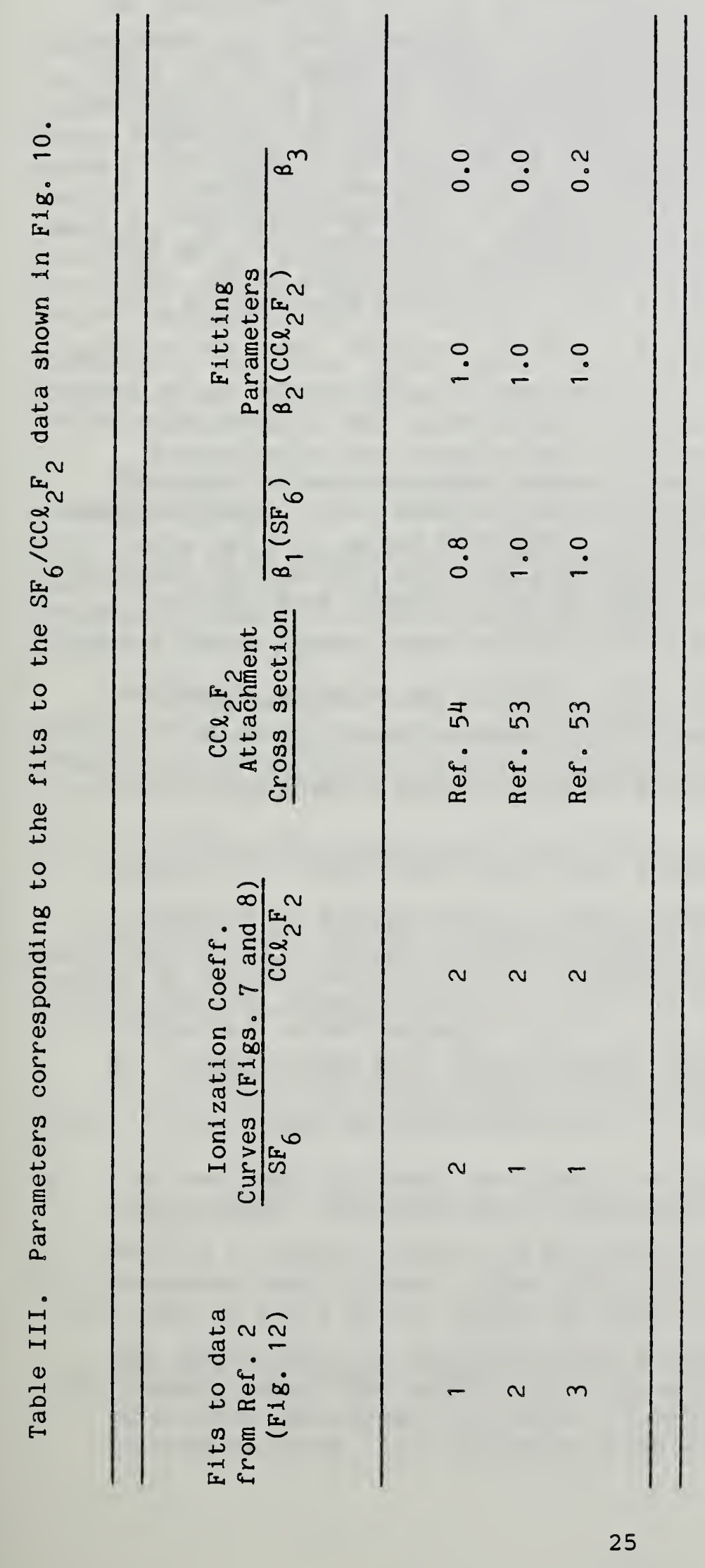


following references: $\mathrm{SF}_{6} / \mathrm{N}_{2}[32,42-44] ; \mathrm{CCl}_{2} \mathrm{~F}_{2} / \mathrm{N}_{2}[44-47]$; $\mathrm{CCl}_{2} \mathrm{~F}_{2} / \mathrm{SF} 6[44,47-50]$.

For the mixture $\mathrm{SF}_{6} / \mathrm{N}_{2}$ the data of Aschwanden [32] and Verhaart [42] are in close agreement; therefore only the fits to the Verhaart data are shown in Fig. 10 together with the best fit to the data of Siddagangappa, et al. [43]. The solid and dot-dashed lines correspond respectively to fits for the data of Verhaart and Siddagangappa et al. made using numerical cross section data. The dashed curve is a fit to the Verhaart data using analytical expressions for the cross sections as given for example, by Eq. (20) and specified in [28]. All of the curves in Fig. 10 correspond to the assumption that $g(F)=F$ in Eq. (12). Slight, almost imperceptible improvements in the fits were found for the three data sets selected when $g(F)$ was given by Eq. (19) with parameter values in the range $\left|\beta_{4}\right|<0.5$. It is seen from Table $I$, as judged by the closeness of the parameters $\beta_{1}$ and $\beta_{2}$ to unity, that the results of Verhaart [42] and Siddagangappa, et al. [43] yield respectively the highest and lowest degrees of consistency with the assumed swarm and cross section data. It is worth noting that the results of Boltzmann type calculations $[35,39,51,52]$ also tend to be in better agreement with the data of verhaart. As expected, the fits made using numerical cross sections yield higher degrees of consistency than those using approximate analytical forms. It was also found that for all three data sets, the use of ionization coefficient curves 3 and 2 respectively for $\mathrm{N}_{2}$ and $\mathrm{SF}_{6}$ (see Figs. 6 and 7) always gave the best fits for the highest degrees of consistency. In the case of $\mathrm{SF}_{6}$, curve 2 best represents an average of the available data. Within the relevant breakdown range $3.7 \times 10^{-19} \mathrm{Vm}^{2}>\mathrm{E} / \mathrm{N}>1.6 \times 10^{-19} \mathrm{Vm}^{2}$, curve 3 for $\mathrm{N}_{2}$ gives an accurate representation of the data at low $\mathrm{E} / \mathrm{N}$, but falls somewhat below the average at high $\mathrm{E} / \mathrm{N}$.

In the case of the $\mathrm{CCl}_{2} \mathrm{~F}_{2} / \mathrm{N}_{2}$ mixture (see Fig. 11 and Table II) separate fits were made here using the attachment cross section of data of McCorkle, et al. [36] and Pejcev, et al. [34]. Since the data of Maller [53] and Maller and Naidu [46] are in close agreement, only the best fit to the Maller data is shown as indicated by the dashed line in Fig. 11. Also, because the recently reported data of Berril, et al. [47] are in close agreement with the data of Somerville, et al. [44], only the latter data set was used for fitting. The best fits to the data of Malik and Qureshi [45] and Somerville, et al. [44] correspond respectively to the dot-dashed and solid lines in Fig. 11.

The curves drawn in Fig. 11 represent again the best fits obtained in each case for the highest degree of consistency with $g(F)=F$. The $\mathrm{CCl}_{2} F_{2}$ ionization coefficient representation indicated by curve 2 in Fig. 8 yielded the highest degree of consistency in all cases and is seen to best represent an average of all the data. As in the case of $\mathrm{SF}_{6} / \mathrm{N}_{2}$, curve 3 for $\mathrm{N}_{2}$ gave the best consistency. The fit to the data of Somerville, et al. [44] using the attachment cross section of McCorkle et al. [36] yielded the highest degree of consistency. The data of Somerville, et al. also agree best with results of Boltzmann type calculations [41]. The data of Maller [46], which is seen to 
disagree significantly with that of Somerville, et al., yielded the lowest degree of consistency. For both the data of Maller and Malik and Qureshi [45], the best fits for the highest levels of consistency required use of the attachment cross sections given by Pejcev, et al. [34].

As shown in Fig. 12, all the available experimental $(\mathrm{E} / \mathrm{N})_{\mathrm{c}, \mathrm{m}}$ data for SF6/CCl2F2 tend to agree and all exhibit slight degrees of positive synergism in which the breakdown strength of the mixture is greater than that of either constituent. The results, not shown here, of Boltzmann type calculations by Okabe and Kouno [50] and Frechette and Novak [54] also exhibit this positive synergism. The fit to the data of Wootton, et al. [48] yielded the highest degree of consistency with swarm and collision cross section data. The curves labeled 1 through 3 in Fig. 12 correspond to fits made only using the data of Wootton, et al. with the corresponding parameters indicated in Table III. It was found that the positive synergistic behavior could be obtained with a high degree of consistency ( $\beta_{1}$ and $\beta_{2}$ close to unity) by using the attachment cross sections of McCorkle, et al. [36], but not by using the cross sections of Pejcev, et al. [34]. This is also consistent with the Boltzmann calculation [54].

The fits corresponding to curves 1 and 2 in Fig. 12 were obtained assuming $\mathrm{g}(\mathrm{F})=\mathrm{F}$. The dashed curve was obtained using Eq. (19) with $\beta_{3}=$ 0.2. This is an example of a case where a noticeable improvement in the fit is found using Eq. (19) under conditions of highest consistency. It was generally found that significant improvement to fits using either Eq. (18) or (19) most often occurs when the degree of consistency is low.

From the examples considered here it would appear that the proposed method of analysis shows promise as a convenient approach for determining the consistency among various types of fundamental data relevant to uniform-field electrical breakdown in electronegative gas mixtures.

3.3. Gas-Phase Hydrolysis Rates for $\mathrm{SOF}_{2}$ and $\mathrm{SOF}_{4}$

This work was carried out in collaboration with I. Sauers of the Oak Ridge National Laboratory and the results have recently been published in the Journal of Chemical Physics [55]. The significant data obtained from this investigation are summarized here.

It is known that $\mathrm{SOF}_{2}$ (thionylfluoride) and $\mathrm{SOF}_{4}$ (thionyl tetrafluoride) hydrolyze according to the reactions

$$
\mathrm{SOF}_{2}+\mathrm{H}_{2} \mathrm{O}^{\mathrm{k}}{ }^{1} \mathrm{SO}_{2}+2 \mathrm{HF}
$$

and

$$
\mathrm{SOF}_{4}+\mathrm{H}_{2} \mathrm{O} \stackrel{\mathrm{k}_{2}}{2} \mathrm{SO}_{2} \mathrm{~F}_{2}+2 \mathrm{HF}
$$


Because both $\mathrm{SOF}_{2}$ and $\mathrm{SOF}_{4}$ are known $[56,57]$ to be major long-lived stable gaseous by-products from $\mathrm{SF}_{6}$ decomposition induced by electrical discharges in the presence of oxygen and water vapor, a knowledge of the rates $k_{1}$ and $k_{2}$ for the above reactions is needed for the design of chemical diagnostics applied to $\mathrm{SF}_{6}$-insulated, high-voltage systems $[58,59]$. Ruegsegger, et a1. [60] recently reported a gas-phase rate constant for reaction (21) of $(4.0 \pm 1.5) \times 10^{-20} \mathrm{~cm}^{3} / \mathrm{s}$ at a temperature of $340 \mathrm{~K}$. This rate is about two to three orders of magnitude greater than the rate estimated by Sauers, et al. [61] at a comparable temperature, and is also greater than that expected from measurements of oxyfluoride and $\mathrm{SO}_{2}$ yields from electrical discharges in $\mathrm{SF}_{6}$ reported by Van Brunt [56] and Latour-Slowikowska, et al. [62]. There has been no previously reported information on the $\mathrm{SOF}_{4}$ gas-phase hydrolysis rate $\mathrm{k}_{2}$.

The rate constants $k_{1}$ and $k_{2}$ were measured directly in the present work using a gas chromatograph-mass spectrometer (GC/MS) to periodically monitor $\mathrm{SOF}_{4}, \mathrm{SOF}_{2}, \mathrm{SO}_{2} \mathrm{~F}_{2}, \mathrm{SO}_{2}$, and $\mathrm{H}_{2} \mathrm{O}$ concentrations from a vessel containing $\mathrm{SOF}_{2}$ (or $\mathrm{SOF}_{4}$ ) in either $\mathrm{N}_{2}$ or $\mathrm{SF}_{6}$ buffer gas at a total pressure of $200 \mathrm{kPa}$ $(-2 \mathrm{~atm})$ and at a room temperature of $298 \mathrm{~K}$. Details of the gas analysis and mixture preparation procedures can be found in Refs. [55,56,63]. Examples of the data from which the rate constants were derived are shown in Figs. 13 and 14 which display measured concentrations-versus-time for the observed reactants and products. The second order rate constants were derived from data such as shown in these figures assuming that the time dependences of the observed species are governed by the following set of rate equations:

$$
\begin{aligned}
& \frac{d[X]}{d t}=k_{i}[Y]\left[\mathrm{H}_{2} \mathrm{O}\right], \\
& \frac{d[Y]}{d t}=-k_{i}[Y]\left[\mathrm{H}_{2} \mathrm{O}\right], \\
& \frac{d\left[\mathrm{H}_{2} \mathrm{O}\right]}{d t}=-k_{i}\left[\mathrm{Y}^{\mathrm{O}}\right]\left[\mathrm{H}_{2} \mathrm{O}\right]+\mathrm{k}^{\prime} \Delta\left[\mathrm{H}_{2} \mathrm{O}\right],
\end{aligned}
$$

where $[Y]$ and $[X]$ are the reactant and product concentrations, $i_{.} e . S O F_{2}$ or $\mathrm{SOF}_{4}$ and $\mathrm{SO}_{2}$ or $\mathrm{SO}_{2} \mathrm{~F}_{2}$ for $\mathrm{i}=1,2$ respectively. The term $\mathrm{k}^{\prime} \Delta\left[\mathrm{H}_{2} \mathrm{O}\right]$ is included to account for absorption or evaporation of water vapor from surfaces. This rate is assumed to be proportional to the deviation $\Delta\left[\mathrm{H}_{2} \mathrm{O}\right]=\left[\mathrm{H}_{2} \mathrm{O}\right] \mathrm{e}-\left[\mathrm{H}_{2} \mathrm{O}\right]$, of the water vapor concentration from equilibrium with the walls, where $\left[\mathrm{H}_{2}{ }^{\mathrm{O}]} \mathrm{e}\right.$ is the normal equilibrium level. The rate factor $k_{i}[Y]$ in the first term on the right-hand side of Eq. (5) was sufficiently small compared to $k^{\prime}$ in the second term that decreases in water vapor concentrations due to the hydrolysis reaction were not discernible. The rate constants were computed using 


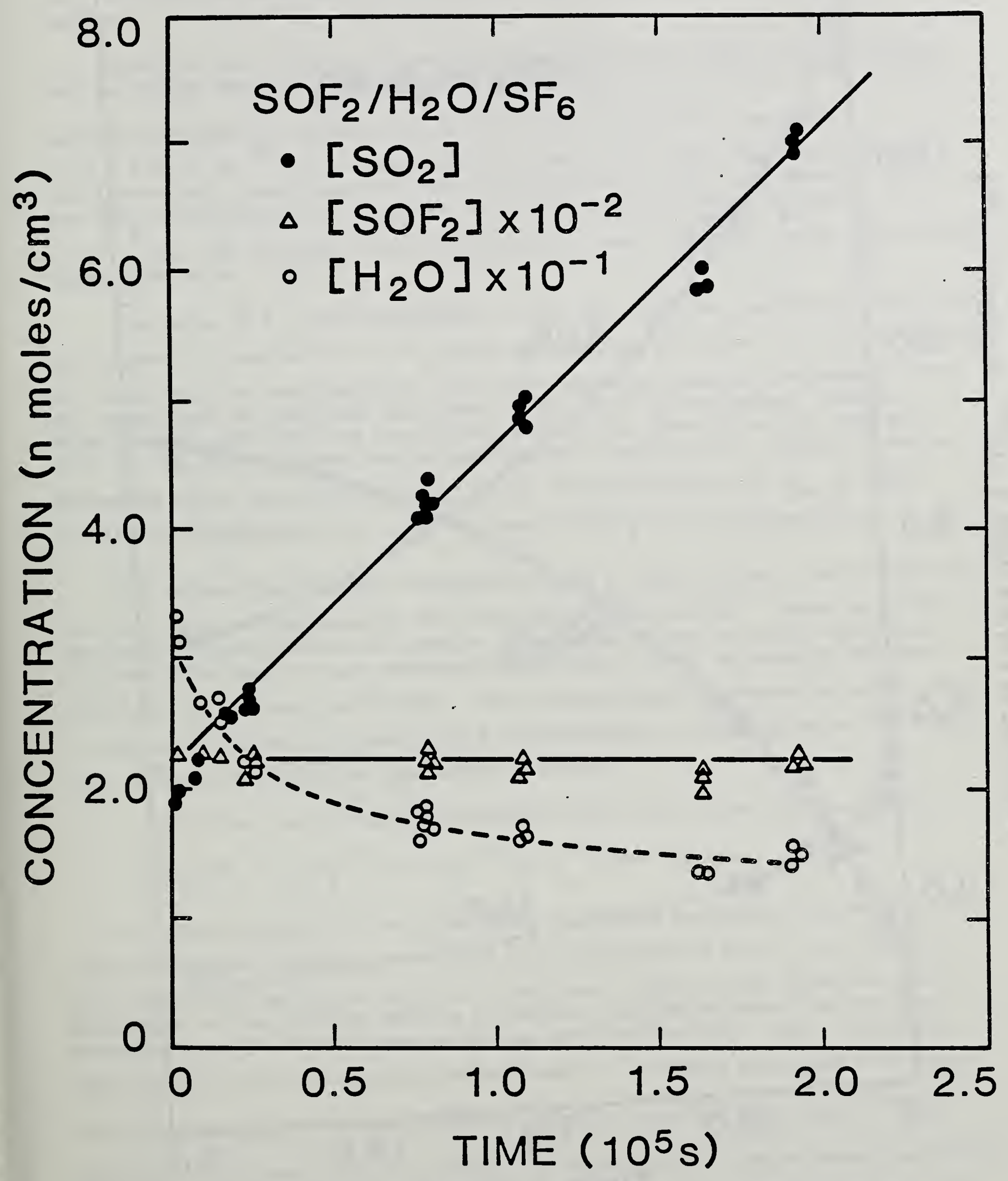

Figure 13. Measured $\mathrm{SO}_{2}, \mathrm{SOF}_{2}$ and $\mathrm{H}_{2} \mathrm{O}$ concentrations versus time in $\mathrm{SF}_{6}$ buffer gas. 


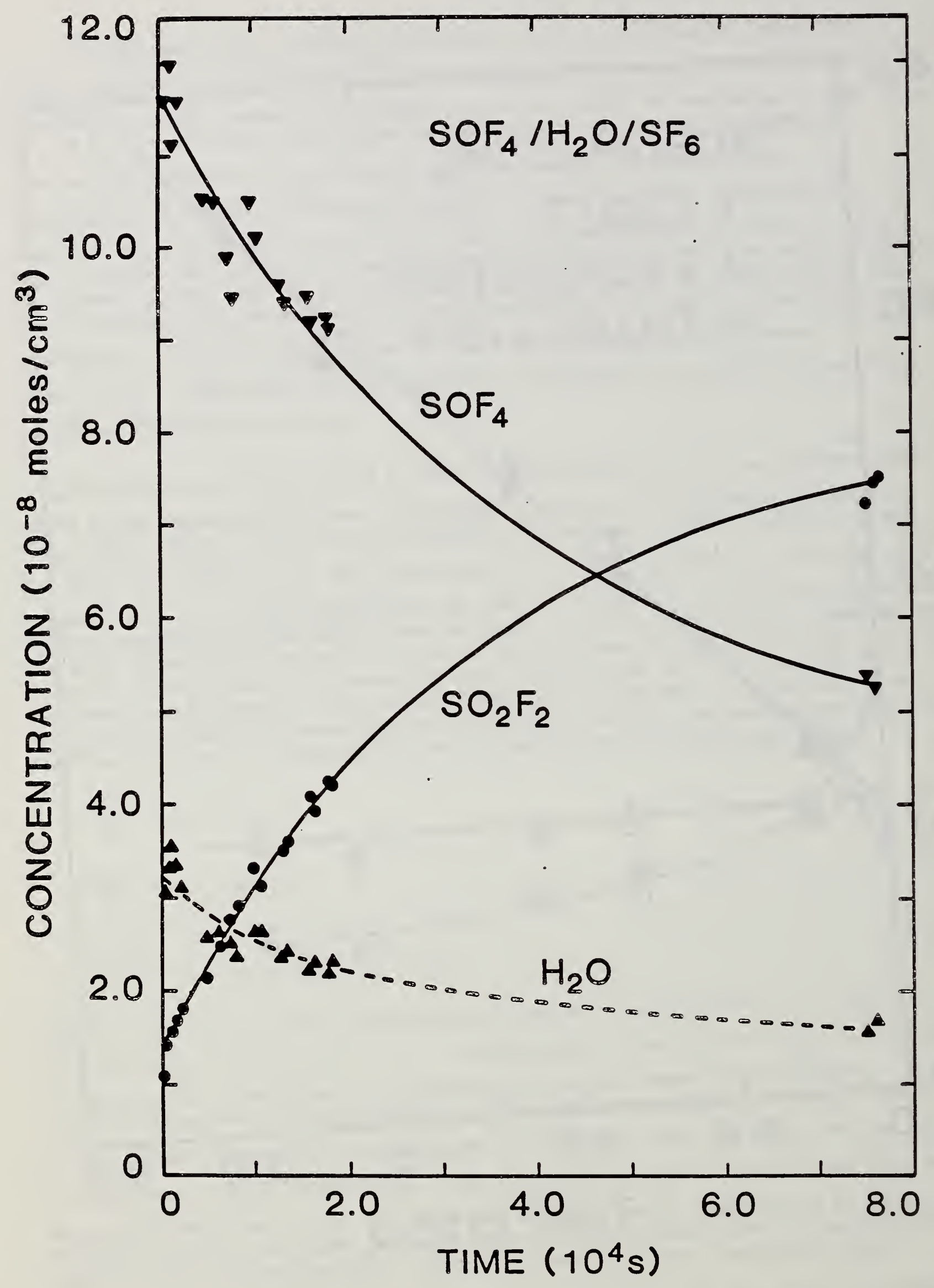

Figure 14. Measured $\mathrm{SO}_{2} \mathrm{~F}_{2}, \mathrm{SOF}_{4}$, and $\mathrm{H}_{2} \mathrm{O}$ concentrations versus time in $\mathrm{SF}_{6}$ buffer gas. 
Eq. (23) and the averages of the slopes of the [X]-versus-time production curves.

Based on the analysis discussed above, the second-order rate constants for gas-phase hydrolysis of $\mathrm{SOF}_{2}$ and $\mathrm{SOF}_{4}$ at $298 \mathrm{~K}$ in both $\mathrm{N}_{2}$ and $\mathrm{SF}_{6}$ buffer gas are assigned the values $(1.2 \pm 0.3) \times 10^{-23} \mathrm{~cm}^{3} / \mathrm{s}$ and $(1.0 \pm 0.3) \times 10^{-21} \mathrm{~cm}^{3} / \mathrm{s}$ respectively. The results were found [55] to be consistent with reactions that occur predominantly in the gas phase. The rate for SOF $_{2}$ hydrolysis is in agreement with previous estimates of Sauers, et al. [61], but is three orders of magnitude lower than the value obtained by Ruegsegger et al. [60].

The value of $k_{1}$ from Ruegsegger, et al. was obtained indirectly from mass spectrometric observation of $\mathrm{SO}_{2}$ production during gas-phase hydrolysis of $\mathrm{SF}_{4}$ at relatively low gas pressures. The mass spectral data of Ruegsegger, et al. was reanalyzed by Van Brunt and Sauers [55] using an isothermal chemical kinetics code developed by Brown [64], and it was shown from this analysis that the $\mathrm{SO}_{2}$ in this case was formed directly from $\mathrm{SF}_{4}$ by a surface reaction mechanism since there is evidence $[61,65]$ that hydrolysis of $\mathrm{SF}_{4}$ in highdensity or liquid-phase $\mathrm{H}_{2} \mathrm{O}$ need not involve $\mathrm{SOF}_{2}$ as an intermediate.

The values for the rate constants $k_{1}$ and $k_{2}$ reported here for reactions (21) and (22) are undoubtedly the most reliable available. These rates are needed for interpretation of results obtained from gas analysis applied to $\mathrm{SF}_{6}$-insulated high-voltage systems because water vapor is usually the most prevalent contaminant in the gas. The possibilities of observing either $\mathrm{SOF}_{2}$ or $\mathrm{SOF}_{4}$ will certainly depend on $\mathrm{H}_{2} \mathrm{O}$ contamination in the system as well as that introduced during the gas sampling process.

3.4. Identification of Corona Discharge-Induced $\mathrm{SF}_{6}$ Oxidation Mechanisms using $\mathrm{SF}_{6} /{ }^{18} \mathrm{O}_{2} / \mathrm{H}_{2}{ }^{16} \mathrm{O}$ and $\mathrm{SF}_{6} /{ }^{16} \mathrm{O}_{2} / \mathrm{H}_{2}{ }^{18} \mathrm{O}$ Gas Mixtures.

An understanding of the primary $\mathrm{SF}_{6}$-oxidation mechanisms is required to predict chemical activity associated with dissociation of $\mathrm{SF}_{6}$ in electrical discharges such as can occur in gas-insulated, high-voltage apparatus. The motivation of the present work is to obtain information about the dominant processes that lead to formation of the oxyfluorides $\mathrm{SOF}_{2}, \mathrm{SOF}_{4}$, and $\mathrm{SO}_{2} \mathrm{~F}_{2}$ from $\mathrm{SF}_{6} / \mathrm{O}_{2}$ mixtures containing water vapor in a highly localized corona discharge using gas mixtures in which normally occuring ${ }^{16} \mathrm{O}_{2}$ and $\mathrm{H}_{2}{ }^{16} \mathrm{O}$ are replaced or enriched with ${ }^{18} \mathrm{O}_{2}$ and $\mathrm{H}_{2}{ }^{18} \mathrm{O}$ respectively. The approach used here is similar to that taken by Velichko, et al. [66] in the investigation of $\mathrm{SF}_{6}$ 
oxidation induced by multiphoton dissociation. The predominant sources of oxygen for formation of the oxyfluorides have been identified here by mass spectrometric determination of the relative ${ }^{16} \mathrm{O}$ and ${ }^{18} \mathrm{O}$ content in these species formed in different gas mixtures containing either ${ }^{18} \mathrm{O}_{2}$ or $\mathrm{H}_{2}{ }^{18} \mathrm{O}$. A preliminary report of these observations was given at that 1986 Gaseous Electronics Conference [67], and a complete discussion of the work is covered in an archival paper recently submitted for publication [67].

The experimental procedure used to obtain the results reported here is identical to that previously described [56]. A continuous, direct current, negative, point-plane corona discharge was operaced for up to 30 hours at $40 \mu \mathrm{A}$ in the gas mixture of interest at a total pressure of $200 \mathrm{kPa}$ in a 3.7 liter cell. During operation of the discharge, small gas samples were periodically extracted with a gas tight syringe and injected into the column of a GC/MS.

The GC/MS was operated in the single-ion monitoring mode whereby ions of particular mass-to-charge ratios (m/e) characteristic of the $70 \mathrm{eV}$ mass spectra for the various gaseous species of interest were sequentially detected during the time that the injected gas sample eluted from the GC column. To determine the influence of molecular oxygen on oxyfluoride formation, comparable measurements were performed using the following two sets of similar gas mixtures: $\mathrm{SF}_{6} / 208^{16} \mathrm{O}_{2}, \mathrm{SF}_{6} / 208^{18} \mathrm{O}_{2}$, and $\mathrm{SF}_{6} / 28^{16} \mathrm{O}_{2}, \mathrm{SF}_{6} / 28^{18} \mathrm{O}_{2}$. In all of these mixtures, varying trace amounts of water vapor were present in the form of $\mathrm{H}_{2}{ }^{16} \mathrm{O}$.

The influence of water vapor on oxyfluoride formation was investigated using mixtures initially prepared with $97.58^{18} \mathrm{O}$ enriched $\mathrm{H}_{2} \mathrm{O}$ by the method previously described [27,35]. It was found, as expected for a static gas system, that because water vapor exchanges with the walls of the vessel enclosing the discharge, the $\mathrm{H}_{2}{ }^{18} \mathrm{O}$ concentration relative to $\mathrm{H}_{2}{ }^{16} \mathrm{O}$ diminishes with time.

Examples of data obtained for $\mathrm{SO}_{2} \mathrm{~F}_{2}$ are shown in Figs. 15-17. Results for the other oxyfluorides can be found in [67]. The data shown in Figs. 15 and 16 are single-ion chromatograms for ions with $\mathrm{m} / \mathrm{e}=87$ and $\mathrm{m} / \mathrm{e}=83$ respectively showing features associated with $\mathrm{s}^{18} \mathrm{O}_{2} \mathrm{~F}_{2}$ and $\mathrm{s}^{16} \mathrm{O}_{2} \mathrm{~F}_{2}$ formed in various indicated gas mixtures after comparable amounts of charge $Q$ had been transported, where $Q$ is related to discharge current $i$, and time $t$ by

$$
Q=i t .
$$

These chromatograms indicate that $\mathrm{S}^{18} \mathrm{O}_{2} \mathrm{~F}_{2}$ is prevalent in mixtures containing ${ }^{18} \mathrm{O}_{2}$ and $\mathrm{s}^{16} \mathrm{O}_{2} \mathrm{~F}_{2}$ is prevalent in mixtures containing ${ }^{16} \mathrm{O}_{2}$ thus suggesting that 


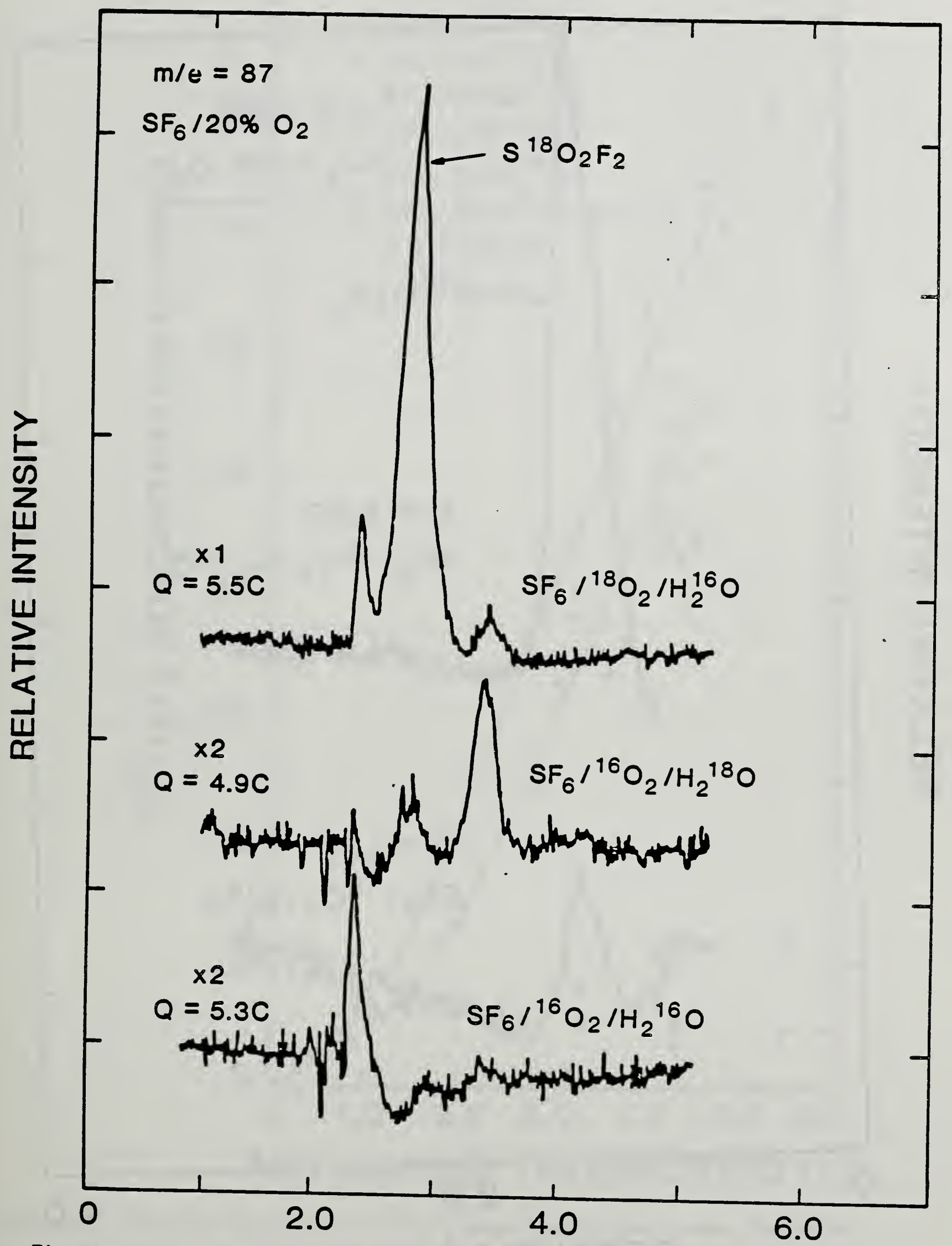
Figure 15. Single-ion chromatograms at m/e $=87$ from the different indicated
$\mathrm{SF}_{6} / \mathrm{O}_{2} / \mathrm{H}_{2} \mathrm{O}$ gas mixtures and net charge transported, Q. Of significance here are the relative changes in the feature associated with $\mathrm{s}^{18} \mathrm{O}_{2} \mathrm{~F}_{2}$ 


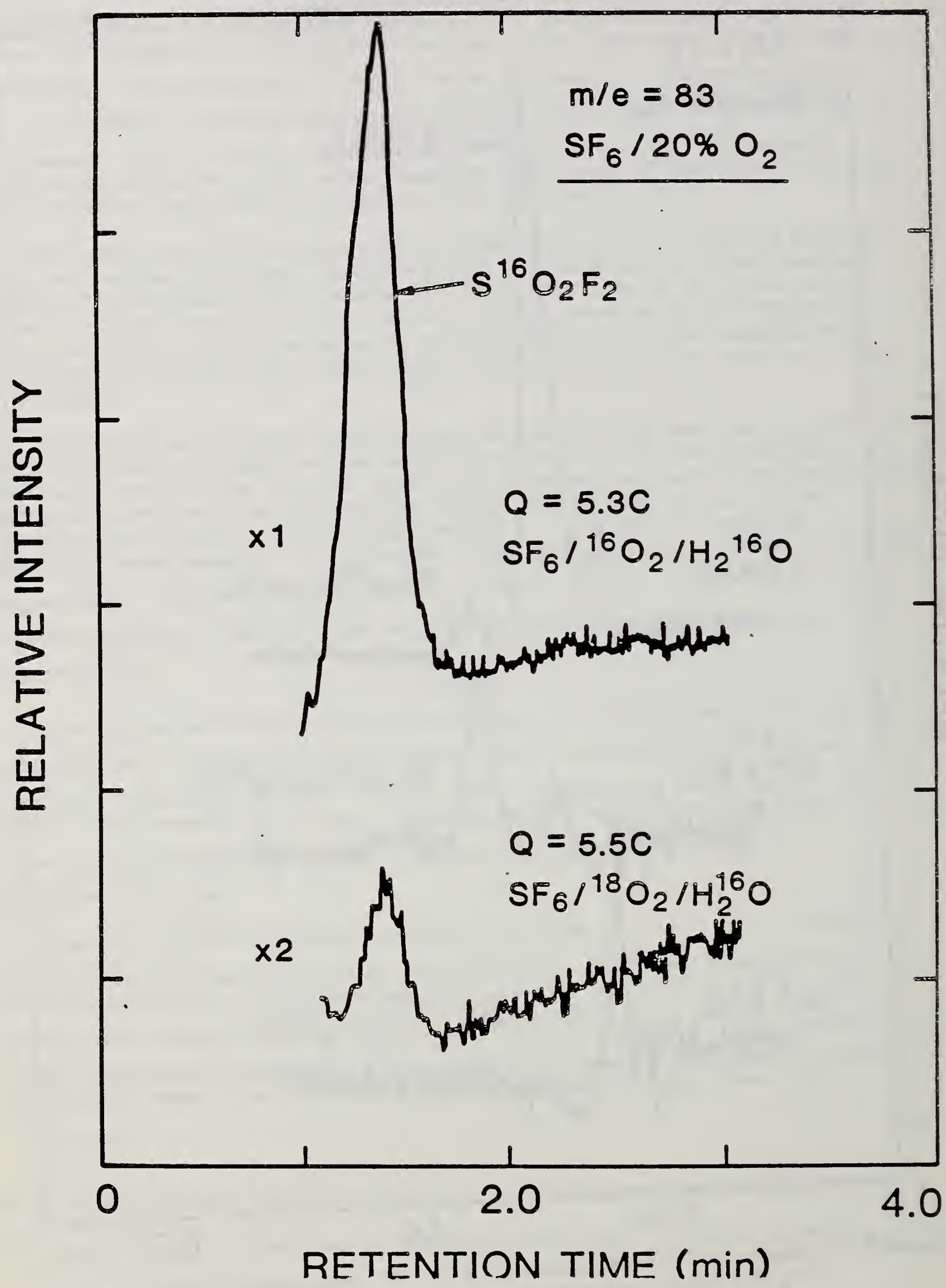

Figure 16. Single-ion chromatograms at $\mathrm{m} / \mathrm{e}-83$ showing features associated with $\mathrm{S}^{16} \mathrm{O}_{2} \mathrm{~F}_{2}$ from the different indicated $\mathrm{SF}_{6} / \mathrm{O}_{2} / \mathrm{H}_{2} \mathrm{O}$ gas mixtures and net charge transported $Q$. 
$\mathrm{SO}_{2} \mathrm{~F}_{2}$ formation preferentially utilizes molecular oxygen. This is indicated more quantitatively in Fig. 17 which shows absolute yields of $\mathrm{s}^{16} \mathrm{O}_{2} \mathrm{~F}_{2}$ versus $Q$ from various $\mathrm{SF}_{6} / \mathrm{O}_{2}$ mixtures. The present data for mixtures containing 2 and $208{ }^{18} \mathrm{O}_{2}$ (or ${ }^{16} \mathrm{O}_{2}$ ) are shown for comparison with previously reported data from $\mathrm{SF}_{6} /$ trace ${ }^{16} \mathrm{O}_{2}$ and $\mathrm{SF}_{6} / 18^{16} \mathrm{O}_{2}$ mixtures obtained under comparable conditions [56]. The present results for the ${ }^{16} \mathrm{O}_{2}$ mixtures are consistent with the earlier data. The most significant observation from the results shown in Figs. 16 and 17 is the dramatic drop off in $\mathrm{s}^{16} \mathrm{O}_{2} \mathrm{~F}_{2}$ yield when ${ }^{18} \mathrm{O}_{2}$ is substituted for ${ }^{16} \mathrm{O}_{2}$. This observation is consistent with the previous suggestion [56] that $\mathrm{SO}_{2} F_{2}$ is formed predominantly by the relatively slow [68] reaction

$$
\mathrm{SF}_{2}+\mathrm{O}_{2} \rightarrow \mathrm{SO}_{2} \mathrm{~F}_{2}
$$

which occurs at ambient temperature in the main gas volume surrounding the active discharge region.

Similar data obtained for SOF $_{2}$ show that its production is insensitive to the presence of $\mathrm{O}_{2}$. It was found, however, that $\mathrm{s}^{18} \mathrm{OF}_{2}$ appears in significant quantities when $\mathrm{H}_{2}{ }^{18} \mathrm{O}$ is present in the gas. The rate of $\mathrm{s}^{18} \mathrm{OF}_{2}$ production was, in fact, found to be proportional to the $\mathrm{H}_{2}{ }^{18} \mathrm{O}$ concentration, thus suggesting that $\mathrm{SOF}_{2}$ is predominantly formed by the relatively slow [61] gas phase reaction

$$
\mathrm{SF}_{4}+\mathrm{H}_{2} \mathrm{O} \rightarrow \mathrm{SOF}_{2}+2 \mathrm{HF}
$$

which again occurs predominantly in the main gas volume of the discharge vessel as proposed by Van Brunt [56].

The rates for $\mathrm{SO}_{2} \mathrm{~F}_{2}$ and $\mathrm{SOF}_{2}$ production should thus be controlled by the rates at which $S F_{2}$ and $S F_{4}$ diffuse out of the active discharge volume. The fact that $\mathrm{SO}_{2} \mathrm{~F}_{2}$ and $\mathrm{SOF}_{2}$ production rates are observed $[56,69]$ to be relatively insensitive to either $\mathrm{O}_{2}$ or $\mathrm{H}_{2} \mathrm{O}$ content is consistent with the assumption that $\mathrm{SF}_{2}$ and $\mathrm{SF}_{4}$ react preferentially with $\mathrm{O}_{2}$ and $\mathrm{H}_{2} \mathrm{O}$ respectively in the main gas volume.

The results for $\mathrm{SOF}_{4}$ production are found also to be consistent with the proposed [56] mechanisms for its formation involving the fast reactions 


$$
\begin{aligned}
& \mathrm{SF}_{5}+\mathrm{OH} \rightarrow \mathrm{SOF}_{4}+\mathrm{HF}, \\
& \mathrm{SF}_{5}+\mathrm{O} \rightarrow \mathrm{SOF}_{4}+\mathrm{F}, \\
& \mathrm{SF}_{4}+0 \rightarrow \mathrm{SOF}_{4},
\end{aligned}
$$

which occur in the small active discharge volume near the point cathode. Thus $\mathrm{SOF}_{4}$ can utilize both $\mathrm{O}_{2}$ and $\mathrm{H}_{2} \mathrm{O}$ in obtaining oxygen for its formation. At relatively low $\mathrm{O}_{2}$ concentrations (below about $5 \%$ by volume) the data indicate that reaction (29) predominates, i.e. the $\mathrm{SOF}_{4}$ yield is not significantly dependent on $\mathrm{O}_{2}$ content. This may be the consequence of an enhancement in $\mathrm{OH}$ concentration in the discharge by the fast reaction

$$
\mathrm{F}+\mathrm{H}_{2} \mathrm{O} \rightarrow \mathrm{HF}+\mathrm{OH} \text {. }
$$

When the $\mathrm{O}_{2}$ content is increased to about 20\%, it is found that reactions (30) and (31) become relatively more important, i.e. SOF $_{4}$ appears to derive increasingly more of its oxygen from $\mathrm{O}_{2}$ as expected.

\subsection{Transfer of $\mathrm{F}^{-}$in $\mathrm{SF}_{6}^{-}+\mathrm{SOF}_{4}$ Collisions and Its Influence on SOF 4 Yield from Corona Discharges in $\mathrm{SF}_{6}$-Containing Gases.}

This work was carried out in a collaboration involving $R$. J. Van Brunt of the NBS Electrosystems Division, L. W. Sieck of the NBS Chemical Kinetics Division, I. Sauers of the Oak Ridge National Laboratory, and M. C. Siddagangappa of the Indian Institute of Science. A preliminary report of the results was given at the 1986 Gaseous Electronics Conference [70] and the work has now been prepared for archival publication [70]. This report briefly summarizes the significant results and conclusions from this work. A detailed account of the experimental procedures and theoretical model are given in [70].

It is evident from the discussion given in the previous section that $\mathrm{SOF}_{4}$ is a major and often predominant by-product of $\mathrm{SF}_{6}$ oxidation in glow and corona type electrical discharges $[56,71-74]$. In any attempt to understand the magnitude of the $\mathrm{SOF}_{4}$ yield from electrical discharges, it is necessary to have information about the rates for reactions that lead to its formation and destruction. It is known [75] that the energetically favorable reaction

$$
\mathrm{SF}_{6}^{-}+\mathrm{SOF}_{4} \stackrel{\mathrm{k}}{\rightarrow} \mathrm{SOF}_{5}^{-}+\mathrm{SF}_{5}
$$

occurs quite rapidly at near the collision rate. Because of the possible importance of $\mathrm{SF}_{6}{ }^{-}$as a predominant charge carrier in the discharge gap, it 
has been speculated $[70,76]$ that reaction (32) can account for observed nonlinearities in $\mathrm{SOF}_{4}$ yields from corona discharges.

In the present work the temperature ( $T$ ) and electric field-to-gas pressure (E/P) dependences of the rate constant $k$ for reaction (32) were measured using different mass spectrometric techniques $[70,75,77,78]$. The results for the temperature and $E / P$ dependences of $k$ are shown respectively in Figs. 18 and 19. Figure 19 also shows for comparison the thermal rates obtained from Fig. 18 at the indicated effective temperatures $T$ eff, plotted at approximately equivalent $E / P$ values estimated using the relationship [79]

$$
T_{\text {eff }}-T\left[1+\left(M\left(\mu_{0} P_{0}\right)^{2} / 3 k_{\beta} T\right)(E / P)^{2}\right] \text {, }
$$

where $T$ is the actual gas temperature $(350 \mathrm{~K}$ ) in the $E / P$ measurement experiment, $M$ is the $\mathrm{SF}_{6}{ }^{-}$ion mass, $\mu_{0}$ is the reduced $\mathrm{SF}_{6}{ }^{\text {inobility, }}$ $P_{0}=100 \mathrm{kPa}$, and $\mathrm{k}_{\beta}$ is the Boltzmann constant. To within the uncertainties of the data the rate constants $k$ determined at low $E / P$ are in agreement with the thermal results as required.

The temperature dependence for the rate constant can be represented by the empirical expression

$$
\mathrm{k}\left(\mathrm{cm}^{3} / \mathrm{s}\right)=0.124 \exp (-3.3 \ln \mathrm{T}(\mathrm{K})) \text {, }
$$

for $433 \mathrm{~K}>\mathrm{T}>270 \mathrm{~K}$, and $\mathrm{k}$ assumes a constant value of $1.2 \mathrm{x} 10^{-9} \mathrm{~cm}^{3} / \mathrm{s}$ for $\mathrm{T}<270 \mathrm{~K}$. The abrupt leveling off of $\mathrm{k}$ at low temperatures is a behavior observed for other ion-molecule reactions that at present is not thoroughly understood [80-82]. Because neither the dipole moment nor the polarizability of $\mathrm{SOF}_{4}$ are known, it is not possible to predict the limiting classical

collision rate for reaction (32). It can be expected from comparison with other similar fast reactions that the maximum value for $k$ will not be significantly greater than $1.0 \times 10^{-9} \mathrm{~cm}^{3} / \mathrm{s}$.

The $E / P$ dependence of $k$ for a gas temperature of $350 \mathrm{~K}$, can be represented by the approximate formula

$$
k\left(\mathrm{~cm}^{3} / \mathrm{s}\right)-7.0 \times 10^{-10} \exp (-0.022 \mathrm{E} / \mathrm{P})
$$

where $\mathrm{E} / \mathrm{P}$ is expressed in units of $\mathrm{V} / \mathrm{cm} \cdot \operatorname{torr}(1$ torr $=133.3 \mathrm{~Pa}$ ) and lies in the range of 60 to $130 \mathrm{~V} / \mathrm{cm} \cdot$ torr. For $\mathrm{E} / \mathrm{P}<60 \mathrm{~V} \mathrm{~cm} \cdot$ torr, $\mathrm{k}$ assumes an approximate constant value of $2.5 \times 10^{-10} \mathrm{~cm}^{3} / \mathrm{s}$. The results for the $E / P$ dependence given here are consistent with the earlier data of Sauers [75]. Although the results at low $E / P$ tend to agree with the thermal results (see Fig. 19), such agreement need not be expected at high $\mathrm{E} / \mathrm{P}$. Increasing the electric field primarily increases the mean translational energy of the reactants, whereas increasing the gas temperature increases both the mean level of internal excitation and translational energy of the reactants. To 


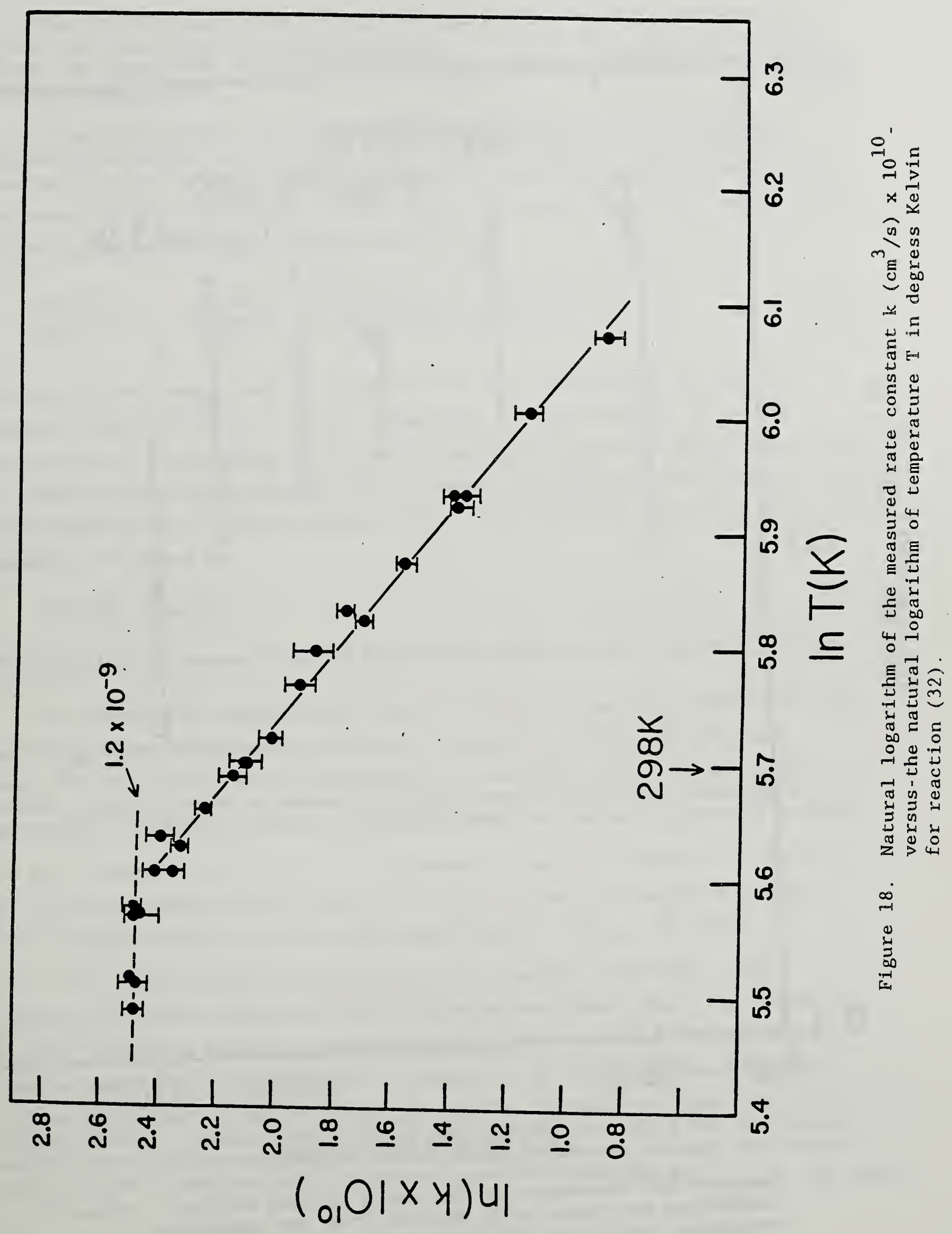




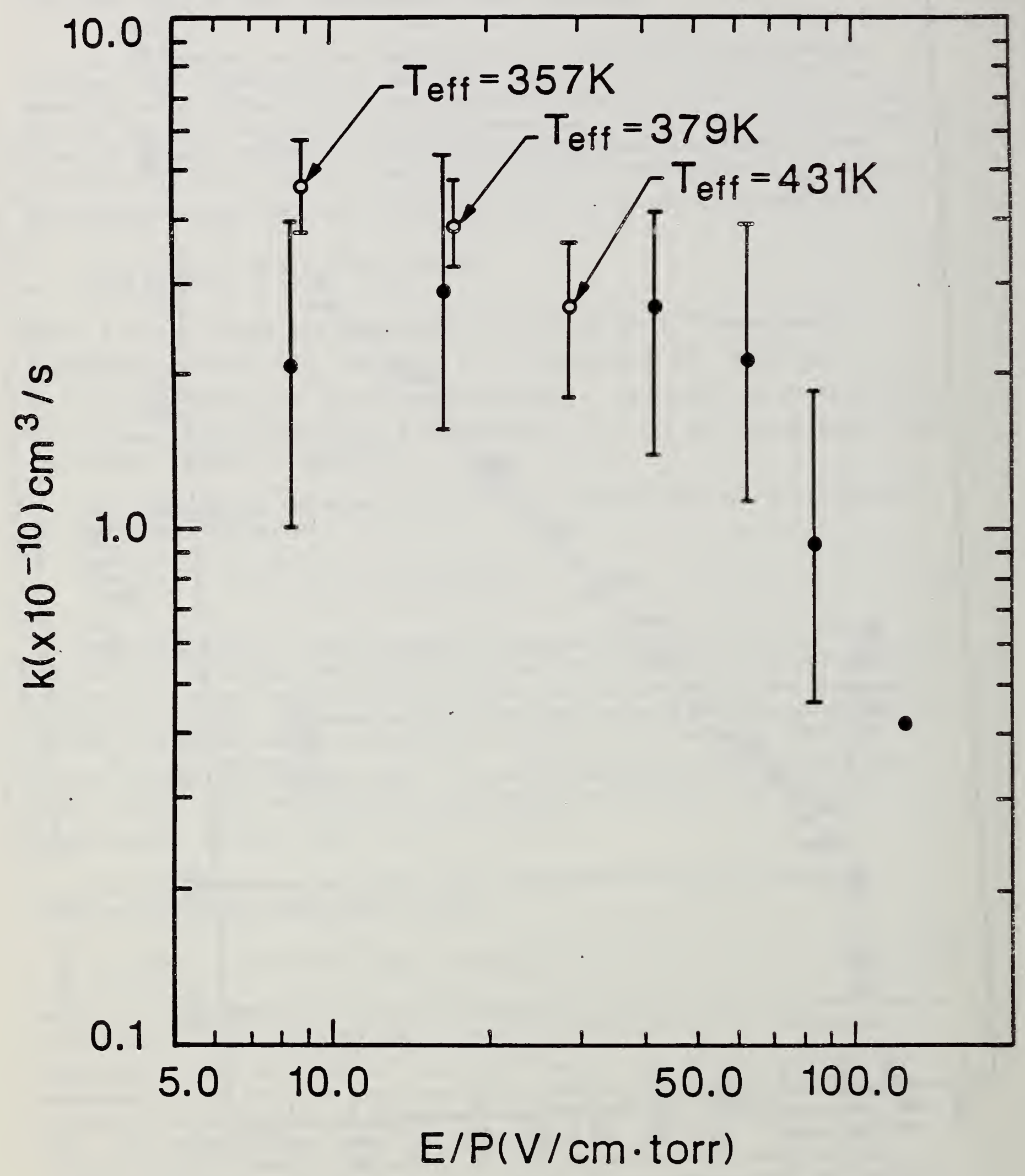

Figure 19. Measured $E / P$ dependence of the rate $k$ (closed circles). Shown for comparison are values of $k$ obtained from the temperature dependence results at the indicated effective temperature $s$ ( $T_{\text {eff }}$ ) that correspond to particular E/P values (open circles). 
the extent that $k$ depends on internal energies, there will be differences between the temperature and $E / P$ dependences at higher $E / P$, and at very high fields, the concept of "effective temperature" associated with the reaction is no longer meaningful.

A theoretical model was proposed [70] which utilizes the information obtained here on the rate constant $k$ for reaction (32) to interpret the observed behavior of $\mathrm{SOF}_{4}$ production rates for negative, point-plane corona discharges in gas mixtures containing $\mathrm{SF}_{6}$. It was shown that the charge rateof-production for $\mathrm{SOF}_{4}$ can be expressed as

$$
\frac{d\left[\mathrm{SOF}_{4}\right]}{d Q}=r_{Q}+\frac{k\left[\mathrm{SOF}_{4}\right]}{e V \tau_{t}} \frac{\exp \left\{\left(-\mathrm{k}\left[\mathrm{SOF}_{4}\right] / v-\mathrm{k}^{\prime}\right) \mathrm{Z}_{0}\right\}-1}{\left(\mathrm{k}\left[\mathrm{SOF}_{4}\right] / v+\mathrm{k}^{\prime}\right)}
$$

where $r_{Q}$ is the charge rate-of-production in the discharge volume due to reactions like (29)-(31), e is the elementary electron charge, $z_{0}$ is the point-to-plane gap spacing, ${ }^{\tau} t$ is the volume of the gas containing vessel, and $k^{\prime}$ a decay constant associated with a process that competes with reaction (32) in the destruction or deactivation of $\mathrm{SF}_{6}{ }^{-}$. The drift velocity $\mathrm{v}$ of $\mathrm{SF}_{6}{ }^{-}$is assumed to be given by

$$
v=\mu_{0} P_{0}\left(E_{a v} / P\right),
$$

where $E_{a v}$ is the average value of the electric field in the ion drift region.

All previously reported data from our laboratory on $\mathrm{SOF}_{4}$ production from negative corona discharges in mixtures like $\mathrm{SF}_{6} / \mathrm{O}_{2}, \mathrm{SF}_{6} / \mathrm{N}_{2}, \mathrm{SF}_{6} / \mathrm{Ne}$ (see Refs. 56, 69, and 76) were successfully fit using Eq. (36). It was found, however, that in order to account for the observed deviations from linearity in the $\mathrm{SOF}_{4}$ production curves, it was necessary to invoke a competing process for $\mathrm{SF}_{6}{ }^{-}$destruction, i.e. $\mathrm{k}^{\prime} \neq 0$. Although it was not possible to identify this process unambiguously, there are at least three that appear plausible. These include formation of the anion complexes $\mathrm{SF}_{6}{ }^{-}\left(\mathrm{H}_{2} \mathrm{O}\right)_{\mathrm{n}}, \mathrm{SF}_{6}{ }^{-}(\mathrm{HF})_{\mathrm{n}}$, $\mathrm{n}=1,2,3, \ldots$ which could be considerably less reactive than $\mathrm{SF}_{6}{ }^{-}$, and $\mathrm{F}^{-}$ exchange with trace amounts of $\mathrm{SiF}_{4}$ that might be present due to reactions of $\mathrm{HF}$ with insulating materials in the discharge cell. It could be concluded from the model calculations that $\mathrm{SF}_{6}{ }^{-}$ceases to be the predominant negative ion charge carrier in the discharge gap within a distance of less than $10 \%$ of the gap spacing. Further measurements are now underway using the NBS pulsed electron-beam, high-pressure mass spectrometer system to identify the terminal negative ions in the ion-drift region of a corona discharge gap. 


\title{
4. INTERFACIAL PHENOMENA IN LIQUIDS \\ Task 04
}

\author{
Edward F. Kelley \\ Electrosystems Division \\ National Bureau of Standards
}

\subsection{Introduction}

The objective of this research is to develop techniques to measure the electrical behavior of liquid-solid composite insulation for use in highvoltage systems. Model systems of practical interest are being investigated, such as the interface between transformer oil and pressboard. The effects of contamination and temperature up to $150^{\circ} \mathrm{C}$ can be documented in these model systems in two ways: 1) breakdown measurements using high-speed photography, and 2) electro-optical measurements of the electric field in the vicinity of the interface. Such field measurements provide an understanding of the role of space charge and surface charge in high-voltage apparatus. Because of possible standards applications afforded by these electro-optical techniques, NBS has a leading role to play in developing and perfecting the measurement techniques.

Electrical failure in high-voltage apparatus often occurs in the vicinity of or upon an interface which serves as an insulator between two conducting regions of differing potential. However, in well-characterized systems, the interface will not necessarily cause the failure [83,84]. Additionally, preliminary measurements of the electric field in the vicinity of a pressboard interface either parallel or perpendicular to the field have been made previously and reported in the literature $[85,86]$. Those measurements demonstrated that the interface parallel to the field showed no dramatic surface charging which would give rise to large field enhancements, whereas the interface perpendicular to the field demonstrated surface charging as would be expected. Thus, the cause of interfacial failure in practical apparatus does not seem to originate from macroscopic field irregularities arising from the presence of the interface parallel with the field in clean systems.

The lack of macroscopic field irregularities suggests that attention to microscopic details in the vicinity of the electrodes is warranted. Much of the thrust of the experimental effort in the last year has been to explore some of the details of the microscopic behavior of the liquid at the electrode surface. Although this represents a slight deviation from electro-optical studies of transformer oil, it is an important departure which prepares the laboratory for the observation of breakdown phenomena with increased spatial and temporal resolution. The techniques employed to examine the liquid system will have immediate application to a composite, interfacial system. The following data represents the most outstanding accomplishment in this area for the last year. A fuller presentation was made at a conference in October 1986 [87] 


\subsection{Streamer Initiation: Electro-Optic Field Measurements}

When considering initiation of prebreakdown phenomena in liquids it is often assumed that charge injection heats and vaporizes the liquid giving rise to an ionized gas or plasma phase. The plasma then acts like a conductor and a process continues whereby the streamer grows across the gap. In this report, estimates are provided of the electric field, amount of injected charge, and joule heating in the vicinity of a needle tip which is the cathode in a needle-sphere electrode geometry. Kerr-effect electro-optical

observations of the impulse field in the vicinity of the tip show a distortion from the geometrical field due to charge injection from the tip prior to any streamer development. The injected charge is not distributed evenly over the surface of the tip, but appears to reside mainly in a relatively narrow channel. Estimates reveal that the injected charge densities are on the order of $100 \mathrm{mC} / \mathrm{cm}^{3}$. The streamer initiates where this charge-injection channel touches the needle tip.

\subsection{Experimental Observations}

Nitrobenzene is used in this measuremnt because of its large Kerr coefficient. Although nitrobenzene is chemically different from transformer oil, similarities in prebreakdown processes in a wide variety of liquids suggest that the specific chemical nature of the liquid used is not important in determining properties of prebreakdown in liquids. The nitrobenzene had a resistivity of about $200 \Omega \cdot \mathrm{cm}$ before the experiment and $50 \Omega \cdot \mathrm{cm}$ after.

A xenon flash tube provides illumination for the high magnification photography using an image converter camera, one frame of which observes an area of $0.76 \mathrm{~mm} \times 0.65 \mathrm{~mm}$ at $22 \mathrm{X}$ at the tip. The wavelength dependence of the Kerr-effect necessitates color filtration. Higher fields produce more fringes which cannot be resolved if the light bandwidth is too large, so a dielectric filter was used [500.7 $\mathrm{nm}$, full-width-half-maximum $3.7 \mathrm{~nm}$ ].

The standard configuration for Kerr-effect observations is to sandwich the liquid cell between quarter-wave plates and polarizers so that circularly polarized light enters the cell [88]. Aligned polarizers (maximum transmission for zero field) or crossed polarizers (minimum transmission for zero field) are used in this experiment. Quarter-wave plates are not used because better image quality was obtained without them. With an axiallysymmetric, nonuniform geometry it can be shown that after the first few fringes the Kerr-effect fringe pattern is nearly the same with or without the quarter-wave plates. This is because the fringe fields elliptically polarize the incident linearly polarized light before that light reaches the highest field regions. Without quarter-wave plates, isoclines (regions where the strongest field is aligned with the polarization axes) are observable only in the first fringe.

The camera can be triggered so that conditions at any time during the applied voltage pulse can be photographed (see Fig. 20). Fig. 21 shows the Kerr effect over the width of the pulse as compared to shadowgraph results. Distortions in the fringe pattern can be clearly observed at the tip as the voltage nears the peak. This distortion persists to the end of the pulse. Comparing the results with crossed and aligned polarizers (Fig. 2lb and 2lc) 


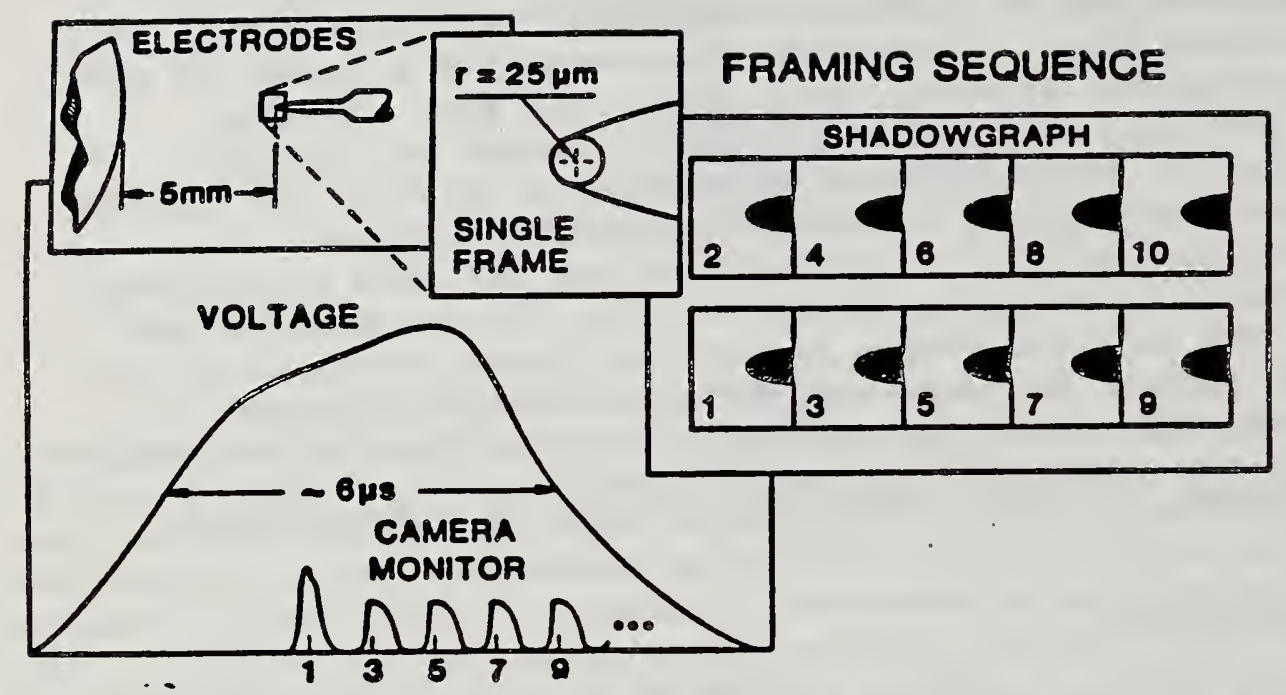

Figure 20. Region observed by the camera, shape of voltage pulse, and framing sequence relative to the pulse.

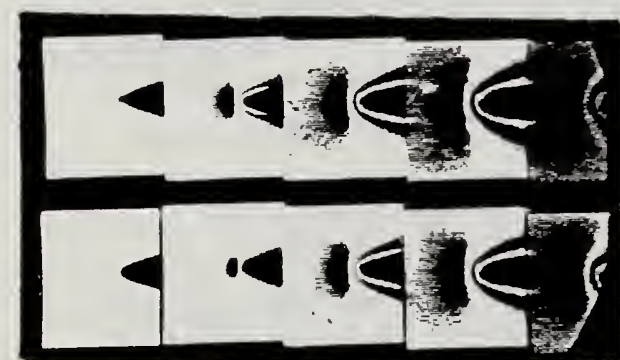

(2)

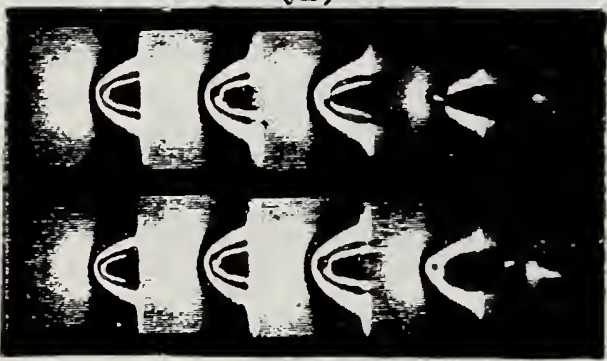

(c)

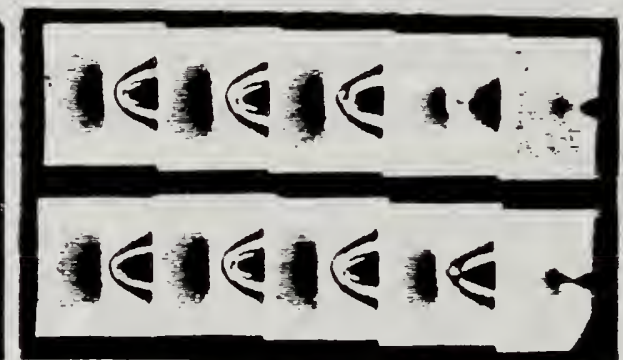

(b)

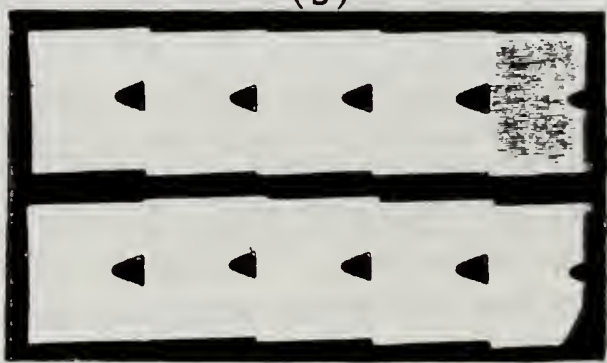

(d)

Figure 21. Kerr effect at needle tip (22X): With aligned polarizers the first dark region ahead (left) of the tip is fringe $n=1$; pulse rise (a) is compared to the peak and fall (b) which is compared to crossed polarizers (c) where the seventh fringe (white) is just coming out of the needle. Shadowgraph results (d) were made under same conditions as (b) and (c), $19.3 \mathrm{kV}$ ( $\pm 3 \%$ ). The framing rate is $2 \times 10^{8}$ frames $/ \mathrm{s}$. 
shows that the highest fringe to exist near the point is fringe $n=7$ at the voltage peak. The distortion of the field due to charge injection amounts to a decrease in the fringe count by at least one fringe (fringe shift $\Delta \mathrm{n}=-1$ ), and possibly two $(\Delta \mathrm{n}=-2)$, as can be seen by the bending of the fringes into the tip. Although the irregular fringe patterns give the impression of streamer development, no streamers can be observed using shadowgraph techniques (Fig. 21d).

\subsection{Order of Magnitude Analysis}

Referring to Fig. 21, if there were no charge injection the fringe $(n=7)$ would not bend back into the tip and the seventh fringe would be fully developed at the tip. The information contained in these fringes is sufficient to make estimates of the quantity of charge injected and the resulting heating of the liquid.

For the Kerr effect, the birefringent phase difference for any light ray path (parallel to the $x$-axis) is given by an integral of the square of the component of the electric field which is perpendicular to the path

$$
\Phi=\int_{p a t h} \pi\left(E_{p}\right)^{2} d x \text {, }
$$

where $B$ is the Kerr coefficient ( $3.24 \mathrm{pm} / \mathrm{v}^{2}$ for nitrobenzene). This phase difference is related to the fringe number by $\Phi=\mathrm{n}$, , whereby the normalized transmitted light for each path is given by $T=\cos ^{2}(\Phi / 2)=\cos ^{2}(n \pi / 2)$ for aligned polarizers, and $T=\sin ^{2}(n \pi / 2)$ for crossed polarizers.

Order-of-magnitude approximations can be made to estimate this phase integral: 1. assume that the perpendicular component of the field within a tip radius ( $r$ in Fig. 29) of the tip has the constant value $E$ over the length $L=3 r$ along the light ray ( $x$-direction); 2 . assume chat this region provides the main contribution to the phase shift. The integral simplifies to $\Phi=2 \pi \mathrm{BLE}^{2}$. Then, the approximate field in terms of the fringe number is

$$
E=(n / 2 B L)^{1 / 2}
$$

Differentiation allows us to determine the change in the field corresponding to a fringe shift $\Delta \mathrm{n}, \mathrm{dE} / \mathrm{d} n=\mathrm{E} / 2 \mathrm{n}$. For example, with $\mathrm{r}=25 \mu \mathrm{m}, \mathrm{n}=7$, and $\Delta \mathrm{n}=-1$, a field strength of $\mathrm{E}=120 \mathrm{MV} / \mathrm{m}$ and a decrease in the field of $\Delta E=-8.6 \mathrm{MV} / \mathrm{m}$ obtains. This change $\Delta E$ from the Laplacian field due to charge occurs in the direction of the charge channel (perpendicular to the $x$ direction) or $z$-direction, the axis of symmetry. Poisson's equation is then $\Delta E / \Delta z=q / e$. With a relative permitivity for nitrobenzene of 35 , the permitivity is $310 \mathrm{pF} / \mathrm{m}$, and assuming that the distance involved is one tip radius, $\Delta z=r$, then the charge density is $q=-110 \mathrm{c} / \mathrm{m}^{3}$.

Referring to Fig. 21, it would appear that the charge extends about four tip radii into the liquid, $z=4 \mathrm{r}$, with a width of about the tip diameter or less, (area $A=\pi r^{2}$ ). Assuming the injection process occurs in $t=1 \mu s$, then 
the current density is $\mathrm{J}=\mathrm{qz} / \mathrm{t}=11 \mathrm{kA} / \mathrm{m}^{2}$, and the total charge $\mathrm{Q}$ contained in the volume $(V=A z)$ is $Q=21 \mathrm{pC}$. To determine the energy expended by joule heating we need the resistivity, taken to be $R=1 \Omega \cdot m$, the density of nitrobenzene $D=1200 \mathrm{~kg} / \mathrm{m}^{3}$, and the heat of vaporization of typical hydrocarbons $\mathrm{h}=420 \mathrm{~kJ} / \mathrm{kg}$. The energy density in the channel is then $K=R J 2 t=110 \mathrm{MJ} / \mathrm{m}^{3}$, and the energy density needed to vaporize the liquid is $\mathrm{H}=\mathrm{Dh}=500 \mathrm{MJ} / \mathrm{m}^{3}$. The ratio of the energy supplied to the heat needed is $\mathrm{K} / \mathrm{H}=0.22$. It should be noted that no streamers initiated at the voltages which would produce only seven fringes at the tip. Higher voltages were needed. Unfortunately, it was not possible to resolve the fringes at the higher voltages with higher magnification because of the poor image quality. However, if we were to repeat the above calculation for seven fringes $(n=7)$ and assume a fringe shift of two $(\Delta n=-2)$ then we would find the same field of $\mathrm{E}=120 \mathrm{MV} / \mathrm{m}$ at the tip, a charge density of $\mathrm{q}=210 \mathrm{c} / \mathrm{m}^{3}$, and an energy density of $\mathrm{K}=450 \mathrm{MJ} / \mathrm{m}^{3}$ which is approximately $90 \%$ of the required energy density to vaporize nitrobenzene. Similarly, if $\mathrm{n}=9$ ( $13 \%$ field increase) and $\Delta n=-2$, then the energy density is $K=350 \mathrm{MJ} / \mathrm{m}^{3}$ which is $70 \%$ of the energy density needed.

\subsection{Conclusion}

Electro-optic Kerr-effect observations of the field at the tip of a needle indicate that a large amount of charge is being injected within a relatively narrow channel at the tip of the needle. An order-of-magnitude calculation reveals that the injected charge density results in joule heating of the liquid which is seen to be of the same order as the heat needed for liquid vaporization. 
Ronald H. McKnight

Electrosystems Division

National Bureau of Standards

\subsection{The Use of E-Dot Sensors in Measuring Fast Rise Pulses}

\section{1 .1 Introduction}

The measurement of fast rise high voltage electrical pulses with rise times less than 100 ns and total pulse duration less than 1000 ns challenges the methods conventionally used by power system engineers. Such pulses may be produced in various ways including disconnect operations in gas insulated equipment, or as a result of nuclear electromagnetic pulse (EMP). Conventional power system dividers have inadequate bandwidth, and so field coupled devices such as capacitive dividers, E-dot (or V-dot) sensors, Rogowski coils and fluxmeters, which find wide application in pulse power and simulator systems, must be considered. Other specialized resistive dividers, using liquids as elements have also been shown to have applicability in measuring fast rise pulses. Although of limited accuracy, these devices are easily constructed and modified to meet experimental conditions. They exhibit a lack of long term stability, however, and must be recalibrated frequently to verify acceptable performance.

The field coupled devices have certain attractive features including a non-intrusive installation, simplicity of construction and potentially wide bandwidth. They share the difficulties of calibration and response characterization common to all fast high voltage sensors. In addition, the most widely used system consisting of a derivative (E-dot) sensor coupled to an integrator has a very low sensitivity and has practical application only for large voltages. However, the system may be useful for some of the evaluations being made of the effects of fast rise pulses on power system equipment where large signals are being used. In particular, these devices may be useful in large transformers where contacting probes are not feasible.

As a first step in a study of field coupled sensors, an analysis of the response of such E-dot sensors to EMP-like waveforms has been made.

Experimental work is presently in progress which is concerned with determining errors associated with E-dot sensors as well as methods for calibration. This report provides a general description of these sensors and presents results of numerical calculations for a selected fast rise waveform.

\subsubsection{Sensor Characterization}

The equivalent circuit of an $E$-dot sensor and its attendant passive integrator is shown in Fig. 22. The physical sensor itself is an electrode which is installed in a grounded part of an enclosure so that it is field coupled to the high voltage element. The signal from the electrode is carried to the integrator by a terminated coaxial line. This high-pass circuit is described in circuit analysis texts as a differentiating circuit, and the 


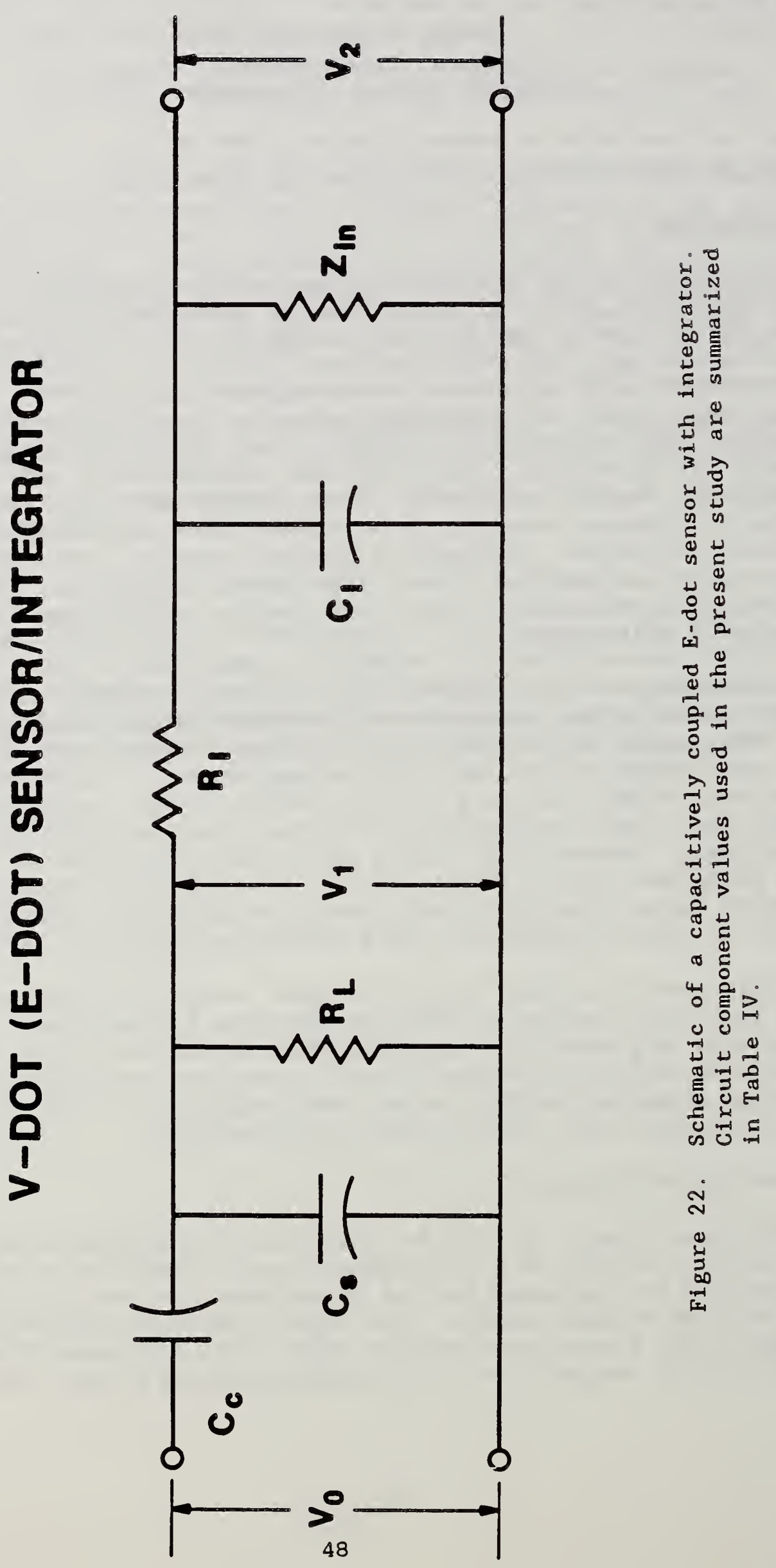


output from the circuit is given by $V_{1}=\left(R_{L} C_{C}\right) d V_{0} / d t$ [89]. This approximate description of the circuit is valid for waveforms whose highest frequency components have periods which are long compared to the time constant ${ }^{T} D=R_{L} C_{C}$ of the differentiator. A similar analysis and appropriate limiting conditions can be used to show that the low pass filter made up of $C_{I}, R_{I}$, acts as an integrator, again over a limited range of frequencies. For the integrator the requirement is that the integrator time constant $\tau_{I}=R_{I} C_{I}$ be long compared with the period of the lowest frequencies of interest in the pulse to be measured. A frequency domain analysis of this system may be summarized as

$$
v_{1} / v_{0}=j \omega \tau_{1} /\left(1+j \omega \tau_{D}\right)
$$

and

$$
V_{2} / V_{1}=1 /\left(1+j \omega r_{I}\right),
$$

Here $V_{0}$ is the input voltage to the differentiating circuit, $V_{1}$ is the differentiator output and $v_{2}$ is the integrator output. If $R_{I} \gg R_{L}$, and $\tau_{I} \gg r_{D}$, the response can be written as

$$
v_{2} / V_{0}=R_{L} C_{C} / R_{I} C_{I}
$$

It must be emphasized that these are approximate expressions and provide only qualitative guides as to what the pulse response of the circuit to different applied waveforms. In addition, the analysis does not include the effects of stray circuit elements such as $C_{s}$ in Fig 22. A circuit analysis program written for use with a personal computer has been lised to study the characteristics of an E-dot/integrator circuit. Table IV summarizes the circuit elements chosen for this study. They are representative of those found in real laboratory systems.

Table IV: Circuit Parameters Used in Sensor Calculations

$$
\begin{aligned}
& C_{C}=1 \mathrm{pF} \\
& R_{L}=50 \Omega \\
& \tau_{I}=1,5,50 \mu \mathrm{s} \\
& C_{S}=1,5,50 \mathrm{pF}
\end{aligned}
$$

It is useful to display the frequency response of the circuit shown in Fig. 22 for the circuit parameters of Table IV. Fig. 23 shows the frequency response 


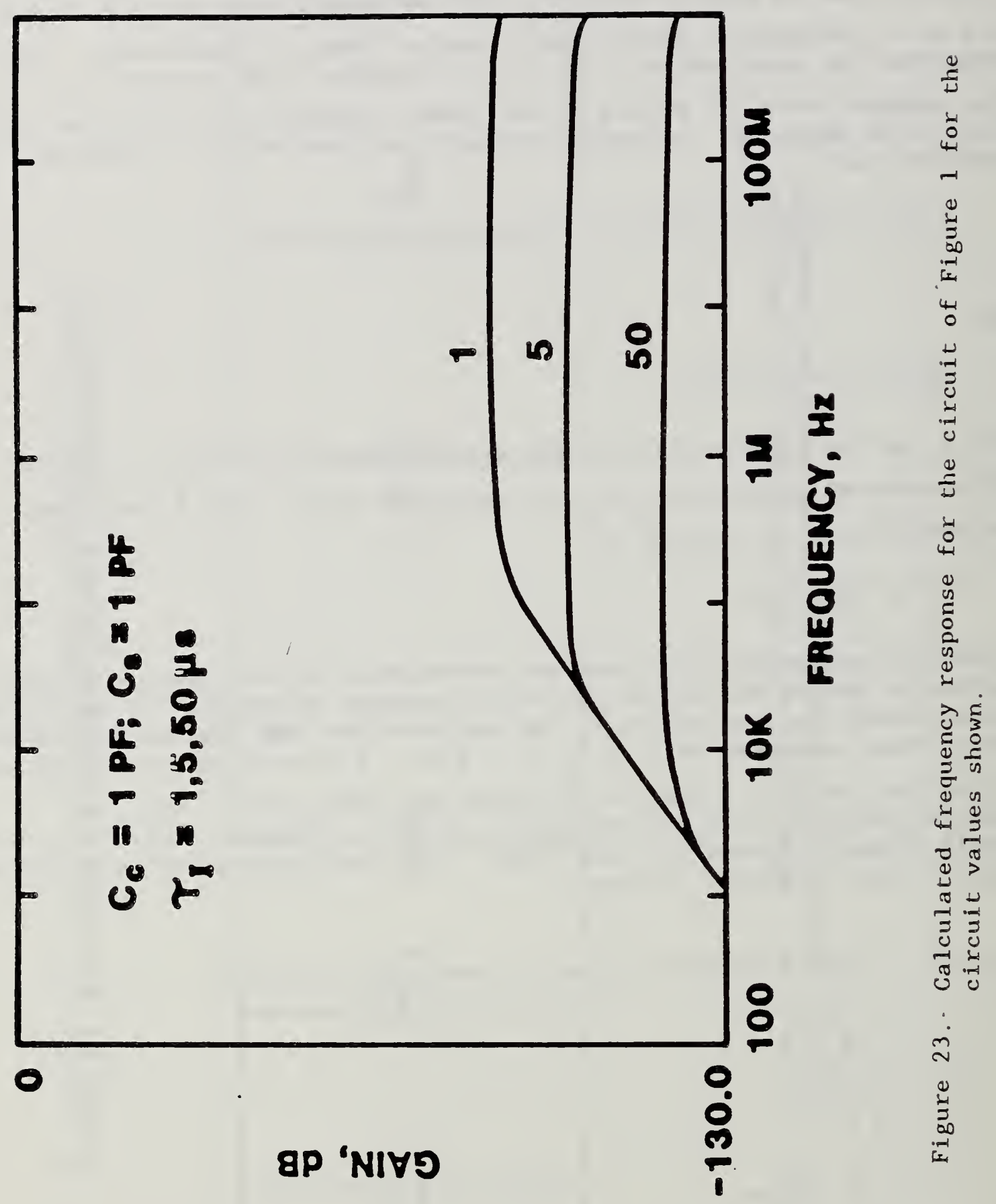


calculated for the parameters indicated. The frequency independence over an extensive bandwidth predicted by eq. 42 is clearly shown as is the effect of changing the integrator time constant. The primary effect of the shunt capacitance, $C_{S}$, is not shown here but results in a loss of high frequency response. Note that the magnitude of the transfer function is very small; 100 $\mathrm{dB}$ attenuation corresponds to a ratio of $10^{-5}$. For proper operation, the integrator must be loaded with a high impedance (for example, the 1 megohm input impedance of an oscilloscope). This presents a practical limit to the upper limit on the bandwidth of the measuring system which will be discussed later.

In order to determine the affects of the finite bandwidth of the measuring system on a given waveform, a double exponential waveform similar to that used in EMP computations was chosen. This waveform was used as an input waveform and the output from an E-dot/integrator circuit with selected components was calculated using the circuit analysis program mentioned previously. The calculated output was multiplied by the theoretical ratio of the circuit and the percentage error between the input and output waveforms was determined.

Examples of these calculations are given in Figs. 24-25. In Fig. 24, the errors are shown for three different integrator time constants for the time span up to $1000 \mathrm{~ns}$. The short time calculations (up to $200 \mathrm{~ns}$ ) are summarized in Fig. 25. It is clear that sizable errors are associated with the $1 \mu s$ integrator are present, even on the shortest time scales. Even the $50 \mu s$ integrator errors are substantial over the 1 s time range.

\subsubsection{Discussion}

The use of $E$-dot sensors to measure fast rise pulses in power system equipment presents an attractive option for selected measurements. These are situations where contacting sensors are impractical. While the field coupled sensor could be used in an open geometry and calibrated against a well characterized sensor using longer pulses, such a calibration is valid only for a fixed geometry and probably is not practical for configurations where different test objects are to be used. The requirement that the integrator be loaded with a high impedance limits the available recording devices to a bandwidth of approximately $200 \mathrm{MHz}$, which is adequate for the waveforms of interest. The low sensitivity of the system is not important where large signals are being used. Because of the extensive use of digital data acquisition systems, it is straightforward to numerically integrate the output of the differentiating circuit, which would result in an increase in available bandwidth since there would be no restrictions on the input impedance of the recording system and substantially higher sensitivity.

The use of the E-dot sensor to measure fast rise pulses is presently being investigated using the NBS test line and several sensor configurations. Means of calibrating the sensors are under consideration as are sources of error. The present numerical analysis will be correlated with the experimental results.

5.2 Streamer Propagation in Transformer 0il Under the Influence of Submicrosecond Rise-Time Pulses. 


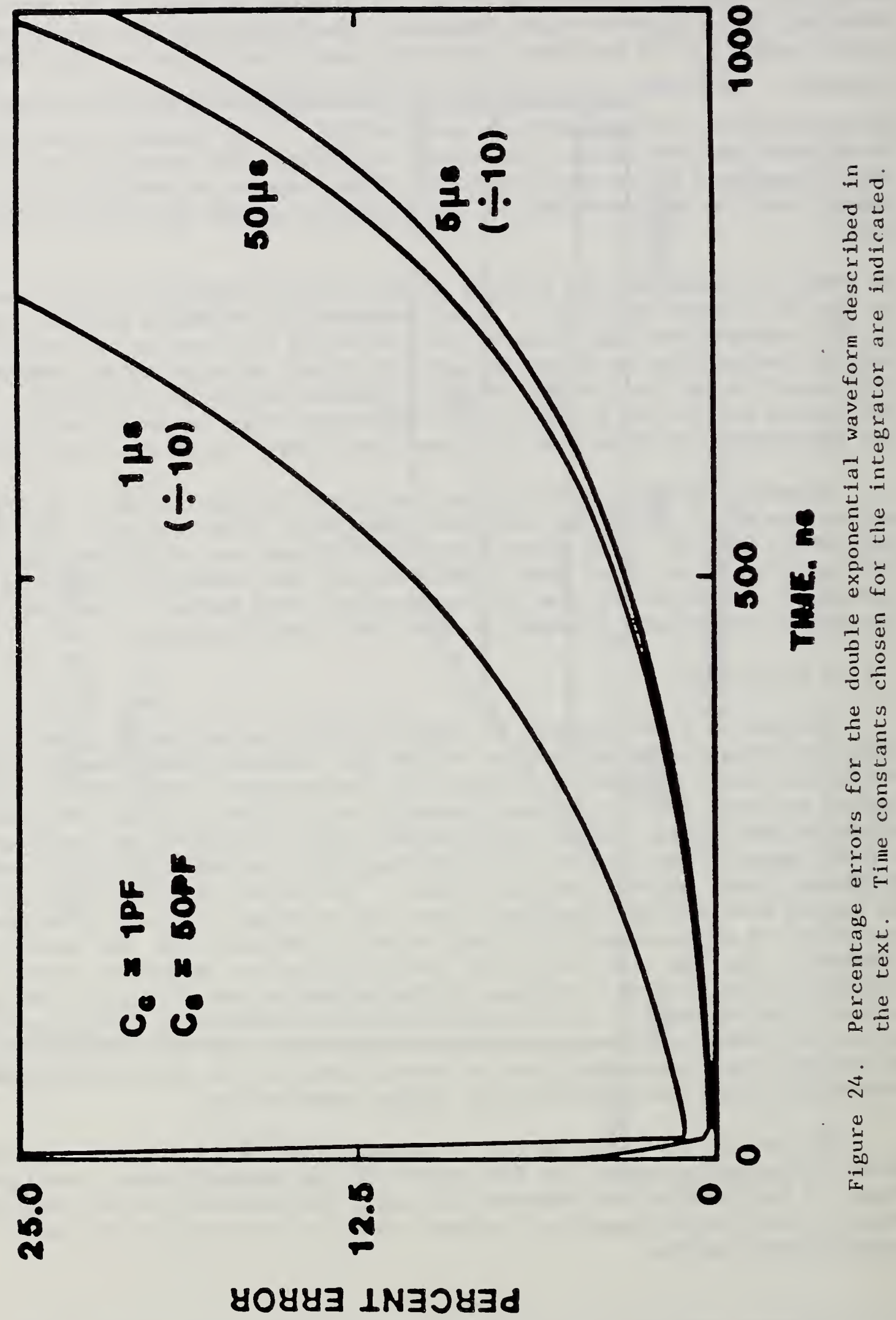




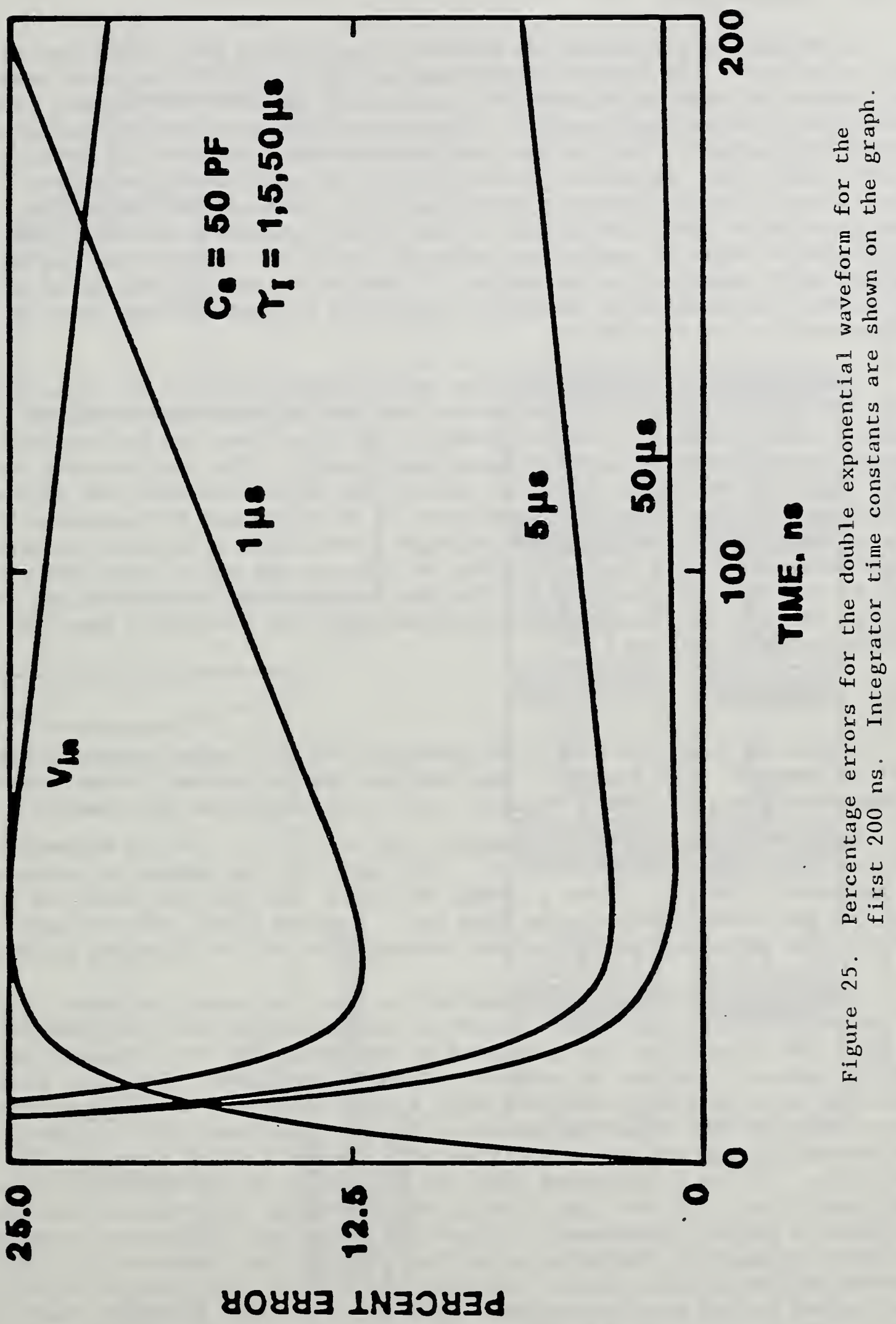




\subsubsection{Introduction}

A variety of phenomena can produce pulses which have risetimes of order $100 \mathrm{~ns}$ or less. The nuclear electromagnetic pulse (EMP) is by no means the only source of such steep-wavefront phenomena; rather, the largest problem comes from conventional sources. Because of nearby switching operations, nearby lightning, or due to gas-insulated-systems connected to apparatus, conventional power apparatus can be exposed to such fast-rise pulses [91]. Thus, there is good reason to investigate the prebreakdown phenomena associated with fast-rise pulses to see if the phenomena differs from prebreakdown behavior associated with pulses in the microsecond regime. It is particularly important to determine if insulation configurations exist for which the fast-rise pulse breakdown occurs at a lower voltage than for microsecond pulse breakdown.

Investigations were made of the prebreakdown behavior of transformer oil when subjected to fast-rise pulses as compared to microsecond pulses. A simple needle-sphere liquid gap geometry was used, and the prebreakdown phenomena monitored using high-speed photography. The results show that the fast-rise prebreakdown structures can be very different than for microsecond breakdown. On the basis of comparisons of $60-\mathrm{Hz}$ ac and dc breakdown voltages with microsecond pulse breakdown voltages, one might be tempted to assume that the breakdown voltage would continue to rise as the pulse rise-time decreases. Such is not the case in general, for the prebreakdown structures may be similar for ac, dc and microsecond pulses, but the similarity need not persist for fast-rise pulses.

\subsubsection{Apparatus}

Figure 26 shows the electrode geometry and the image-converter-camera's view of the gap. The gap was $5 \mathrm{~mm}$, and the camera was set to capture ten exposure of the gap. Three framing rates were used with the camera: $2.0 \mathrm{x}$ $10^{7}, 4.8 \times 10^{6}$, and $2.0 \times 10^{6}$ frames/s (50 ns, $210 \mathrm{~ns}, 500 \mathrm{~ns}$ between the start of the frames, respectively). The needle's tip radius of curvature was approximately $200 \mathrm{fm}$. After a number of shots, the gap was reset to $5 \mathrm{~mm}$ so that the gap never changed more than 5\%. A xenon flash tube was used to provide the illumination to produce shadowgraphs of the streamer phenomena.

Three types of pulses were applied to the electrodes as shown in Fig. 27. A slow pulse with a rise time of several microseconds, and two types of fast pulses. The slow pulse was generated by the discharge of a capacitive pulse forming network into the primary of a pulse transformer. The fast pulse was generated by a specially designed Marx system which had a characteristic rise time of 80 ns. The rise time could be further shortened by a sharpening gap. The sharpening gap was placed just outside the cell which contained the electrodes. It is anticipated that the rise time of the sharpened pulse was less than $10 \mathrm{~ns}$, but the rise time of the protected detection system employed prevented a faster measurement. There was never any difference observed in streamer propagation characteristics for the two fast pulses within the accuracy of these data $( \pm 10 \%)$, therefore no distinction is made between the fast pulses in the data presented. This does not mean, however, that upon a more careful examination a difference would not be resolved. 


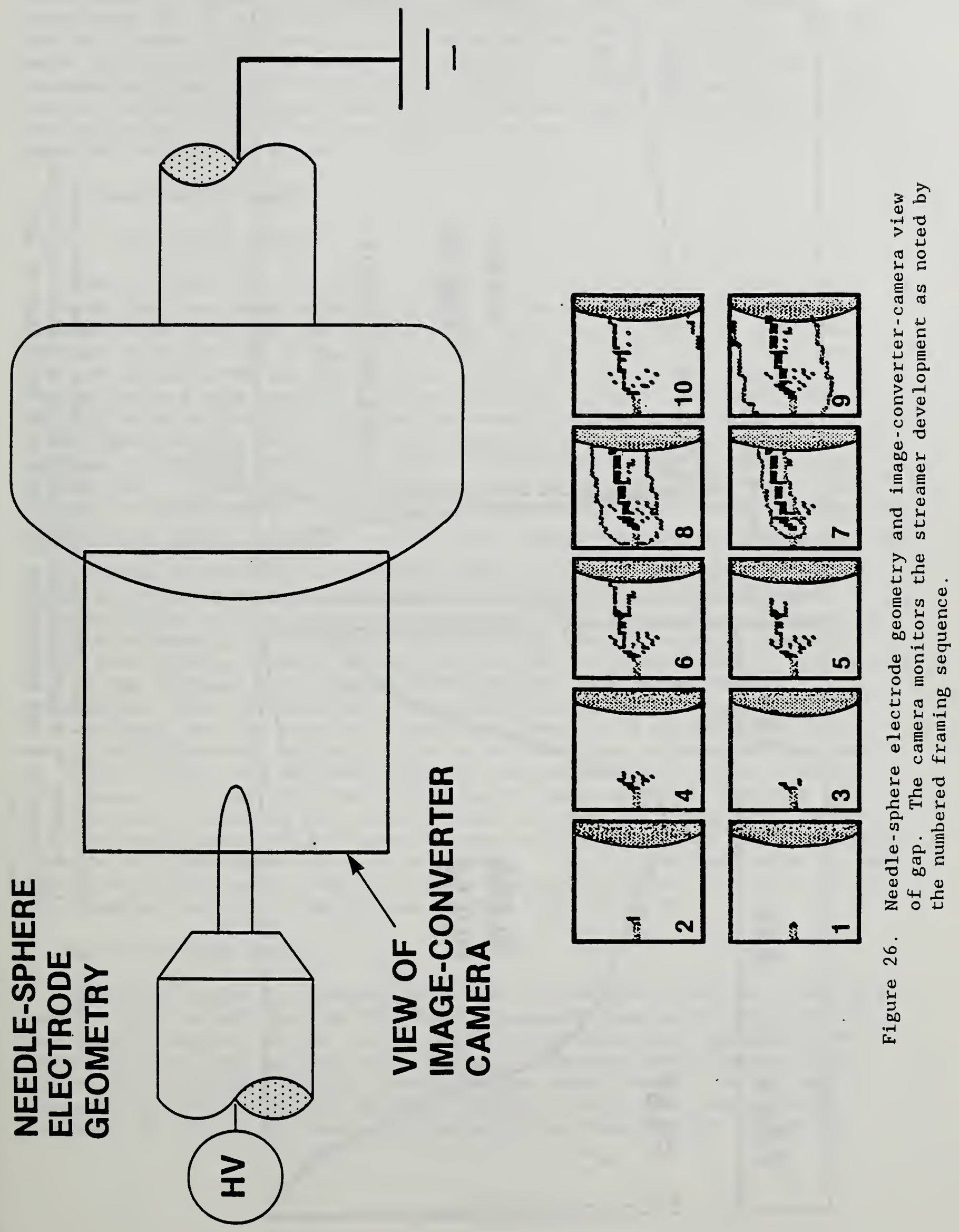



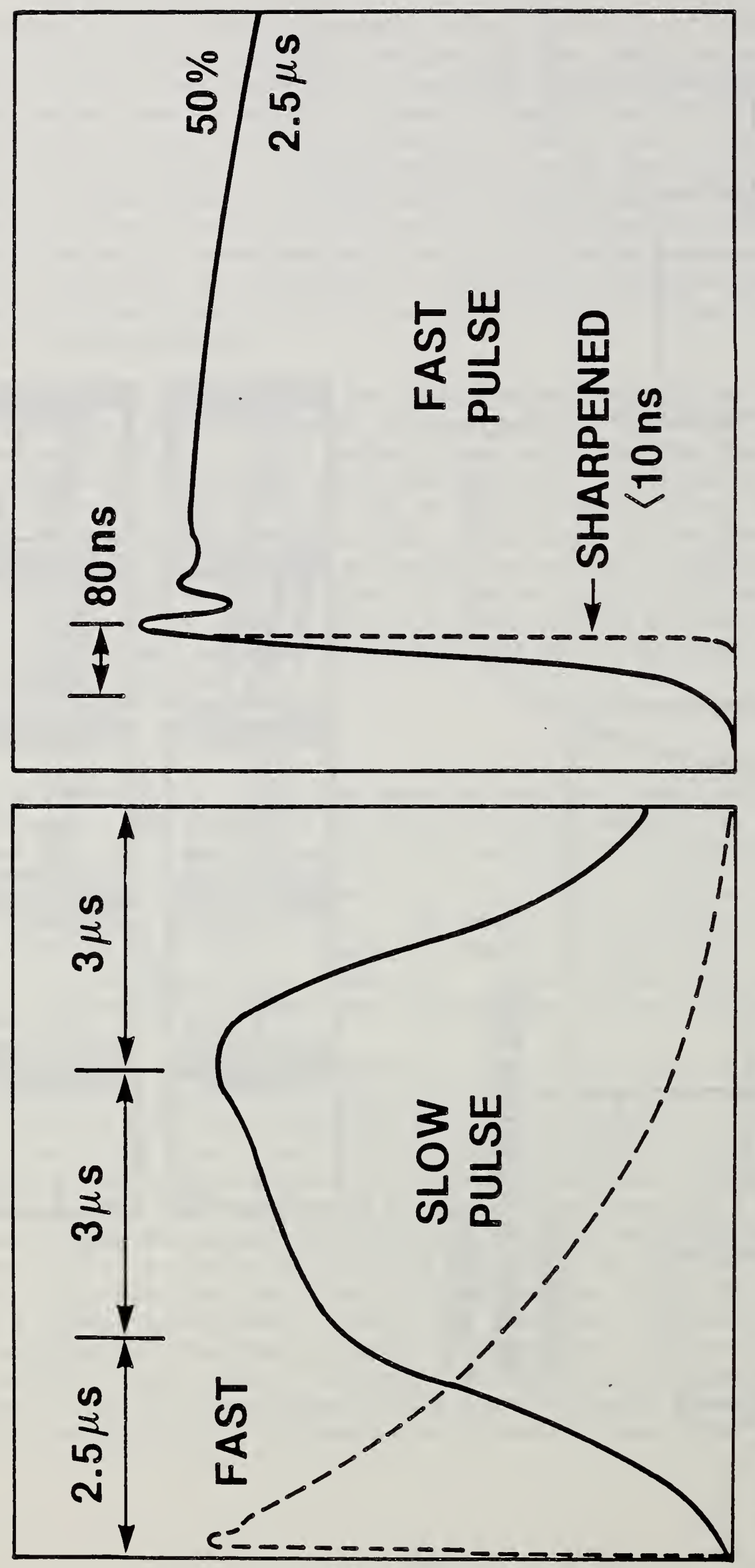

\&

औ

$2=-$

3 导 4

o 3

है

- 10

of on

to

议

0

$\underset{0}{\infty}=$

(อ) ฮ

ए

○ $5 \frac{1}{4}$

$+>$

도

न्न कै न

을

$\sigma$ a

क $4 x$

(4) को

की

可 ข

넝 우

o 0 อ

巳

ᄌั

을 당ㅇ

¿ 웅

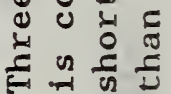

ลั

$\underbrace{10}_{0.1}$ 
The cell and sharpening gap are shown in Fig. 28. The sharpening gap and water resistor chamber was removed for the application of slow pulses.

Transformer oil is circulated through the sharpening-gap chamber and the cell and is filtered continuously during the experiments. The response of the water resistor was tested using step-response techniques to assure that the recorded waveforms were not cluttered with artifacts of the measuring system. Overall voltage measurement inaccuracy is estimated to be \pm 10 s with a shot-toshot precision of $\pm 5 \%$. For this preliminary work it was not considered important to maintain better accuracy.

\subsubsection{Experimental Results}

\subsubsection{Slow Pulse Results}

Results have been obtained for both positive and negative pulses and although there are observed differences, for reasons of brevity detailed discussions of only positive data are displayed here. Figure 29 shows the streamer structure for the slow pulse for positive needle. In photographs a-e, the charging voltage on the pulse forming network is increasing; photographs e-g were taken at the same charging voltage. Increasing the charging voltage linearly increases the output voltage of the pulse transformer, but for overvoltage conditions the peak is never reached and the increase in charging voltage has only the effect of increasing the rate of voltage rise. In general it is observed that as the voltage rises an anode streamer is initiated and grows across the gap with a quasi-spherical shape at a supersonic speed of roughly $4 \times 10^{5} \mathrm{~cm} / \mathrm{s}$. The sonic speed is defined as the speed of the post-breakdown shockwave which is $(1.80 \pm 0.05) \times 10^{5} \mathrm{~cm} / \mathrm{s}$. It should be noted that in Fig. 29a the streamer branching either increases or broadens as the streamer nears the electrode. This feature occurs sooner in the slow streamer growth as the rate of voltage rise increases. However, rather than growing steadily across the gap, at a critical field at one of the tips of the streamer the streamer growth changes to a faster mode of propagation. This critical field is reached sooner for the higher rate-ofrise voltages, and the streamer spends less time in the slower propagation mode. The differences in the initiation of the faster propagation mode seen in Figs. 29e-29g, are presumably due to the random nature of the streamer's development since the charging voltage and the applied pulse shape was the same for each. Whenever the faster propagation mode initiates early in the streamer development, the breakdown voltage will be lower than if it initiated later in the development of the slow streamer. The statistical nature of the initiation of the faster event will produce large deviations in the value of the breakdown voltage as can be seen in Figs. $29 \mathrm{e}-29 \mathrm{~g}$ show.

\subsubsection{Fast Pulse Results}

Figure 30 shows the streamer structure for the fast pulse for a positive needle. For low voltages the slow event propagates much as it does for the slow pulse. However, as the voltage level of the fast pulse is raised, we reach a critical voltage over which the slow phenomena hardly appear at all. For the positive point this occurred at approximately $86 \mathrm{kV}$. We can expect some shot-to-shot variability in this critical voltage since during each breakdown the tip of the needle is changed by the breakdown arc. Even so, 


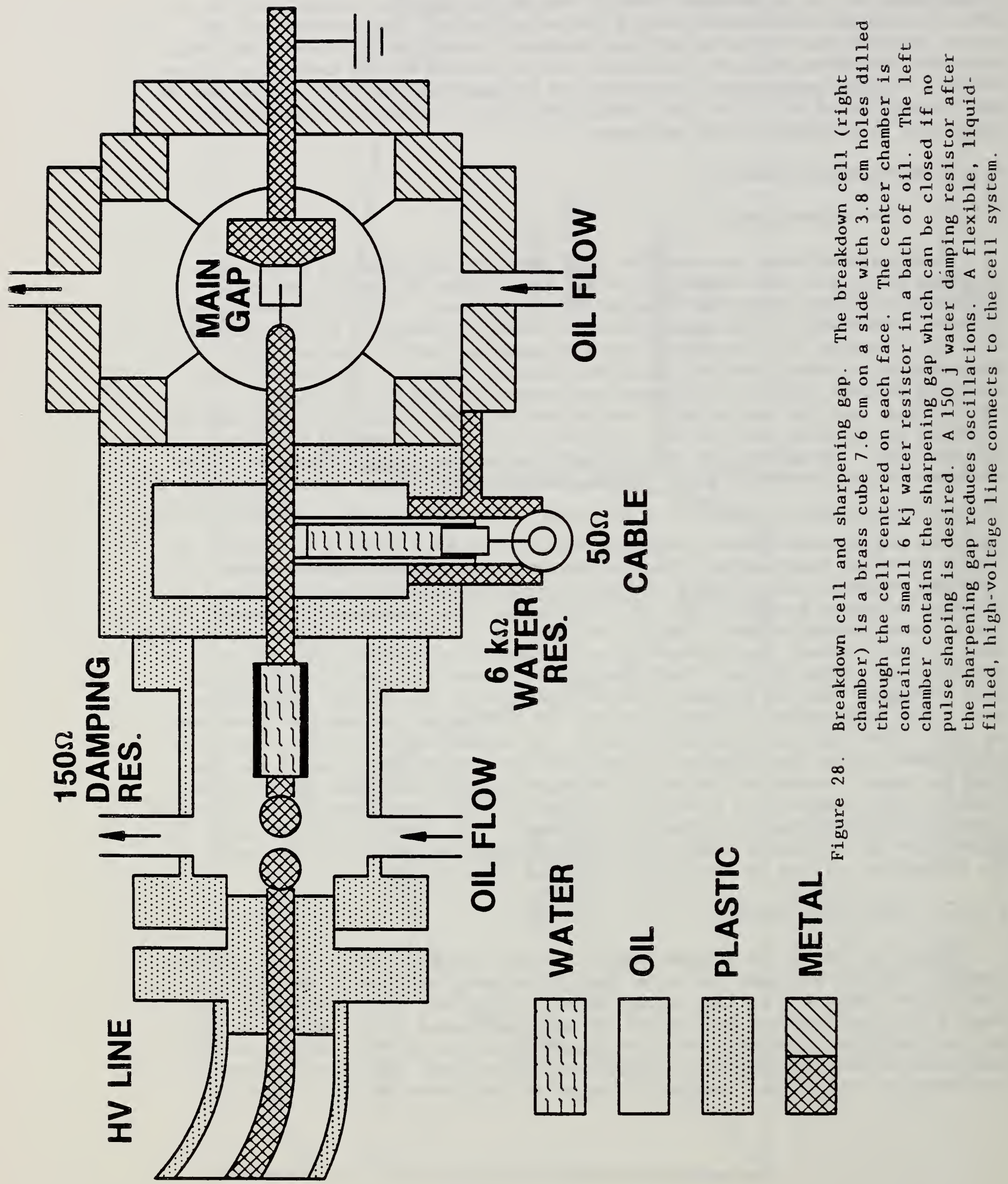




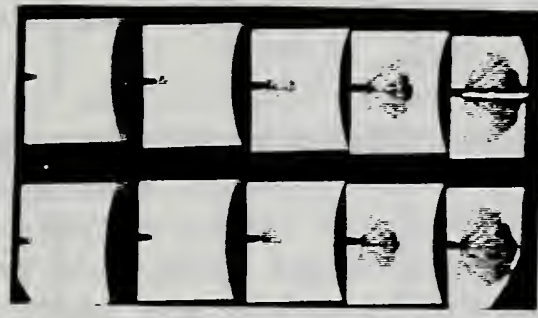

(a) $77 \mathrm{kV} \mathrm{B}, 1.4 \mu \mathrm{s}, 5.6 \mathrm{kV} \mathrm{chg}(210 \mathrm{~ns})$

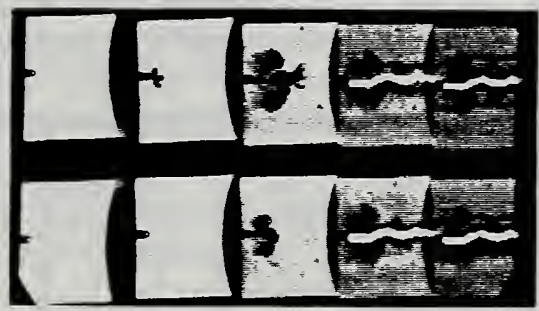

(c) $130 \mathrm{kV} \mathrm{B}, 630 \mathrm{~ns}, 15 \mathrm{kV} \mathrm{chg}(210 \mathrm{ma})$

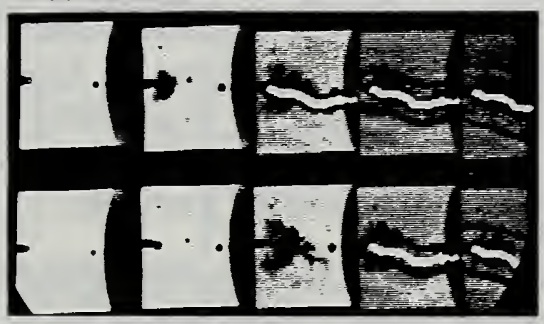

(e) $151 \mathrm{kV}$ B, $500 \mathrm{nat}, 25 \mathrm{kV} \operatorname{chg} 210 \mathrm{na})$

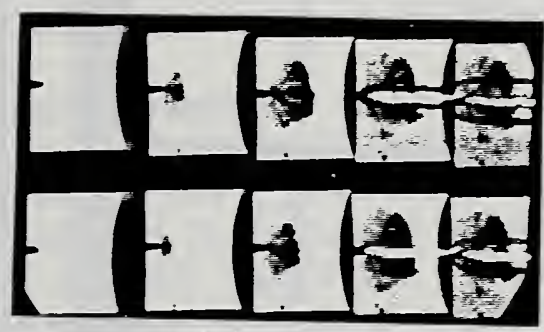

(b) $111 \mathrm{kV} \mathrm{B}, 1.05 \mu \mathrm{s}, 10 \mathrm{kV} \operatorname{chg}(210 \mathrm{~ns})$

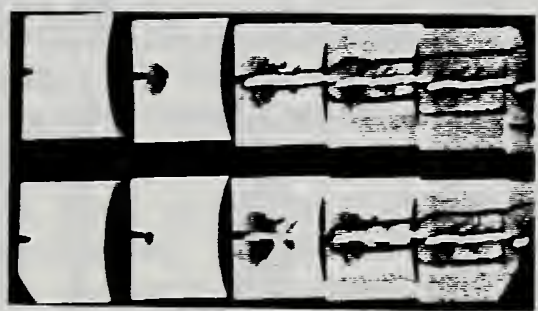

(d) $141 \mathrm{kV} \mathrm{B}, 520 \mathrm{~ns}, 20 \mathrm{kV} \operatorname{chg}(210 \mathrm{~ns})$

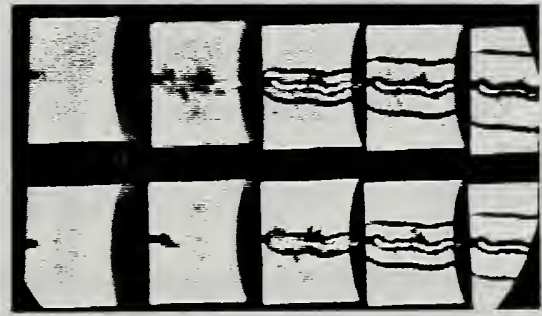

(i) $131 \mathrm{kV} \mathrm{B}, 250 \mathrm{ma}, 25 \mathrm{kV} \mathrm{chg}(210 \mathrm{mas})$

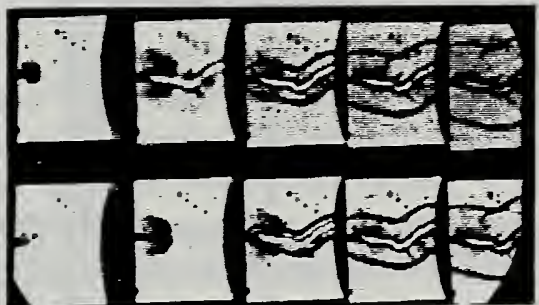

(g) $146 \mathrm{kV} \mathrm{B,} 600 \mathrm{na}, 25 \mathrm{kV} \mathrm{chg}(210 \mathrm{~ms})$

Figure 29. Streamer characteristics for microsecond pulses with positive needle. The experimental conditions appear beneath each picture: The first voltage is the breakdown voltage $(\mathrm{kV} \mathrm{B})$, the first time is the estimated duration of streamer propagation, the second voltage is the charging voltage used in the pulse-generating circuit $(\mathrm{kV} \mathrm{cg})$, and the time in parentheses is the time between the start of each frame. (For all photographs in this figure the framing rate is $48 \times 106$ frames/s or $210 \mathrm{~ns}$ between frames.)

(a) $77 \mathrm{kV} \mathrm{B}, 1.4 \mathrm{fs}, 5.6 \mathrm{kV}$ chg (210 ns).

(b) $111 \mathrm{kV} \mathrm{B}, 1.05 \mathrm{fs}, 10 \mathrm{kV} \cdot \mathrm{chg}$ (210 ns)

(c) $130 \mathrm{kV} \mathrm{B}, .630 \mathrm{~ns}, 15 \mathrm{kV}$ chg (210 ns)

(d) $141 \mathrm{kV} \mathrm{B}, 520 \mathrm{~ns}, 20 \mathrm{kV}$ chg (210 ns)

(e) $151 \mathrm{kV} \mathrm{B}, 500 \mathrm{~ns}, 25 \mathrm{kV}$ chg (210 ns)

(f) $131 \mathrm{kV} \mathrm{B}, 250 \mathrm{~ns}, 25 \mathrm{kV}$ chg (210 ns)

(g) $146 \mathrm{kV} \mathrm{B}, 600 \mathrm{~ns}, 25 \mathrm{kV}$ chg (210 ns) 
less than a $5 \%$ change in voltage about these critical voltages would switch the streamer phenomena between their slow and fast modes of propagation.

At least four types of streamer propagation modes are visible in Fig. 30 with the positive needle: Two slow modes and two fast modes. The slow modes start with a narrow filamentary structure which gives rise to a slightly fastex and either more branched or heavier branched (or both) structure which moves slightly faster; see Figs. $30 \mathrm{a}$ and $30 \mathrm{~b}$. The second slow mode gives rise to a fast mode which is much less branched but the branches are heavy. This fast mode can then give rise to an even faster mode of propagation which shows narrower branches; see especially Fig. 30d. We could venture explanations for these different modes: They could be electrohydrodynamic in nature where the slow phenomena becomes unstable and produces the faster phenomena, or we could be observing a descrete ionization processes where deeper molecular electronic levels are being effected providing more electrons per collisional event as. the field increases at the tip of the streamer branches. However, no certainty attaches to either hypothesis, and an accurate description awaits more refined experiments and more complete computer modeling efforts.

The critical voltage at which the slower phenomena no longer have a chance to form for the positive needle is around $90 \mathrm{kV}$. In Fig. $30 \mathrm{~b}$ a slow event almost bridges the gap, whereas in Fig. $30 \mathrm{c}$ only a small portion of the slow event exists before a faster event takes off to bridge the gap.

In Fig. 31 we show the streamer's formative-time vs. the applied voltage for both the slow and fast pulses. The formative time (borrowing from an older terminology: formative time lag), or streamer duration or growth time, is the gap length divided by the average streamer speed. Fig. 32 shows the average streamer speed as a function of applied voltage comparing the slow and the fast pulse results. For the lower voltages where the slow events dominate the streamer's propagation time, the apparent continuous increase in streamer speed with voltage is an artifact of the switching from slow to fast propagation modes and is not a continuous increase in the speed of the streamer. The high-voltage propagation behavior shows a similar increase in the average streamer velocity with applied voltage. However with the present resolution of the camera it is not possible to determine if the streamer is truly increasing its speed or if it is switching between two fast modes of propagation giving the overall appearance of acceleration with voltage. The medium-voltage behavior is interesting, since there is where the difference between the streamer propagation under fast or slow pulses becomes apparent. Here the fast-pulse streamer switches from the slow to the fast propagation mode with a small change of voltage producing a discrete step in both the time and average speed curves. On the other hand, the slow-pulse streamer's curves exhibit continuity because both fast and slow propagation modes are explored by the streamer to different extents.

\section{2 .4 Discussion}

We have seen that there are a variety of streamer propagation modes and structures in the prebreakdown phenomena in liquids depending upon the voltage pulse applied. Generally speaking, slow events begin the prebreakdown phenomena for both polarities and for slow pulses (and we would expect the same for ac and $d c$ ). However, for fast pulses the streamer need not begin with the slow mode, but can be initiated in the faster modes directly. The 


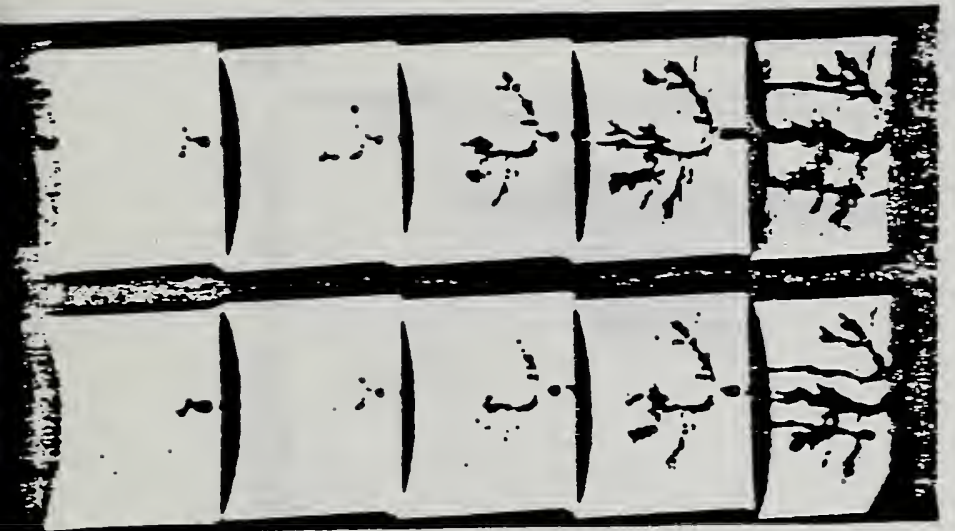

(a) $56 \mathrm{kV}$. $4.7 \mathrm{\mu s}, 4.2 \mathrm{kV}$ ang $(500 \mathrm{~ns})$

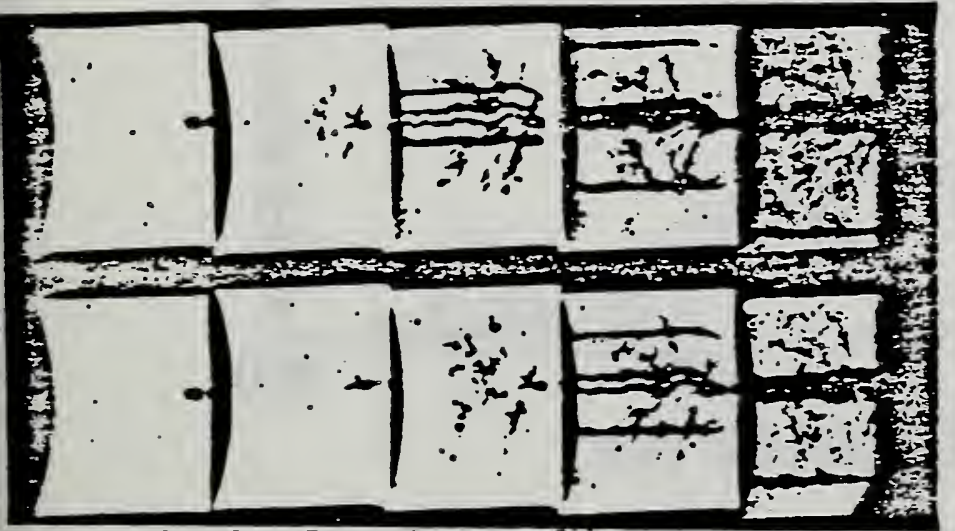

(c) $i 15 \mathrm{kV}$ 5, $3.5 \mathrm{Hs}, \mathrm{ju} \mathrm{kV}$ crig (500 ns)

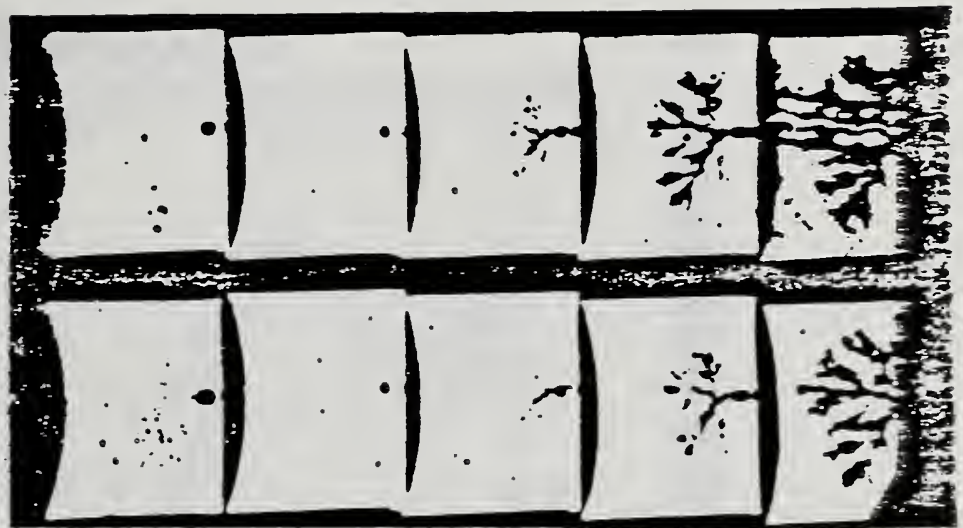

(b) $79 \mathrm{kV} \mathrm{B,} 2.8 \mathrm{\mu s}, 6 \mathrm{kV} \mathrm{chg}(500 \mathrm{~ns})$

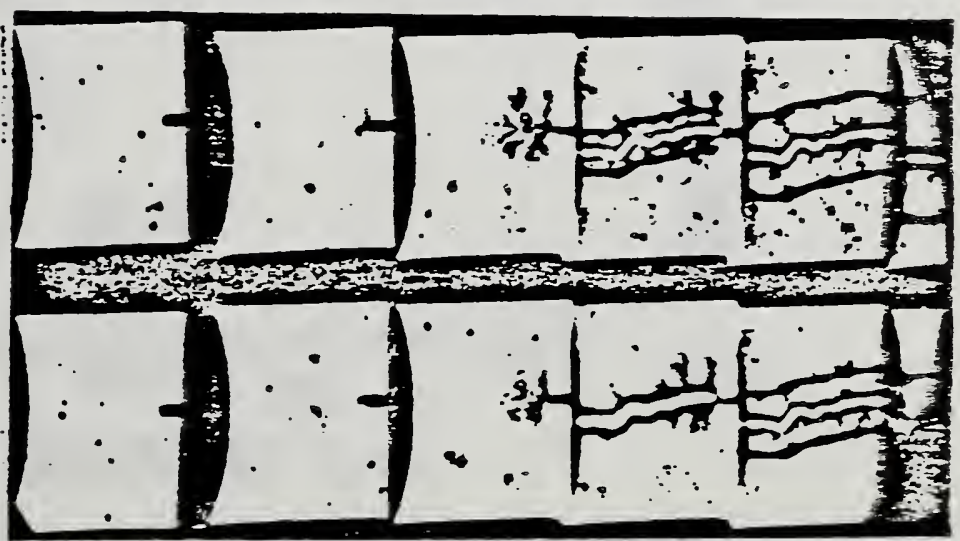

(d) ijs kV 8, $840 \mathrm{ns,} 15 \mathrm{kV} \mathrm{chg}$ (210 RIS)

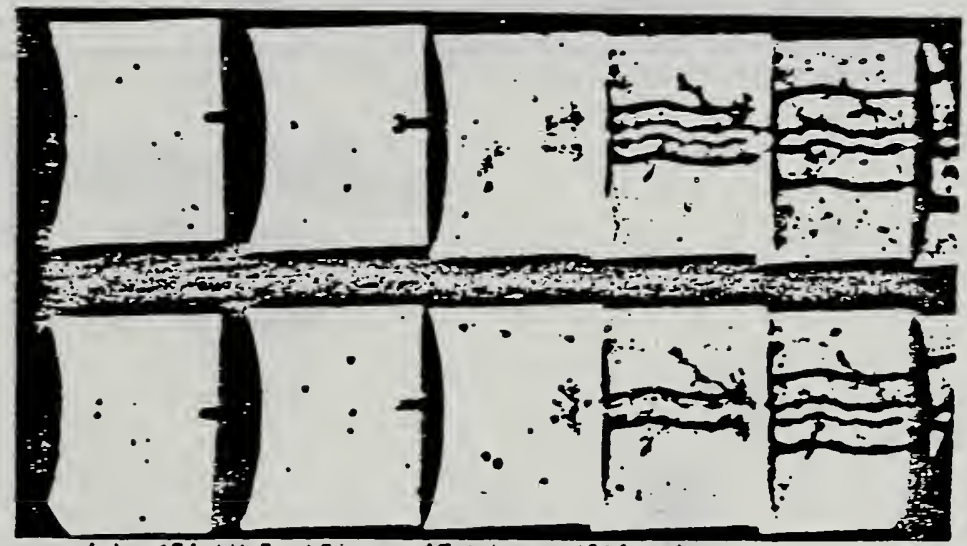

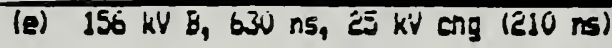

Figure 30. Streamer characteristics for fast pulses with positive needle. Experimental conditions are noted beneath each picture: The breakdown voltage (approximately the peak voltage), the estimated duration of the streamer, and the time between the start of each frame. Note the increase in branching of the slowest phenomen in (a) and (b). Also note the evidence of an ultra-fast event eminating from the second fast phenomena in (d). These photographs show at least four different types of streamer propagation modes.
(a) $55 \mathrm{kV} \mathrm{B}, 1.6 \mathrm{fs}$ ( $210 \mathrm{~ns}$ )
(b) $86 \mathrm{kV} \mathrm{B}, 1.05 \mathrm{fs}$ (210 ns)
(c) $86 \mathrm{kV} \mathrm{B}, 320 \mathrm{~ns}$ (210 ns)
(d) $165 \mathrm{kV} \mathrm{B}, 180 \mathrm{~ns}$ (50 ns)
(e) $249 \mathrm{kV} \mathrm{B}, 46 \mathrm{~ns}$ (50 ns) 


\section{TIME TO CROSS GAP VS APPLIED VOLTAGE}
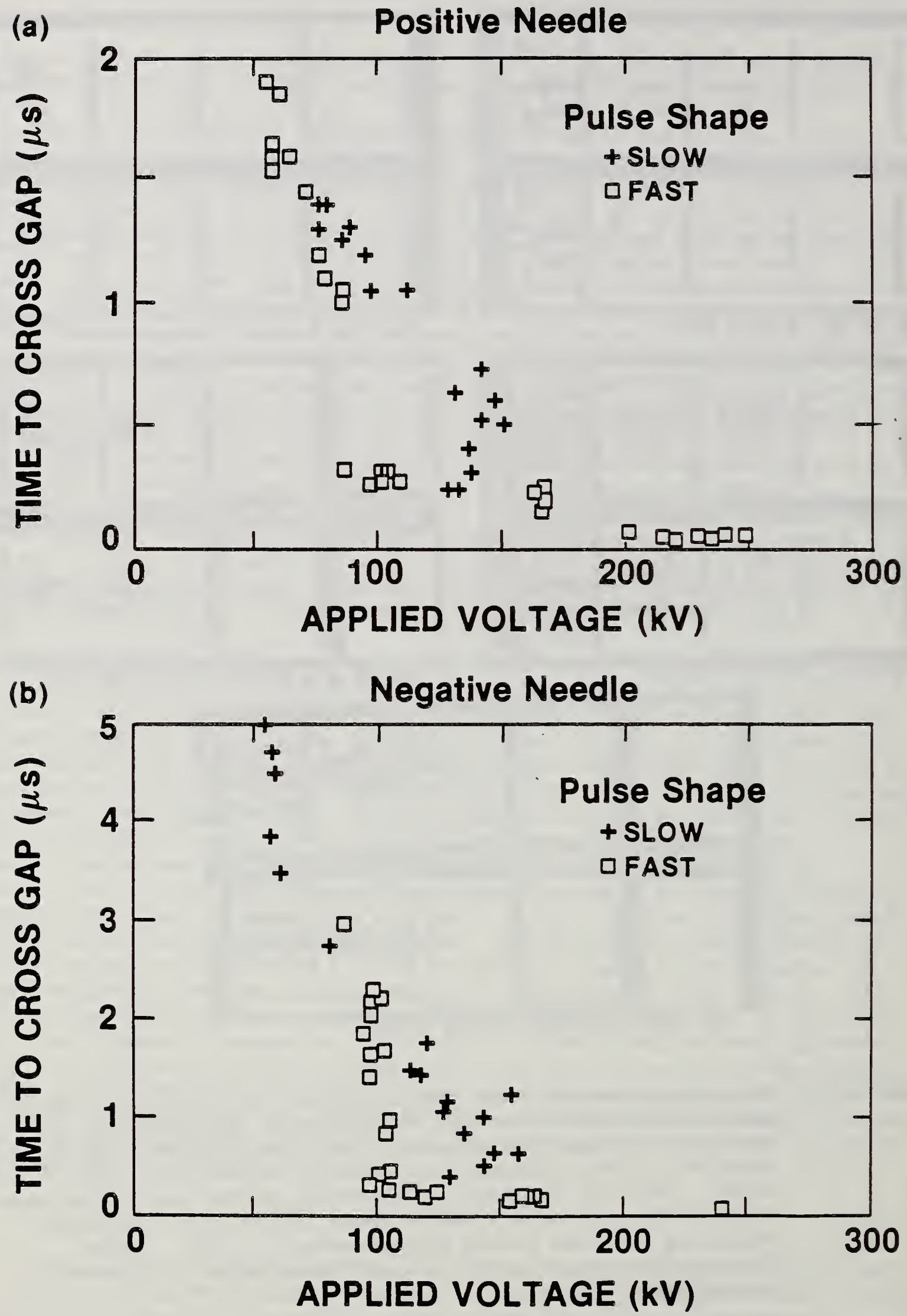

Figure 31. Streamer growth time vs applied voltage for slow and fast pulses with (a) positive and (b) negative needle polarity. Abrupt transitions form slow to fast phenomena are visible when using the fast pulse. As the slow pulse overvoltages the gap, the fast phenomena dominate and the breakdown occurs more rapidly which tends to even decrease the breakdown voltage. 


\section{AVERAGE STREAMER VELOCITY VS VOLTAGE}
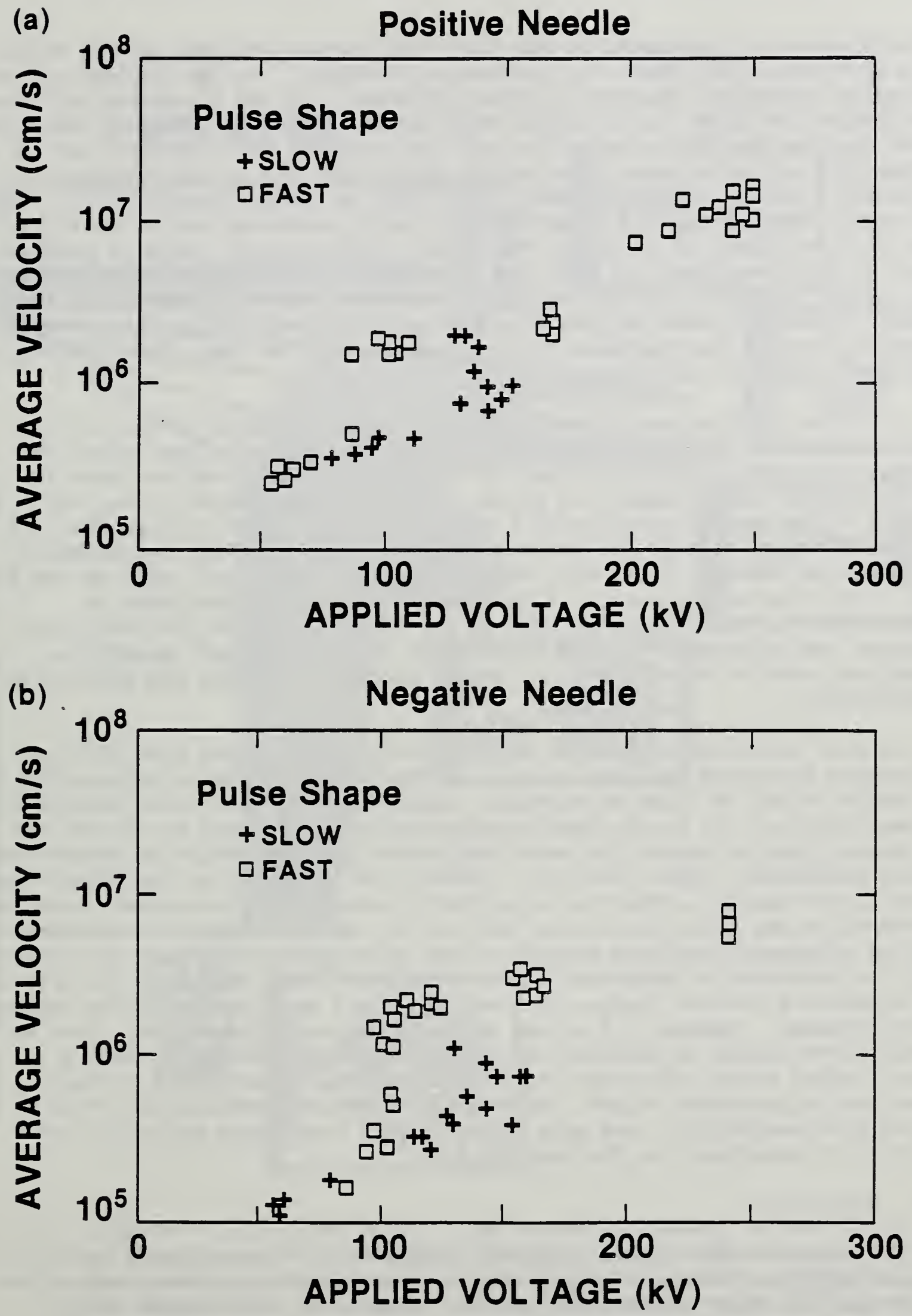

Figure 32. Average streamer speed as a function of applied voltage for slow and fast pulses with (a) positive and (b) negative needle polarity. Average speed on the order of $107 \mathrm{~cm} / \mathrm{s}$ (approaching 0.18 the speed of light) are noteworthy. 
entire picture is diagrammed in Fig. 33. The slowest streamer growth occurs for a slow pulse just above the initiation threshold. As the voltage of the slow pulse increases, the rate of rise increases, and the breakdown will occur at or before the peak. As a slower event moves toward the opposing electrode we can imagine the field at the tips of the streamers will increase due to the conductivity of the streamer, but at the same time, due to the proximity of the nearby branches of the streamer, the field is graded somewhat [92]. When a critical field is reached at any tip, a faster phenomena can be initiated. Under the conditions of a faster-rise pulse, that critical field is reached sooner in the development of the slow phenomena. If the pulse rate-of-rise is fast enough, then most of the streamer development is dominated by the fast events. Since for these extreme overvoltage conditions little time is spent in the slow mode, the breakdown voltage can actually be lower that for a pulse which has a slower rate-of-rise.

With the application of the fast pulse, it is possible to reach the critical field at the tip of the needle before or, at most, just after the streamer initiates. In such a case the breakdown voltage can be lower than for the extreme overvoltage slow pulse. In these experiments it was not possible to breakdown the gap with a fast pulse at a lower voltage than the minimum breakdown voltage for the slow pulse. Based on these measurements, the inception voltage of the slow event would be roughly half that of the fast event. The statistical nature of the initiation of the slow event is suggested by the trend observed that as the rate-of-rise of the slow pulse increased the initiation voltage of the slow event increased, however no attempt was made to resolve the initiation process in detail and under high magnification.

It must be stressed that the system under investigation here is simple: a divergent electrode geometry in oil. Although the breakdown voltage for the fast pulse is not as large as expected compared to the slow pulse because of the complications due to streamer propagation modes, we need not think that fast pulses pose no danger for more complicated systems involving composites such as pressboard, paper, and oil. Indeed, the growth of an initiated event in the liquid medium, either via a partial discharge or microsecond pulse, may be stopped by any solid insulation material in the direction of its growth. The slow phenomena generated because of the more gentle pulse may not have the energy to penetrate or puncture the solid material, and the solid dielectric will accumulate surface charges to grade the field and prevent further growth of the streamer. However, if a fast pulse initiates a fast event, there may be sufficient energy to puncture the solid insulation material. Such a scenario might render the composite system to be more vulnerable to fast pulses than microsecond pulses. However, we have not produced data here to confirm this possibility, and only offer it as a hypothesis which will be subjected to experiment in the near future.

\section{2 .5 Conclusion}

The simple needle-sphere electrode system in oil investigated here has produced different streamer propagation characteristics for fast, nanosecond pulses than for slow, microsecond pulses. Because of the changes in the propagation modes of the streamer as it grows, it is possible to produce breakdown by a fast pulse at a lower voltage than would be expected from looking at the breakdown voltage produced by extreme overvotage conditions 


\section{VOLTAGE}
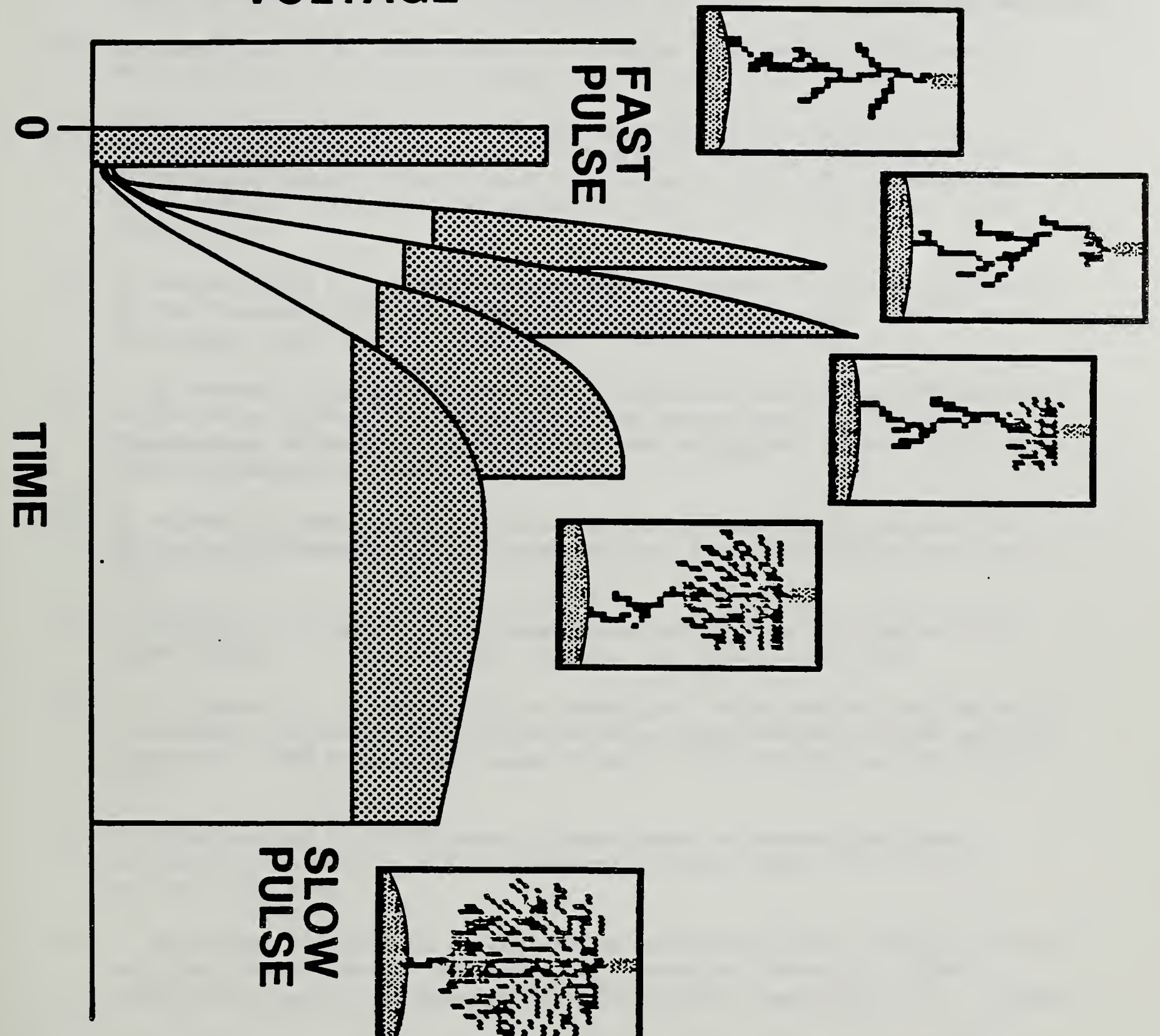

Figure 33. Effects of a fast pulse vs a slow pulse increasing in overvoltage. As the slow pulse overvoltages the gap, less of the streamer development is found in the slower propagation modes. Eventually, the slower pulse can reach such an overvoltage condition that the streamer spends little time in the slower mode. Under such a case the breakdown voltage can be lower for the fast rise pulse. Breakdown voltages with fast rise pulses can be even lower. 
from a slow pulse. Although it was never possible to cause the liquid gap to fail at a lower voltage with the fast pulse than with the minimum breakdown voltage from the slow pulse, concern is expressed over the possible implications the different streamer propagation modes can have on composite insulation systems. 


\section{REFERENCES}

[1] F. R. Kotter and M. Misakian, "AC Transmission Line Field Measurements", prepared for U.S. Department of Energy, DOE Report No. HCP/T-6010/E1, 1977. Available from NTIS, Springfield, VA 22161.

[2] M. Misakian, F. R. Kotter and R. L. Kahler, "Miniature ELF Electric Field Probe", Rev. Sci. Instrum., Vol. 49, pp. 933-935, 1978.

[3] "Working Group on Electrostatic and Electromagnetic Effects of Transmission Lines, Measurement of Electric and Magnetic Fields From Alternating Current Power Lines", prepared at NBS by M. Misakian and F. R. Kotter, IEEE Trans. Power Appar. Syst., Vol. PAS-97, pp. 1104$1114,1978$.

[4] M. Misakian and F. R. Kotter, Discussion of Paper F78 169-5, "Analysis of the Proximity Effects in Electric Field Measurements", IEEE Trans. Pow. Appar. Syst., Vol. PAS-97, pp. 2175-2176, 1978.

[5] F. R. Kotter, "Characterization of the Electric Environment Under HVDC Transmission Lines: Instrumentation and Measurement Techniques", Proceedings of Workshop on Electrical and Biological Effects Related to HVDC Transmission, Richland, WA, 1978.

[6] M. Misakian, "Measurement of AC Transmission Line Fields and Related Electrical Parameters", IEEE Tutorial Text 79-EHO145-3-PWR, pp. 36-46, 1979.

[7] M. Misakian, "Generation and Measurement of DC Electric Fields With Space Charge", J. Appl. Phys., Vol. 52, pp. 3135-3144, 1981.

[8] M. G. Comber, R. Kotter and R. H. McKnight, "Experimental Evaluation of Instruments for Measuring DC Transmission Line Electric Fields and Ion Currents", IEEE Trans. Pow. Appar. Syst., Vol. PAS-102, pp. 3549-3557, 1983.

[9] M. Misakian and P. M. Fulcomer, "Measurement of Nonuniform Power Frequency Electric Fields", IEEE Trans. Elect. Insul., Vol. EI-18, pp. $657-661,1983$.

[10] M. Misakian, "Electrical Parameters in 60- $\mathrm{Hz}$ Biological Exposure Systems and Their Measurement: A Primer", NBS Technical Note 1191, 1984. Available from U.S. Government Printing Office, Washington, D.C. 20402.

[11] P. M. Fulcomer, "Calibration Check of Bonneville Power Administration 60-Hz Electric Field Exposure Monitor", NBS Report NBSIR 84-2885, 1984.

[12] R. H. McKnight, "Measurements of DC Electric Fields and Ion Related Quantities", Proc. of Conf. on Environmental Ions and Related Biological Effects, American Institute of Medical Climatology, pp. 34-61, 1984.

[13] M. Misakian, "Calibration of Flat 60-Hz Electric Field Probes", Bioelectromagnetics, Vol. 5, pp. 447-450, 1984. 
[14] M. Misakian, Discussion of paper, Analysis of Calibration Arrangements for AC Field Strength Meters, by $T$. Tukuma et al. in IEEE Trans. Pow. Appar. Syst., Vol. PAS-104, pp. 489-496, 1985.

[15] P. M. Fulcomer, "NBS Ambient Magnetic Field Meter for Measurement and Analysis of Low-Level Power Frequency Magnetic Fields in Air", NBS Report NBSIR 86-3330, 1985.

[16] R. H. McKnight, F. R. Kotter and M. Misakian, "Measurement of Ion Current Density at Ground Level in the Vicinity of High Voltage DC Transmission Lines", IEEE Trans. Power Appar. Syst., Vol. PAS-102, Pp. 934-941, 1983.

[17] R. H. McKnight and F. R. Kotter, "A Facility to Produce Uniform Space Charge for Evaluating Ion Measuring Instruments", IEEE Trans. Pow. Appar. Syst., Vol. PAS-102, pp. 2349-2357, 1983.

[18] R. H. McKnight and P. M. Fulcomer, "Operation of Ion Counters Near High Voltage DC TRansmission Lines", Proc. 4th Int. Symp. High Voltage Engineering, Athens, Greece, 1984.

[19] R. H. McKnight, "The Measurement of Net Space Charge Density Using Air Filtration Methods", IEEE Trans. Pow. Appar. Syst., Vol. PAS-104, pp. 971-976, 1985 .

[20] M. Misakian, R. H. McKnight and C. Fenimore, "Calibration of AspiratorType Ion Counters and Measurement of Unipolar Charge Densities", NBS Technical Note 1223, 1986. Available from U.S. Government Printing Office, Washington, D.C. 20402; J. App1. Phys., Vol. 61, pp 1276-1287, 1987.

[21] IEEE Std. 644-1987, "Standard Procedures For Measurement of Power Frequency Electric and Magnetic Fields From AC Power Lines", The Institute of Electrical and Electronics Engineers, New York, NY 10017.

[22] G. W. Griffen, I. Dzidic, D. I. Caroll, R. N. Stillwell and E. C. Horning, "Ion Mass Assignments Based on Mobility Measurements", Anal. Chem., Vol. 45, pp. 1204-1209, 1973.

[23] N. E. Bradbury and R. A. Nielsen, "Absolute Values of the Electron Mobility in Hydrogen", Phys. Rev., Vol. 49, pp. 388-393, 1936.

[24] M. M. Shahin, "Mass-Spectrometric Studies of Corona Discharges in Air at Atmospheric Pressure", J. Chem. Phys., Vo1. 45, pp. 2600-2605, 1966.

[25] L. B. Loeb, Basic Processes of Gaseous Electronics (University of California Press, Berkeley, California 1955). Chapter 1.

[26] A. M. Tyndall and C. F. Powe11, "The Mobility of Ions in Pure Gases", Proc. Roy. Soc., Vol. 129, pp. 162-180, 1930.

[27] Determination of corona inception involves separating corona induced noise from other radio background noise. Normally this is not a serious problem. However, to make the distinction easier, all other 
controllable sources of radio noise, such as florescent lights, etc., should be shut down or reduced if possible. The AM frequency setting seems to have little effect on the corona induced noise but it can have a large effect on the noise produced by other sources. For this reason the AM frequency should be adjusted for minimum quiescent noise.

[28] R. J. Van Brunt, "Common Parameterizations of Electron Transport, Collision Cross Section, and Dielectric Strength Data for Binary Gas Mixtures," J. Appl. Phys. (in press, to be published, Feb 1, 1987 issue).

[29] J. W. Gallagher, E. C. Beaty, J. Dutton, and L. C. Pitchford, J. Phys. Chem. Ref. Data 12, 109 (1983).

[30] A. B. Wedding, H. A. Blevin, and J. Fletcher, J. Phys. D: Appl. Phys. 18, 2361 (1985).

[31] J. Dutton, J. Phys. Chem. Ref. Data 4, 577 (1975).

[32] Th. Aschwanden, Gaseous Dielectrics IV, Proc. 4th Int. Symp. on Gaseous Dielectrics, Ed. by L. G. Christophorou (Pergamon Press, New York, 1984) Pp. $24-33$.

[33] D. Rapp and P. Englander-Golden, J. Chem. Phys. 43, 1464 (1965); B. L. Schramm, F. J. deHeer, M. J. vander Wiel, and J. Kistemaker, Physica (Utrecht) 31, 94 (1955).

[34] V. M. Pejcev, M. V. Kurepa, and I. M. Cadez, Chem. Phys. Lett. 63, 301 (1979).

[35] L. E. KIine, D. K. Davies, C. L. Chen, and P. J. Chantry, J. Appl. Phys. 50, 6789 (1979).

[36] D. L. McCorkle, A. A. Christodoulidas, L. G. Christophorou, and I. Szamrej, J. Chem. Phys. 72, 4049 (1980).

[37] A. V. Phelps and L. C. Pitchford, Joint Institute for Laboratory Astrophysics Information Center Report No. 26 (1985).

[38] A. G. Englehardt, A. V. Phelps, and C. G. Risk, Phys. Rev. 135, A1566 (1964).

[39] A. V. Phelps (private communication).

[40] G. R. Govinda Raju and R. Hackam, J. Appl. Phys. 52, 3912 (1981); $\underline{33}$, 5557 (1982).

[41] J. P. Novak and M. F. Frechette, J. Appl. Phys. 57, 4368 (1985).

[42] H. F. A. Verhaart, Thesis, Eindhoven University of Technology, Netherlands, 1982 (unpublished). 
[43] M. C. Siddagangappa, C. S. Lakshminarasimha, and M. S. Naidu, J. Phys. D: Appl. Phys. 15, L83 (1982); 16, 763 (1983); IEEE Trans. Elec. Insul. EI-19, 434 (1982).

[44] I. C. Somerville, D. J. Tedford, and A. Thurogood, Proc. 6th Int. Conf. on Gas Discharges (IEE, London, 1980) p. 271.

[45] N. H. Malik and A. H. Qureshi, Proc. IEEE Int. Symp. Elec. Insul. (IEEE, New York, 1980) p. 38.

[46] V. N. Maller and M. S. Naidu, Proc. 3rd Int. Conf. on Gas Discharges (IEE, London, 1974) p. 409; V. N. Maller, IEEE-IAS Annual Meeting, New York, IAS78:75 (IEEE, New York, 1978).

[47] J. Berril, J. M. Christensen, and I. W. McAllister, Proc. 1986 IEEE Int. Symp. Elec. Insul., Washington, D.C. (IEEE, New York, 1986) pp. 251-257.

[48] R. E. Wootton and M. R. Kegelman, Gases Superior to $S_{6}$ for Insulation and Interruption, Electric Power Research Institute Report EL-2620 (1982); R. E. Wootton, S. J. Dale, and N. J. Zimmerman, Gaseous Dielectrics II, Proc. 2nd Int. Symp. on Gaseous Dielectrics, Ed. by L. G. Christophorou (Pergamon Press, New York, 1980) pp. 137-148.

[49] M. F. Frechette, J. App1. Phys. 59, 3684 (1986).

[50] S. Okabe and T. Kouno, Japanese J. Appl. Phys. 24, 836 (1985); 25, 453 (1986).

[51] H. Itoh, M. Shimozuma, and H. Tagashira, J. Phys. D: App1. Phys. 13, 1201 (1980).

[52] J. P. Novak and M. F. Frechette, J. App1. Phys. 55, 107 (1984).

[53] V. N. Maller, IEEE - IAS Annual Meeting, New York, No. IAS78:75 (IEEE, New York, 1978).

[54] M. F. Frechette and J. P. Novak, J. App1. Phys. 60, 552 (1986).

[55] R. J. Van Brunt and I. Sauers, "Gas-Phase Hydrolysis of SOF 2 and SOF 4 ," J. Chem. Phys. 85, 4377 (1986).

[56] R. J. Van Brunt, Nat1. Bur. Stand. J. Res. 90, 229 (1985).

[57] F. Y. Chu, IEEE Trans. Elec. Insul. EI-21, 693 (1986).

[58] T. R. Ophe1, D. C. Weisser, A. Cooper, L. K. Fifield, and G. D. Putt, Nucl. Instrum. Methods 217, 383 (1983).

[59] H. Grasselt, W. Ecking, and H. J. Polster, Elektrie 32, 369 (1978).

[60] W. Ruegsegger, R. Meier, F. K. Kneubuh1, and H. J. Schotzau, App1. Phys. B37, 115 (1985). 
[61] I. Sauers, J. L. Adock, L. G. Christophorou, and H. W. Ellis, J. Chem. Phys. 13,2618 (1985).

[62] H. Latour-Slowikowska, J. Lampe, and J. Slowikowska, Gaseous Dielectrics IV, Proc. 4th Int. Symp, on Gaseous Dielectrics, Ed. by

L. G. Christophorou (Pergamon Press, New York, 1984) pp. 286-291.

[63] R. J. Van Brunt, J. Appl. Phys. 59, 2314 (1986).

[64] R. L. Brown, Natl. Bur. Stand. Interagency Report No. NBSIR 81-2281 (1981).

[65] K. D. Asmus, W. Grunbein, and J. H. Fendler, J. Am. Chem. Soc. 92, 2625 (1970).

[66] A. M. Velichko, I. O. Leipunskii, A. A. Nadeikin, A. I. Nikitin, and V. L. Talroze, High Energy Chem. 17, 124 (1983).

[67] R. J. Van Brunt and M. C. Siddagangappa, Proc. 1986 Gaseous Electronics Conf. Bull. Am. Phys. Soc. (to be published, 1987); Plasma Chem. Plasma Proc. (submitted for publication, 1987).

[68] I. C. Plumb and K. R. Ryan, Plasma Chem. Plasma Proc. 6, 247 (1986).

[69] M. C. Siddagangappa, R. J. Van Brunt, and A. V. Phelps, "Influence of Oxygen on the Decomposition Rate of $\mathrm{SF}_{6}$ in Corona," Conf. Rec.; 1986 IEEE Int. Symp. on Elec. Insul. (IEEE, New York, 1986) pp. 225-229; "Decomposition Rates of $\mathrm{SF}_{6}$ in $\mathrm{SF}_{6} / \mathrm{Ne}$ and $\mathrm{SF}_{6} / \mathrm{N}_{2}$ Corona Discharges," Bul1. Am. Phys. Soc. 31, 145 (1986).

[70] R. J. Van Brunt, I. Sauers, L. W. Sieck, and M. C. Siddagangappa, Proc. 1986 Gaseous Electronics Conf. Bull. Am. Phys. Soc. (to be published, 1987); Plasma Chem. Plasma Proc. (submitted for publication, 1987).

[71] R. d'Agostino and D. L. Flamm, J. Appl. Phys. 52, 162 (1981).

[72] H. J. Emeleus and B. Tittle, J. Chem. Soc., 1644 (1963).

[73] H. Gutbier, Phys. Verh. 17, 163 (1966)。

[74] G. Bruno, P. Capezzuto, and F. Crannarossa, J. Flour. Chem. 14, 115 (1979).

[75] I. Sauers, IEEE Trans. Elec. Insul. EI-21, 105 (1986).

[76] M. C. Siddagangappa and R. J. Van Brunt, Proc. 8th International Conference on Gas Discharges and their Applications (Leeds University Press, London, 1985) pp. 247-250.

[77] L. W. Sieck and M. Meot-Ner, J. Phys. Chem. 88, 5324 (1984).

[78] L. W. Sieck, J. Phys. Chem. 89, 5552 (1985). 
[79] H. E. Revercomb and E. A. Mason, Anal. Chem. 47, 970 (1975).

[80] T. F. Magnera and P. Kebarle in Ionic Processes in the Gas Phase, edited by M. A. Almoster Ferreira (D. Reidel, Boston, 1984) pp. 135-157.

[81] M. Neot-Ner and F. H. Field, J. Chem. Phys. 64, 277 (1976).

[82] D. K. Sen Sharma and P. Kobarle, J. Am. Chem. Soc. 104, 19 (1982).

[83] E. F. Kelley and R. E. Hebner, "Electrical Breakdown in Composite Insulating Systems: Liquid-Solid Interface Parallel to the Field," IEEE Trans. Elec. Insul., Vol. EI-16, No. 4, pp. 297-303, August, 1981.

[84] E. F. Kelley and R. E. Hebner, "The Effect of an Oil-Paper Interface Parallel to an Electric Field on the Breakdown Voltage at Elevated Temperatures," in press. This paper verifies the above work and exterids its results to higher temperatures. The conclusions all remain the same: A clean paper interface parallel to the field and touching both electrodes does not necessarily cause interfacial breakdown or even lower the breakdown voltage.

[85] E. F. Kelley and R. E. Hebner, "Measurement of the Electric Field in the Vicinity of an Oil-Pressboard Interface Parallel to the Field," IEEE Trans. Elec. Insul., Vol. EI-19, No. 6, pp. 519-523 Dec. 1984.

[86] E. F. Kelley and R. E. Hebner, "Electro-Optic Electric-Field Measurements Near Oil-Pressboard Interfaces," Conference Record of 1984 IEEE International Symposium on Electrical Insulation, Montreal, pp. 311-314, June 11-13, 1984.

[87] E. F. Kelley and R. E. Hebner, "Electro-Optic Field Measurement at a Needle Tip and Streamer Initiation in Nitrobenzene, "Annual Report, Conference on Electrical Insulation and Dielectric Phenomena, pp. 171-177, October 1986.

[88] E. C. Cassidy, R. E. Hebner, M. Zahn, and R. J. Sojka, "Kerr-Effect Studies of an Insulating Liquid Under Varied High-Voltage Conditions," IEEE Trans. Elec. Insul., Vol. EI-9, No. 2, pp 43-56, June 1974.

[89] J. Millman and H. Taub, "Pulse, Digital, and Switching Waveforms", McGraw Hill, 1965, pp 38-50.

[90] M. Wilkinson and E. Chu, "Calibration of Capacitive Voltage Probes in Water-Dielectric, High Power Pulse Generators", in measurement of Electrical Quatntities in Pulse Power Systems, R. H. McKnight and R. E. Hebner, eds., NBS Spec. Pub. 628, 1982.

[91] Conference Record of the 1986 IEEE International Symposium on Electrical Insulation, see session D -. Steep Wavefront Phenomena, pp. 145-169. In particular, see "Impact of Steep Front, Short Duration Impulses on Power System Apparatus and Insulation: A Critical Review," L. M. Burrage, P. F. Hettwer, B. W. McConne11, p. 159 (June 1986). 
[92] E. F. Kelley and R. E. Hebner, "The Electric Field Distribution Associated with Prebreakdown Phenomena in Nitrobenezene, " J. App1. Phys., Vo1. 52, No. 1, pp 191-195, January 1981. 
NBS-114A (REV. 2AC)

U.3. DCP T. OF COMNA.

BIBLIOGRAPHIC DATA

SHEET (See in structions)

1. PUBLICATION OR REPORT NO.

NBSIR $87-3643$

2. Performing Organ. Report Nof 3. Publication Date

722

September 1987

4. TITLE ANO SUBTITLE

Research for Electric Energy Systems - - An Annual Report

5. AUTHOR(S)

R. Hebner

6. PERFORMING ORGANIZATION (If joint or other than NBS. see in structions)

7. Contracu Grane No.

Task Order \#137

NATIONAL BUREAU OF STANDARDS
U.S. DEPARTMENT OF COMMERCE
GAITHERSBURG, MD 20899

8. Type of Report \& Period Covered Annual - 1986

9. SPONSORING ORGANIZATION NAME AND COMPLETE ADDRESS (Street. City. State, ZIP)

Department of Energy

Division of Electric Energy Systems

1000 Independence Avenue, SW

Washington, D.C. 20585

10. SUPPLEMENTARY NOTES

Document describes a computer program; SF-185. FIPS Software Summary, is attached.

11. ABSTRACT (A 200-word or less foctual summory of most significont infomotion. If document includes a significont bibliography or literature survey. mention it here)

This report documents the technical progress in the five investigations which make up the project "Support of Research Projects for Electrical Energy Systems", funded by the U.S. Department of Energy. To support the measurement of ions in the dc transmission line environment, techniques to measure ion mobility were evaluated. In addition, techniques were developed to determine the sensitivity of an AM radio to detect partial discharges in a biological exposure facility. Within the project to develop measurement techniques and obtain basic data for gaseous dielectrics, a theoretical method was developed to evaluate the consistency among electron collision, transport, and dielectric strength data for binary gas mixtures; the gas phase hydrolysis rates for $\mathrm{SOF}_{2}$ and $\mathrm{SOF}_{4}$ were measured; the corona discharge oxidation mechanisms were identified and the role of negative ions on the SOF 4 yield was determined. Progress in interfacial measurements included the optical measurement of the electric field distribution as a streamer initiates. Progress in developing measurements for nanosecond dielectrics was in the characterization of the errors in the measurement of voltage pulses using E-dot probes and the identification of the reducation of breakdown voltage in oil for faster pulses.

12. KEY WORDS (Six to twelve entries: alphabetical order: copitalize only proper names; and separate key words by semicolons)

\section{AVAILABILITY}

Unlimited

For Official Distribution. Do Nor Release to NTIS Order From Suderintendent of Documents, U.S. Government Printing Office, Washington. D.C.
20402 .

Order From National Technical Information Service (NTIS). Springfield, VA. 2216I
14. NO. OF

PRINTED PAGES

15. Price 


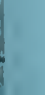


